\title{
Cocaine-induced synaptic changes in the nucleus accumbens: role in drug-motivated behaviour and relapse risk
}

\author{
Dissertation
}

in partial fulfilment of the requirements

for the award of the degree

Doctor rerum naturalium (Dr. rer. nat.)

within the doctoral programme IMPRS Neurosciences

of the Georg-August University School of Science (GAUSS)

submitted by

Myrto Panopoulou

from Athens, Greece

Göttingen, 2020 


\section{Thesis committee members}

Dr. Dr. Oliver Schlüter (reviewer)

Molecular Neurobiology, Dept. of Psychiatry and Psychotherapy, University Medical Center, Göttingen

Prof. Dr. André Fischer (reviewer)

Epigenetics and Systems Medicine in Neurodegenerative Diseases, German Center for Neurodegenerative Diseases (DZNE), Göttingen

Prof. Dr. Siegrid Löwel

Systems Neuroscience, Johann-Friedrich-Blumenbach-Institute for Zoology and Anthropology, Göttingen

\section{Extended thesis committee members}

Prof. Dr. Manuela Schmidt

Somatosensory Signaling, Max Planck Institute for Experimental Medicine, Göttingen

Prof. Dr. Silvio Rizzoli

Dept. of Neuro- and Sensory Physiology, University Medical Center, Göttingen

Prof. Dr. Ralf Heinrich

Dept. of Cellular Neurobiology, University of Göttingen

Date of oral examination: May $18^{\text {th }}, 2020$ 


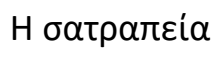

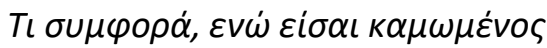

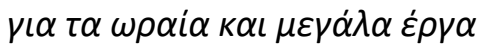

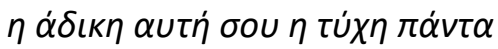
$\varepsilon v \vartheta \alpha \dot{\rho} \rho u v \sigma \iota \kappa^{\prime} \varepsilon \pi \iota \tau u x i \alpha$ va $\sigma \varepsilon \alpha \rho v \varepsilon i \tau \alpha l^{\circ}$

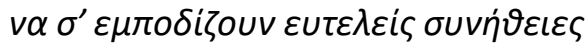

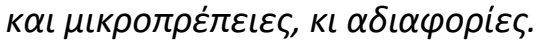

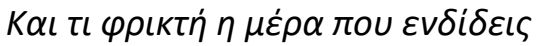

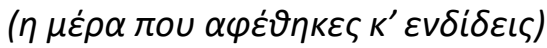

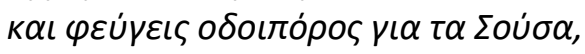

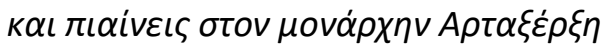

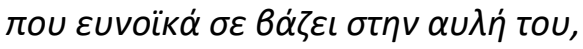

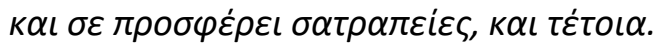

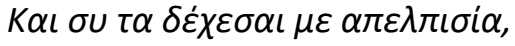

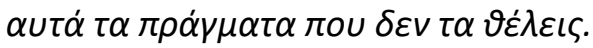

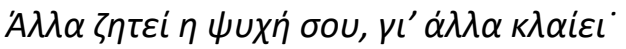

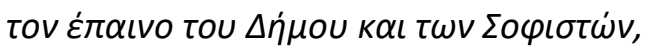

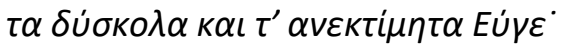

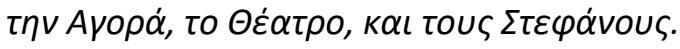

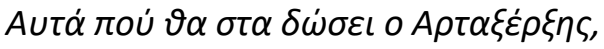

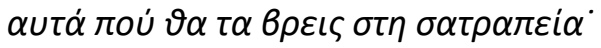

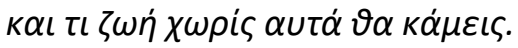

Constantine P. Cavafy (1910)
The satrapy

What a misfortune, though you are made for fine and great works, this unjust fate of yours ever to deny you encouragement and success; to be hindered by worthless habits and pettiness and indifferences. And how dreadful the day you yield (the day you give in and yield) and depart on foot for Susa,

and come before the monarch Artaxerxes

who favourably places you in his court, and presents you with satrapies, and the like.

And you, despairing, accept them, those, which you do not desire. Other things your soul longs for, for other things it weeps; the praise of the People and the Sophists, the hard-won and inestimable Well Done; the Agora, and the Theatre, and the Laurels.

These - how could Artaxerxes ever offer, how should you find these in the satrapy; and what sort of life will you live now, without them. 
Herewith I declare that I prepared the Doctoral Thesis "Cocaine-induced synaptic changes in the nucleus accumbens: role in drug-motivated behaviour and relapse risk" on my own with no other sources and aids than quoted. 


\section{Table of contents}

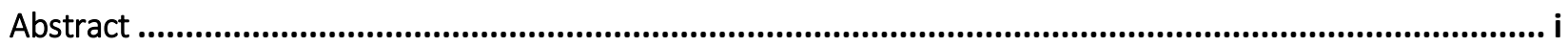

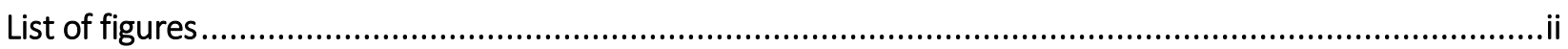

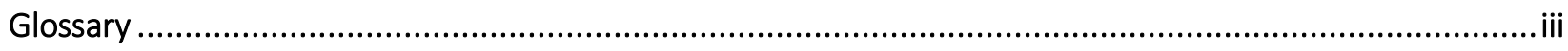

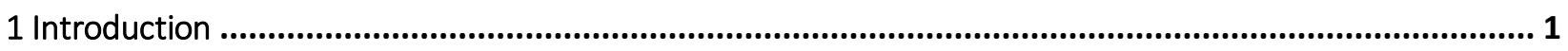

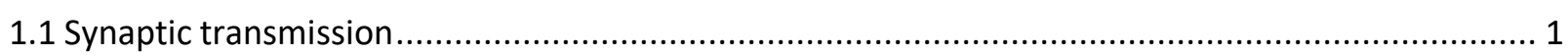

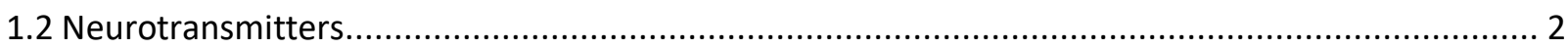

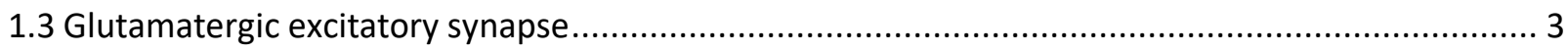

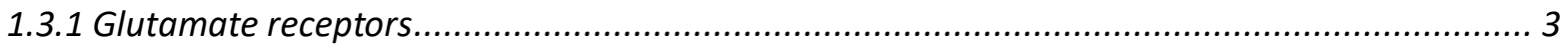

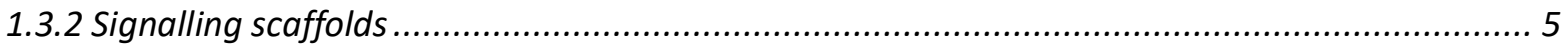

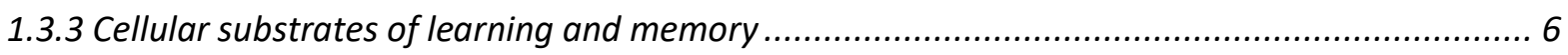

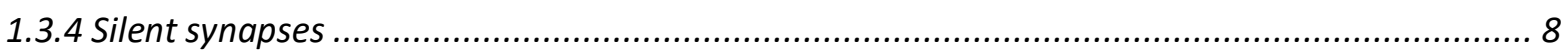

1.4 Drug addiction and synaptic plasticity - a pathological model of learning................................... 9

1.4.1 Behavioural paradigms for drug-reinforcement learning ................................................ 10

1.4.2 Drugs of abuse hijack the reward circuit of the brain....................................................... 11

1.4.3 Cocaine induces silent synapses in the adult brain........................................................ 12

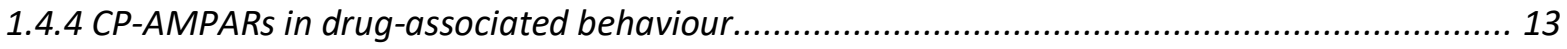

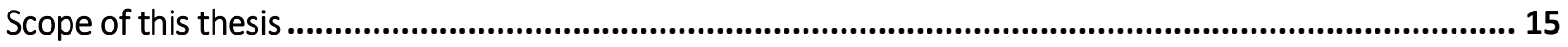

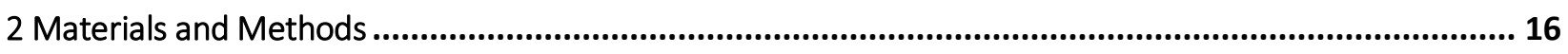

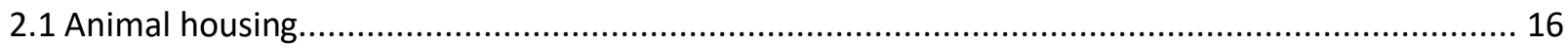

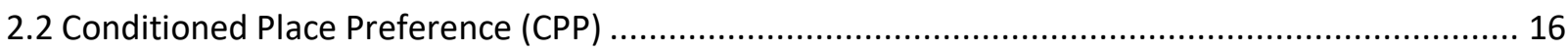

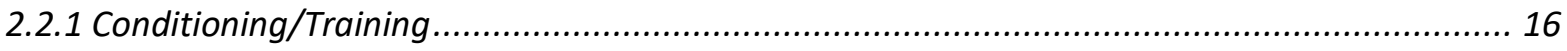

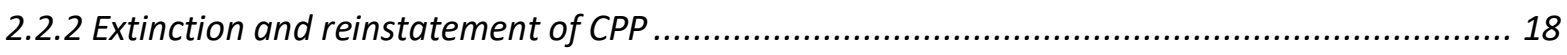

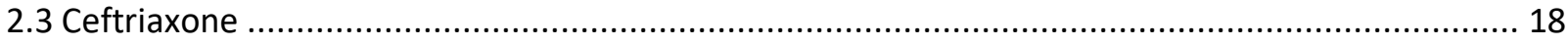

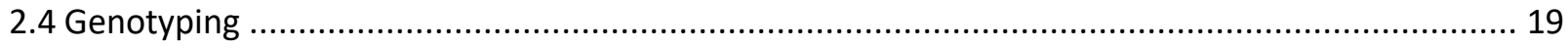

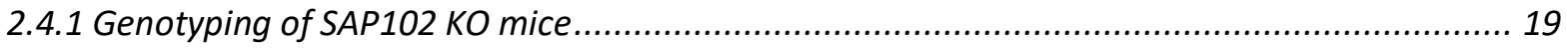

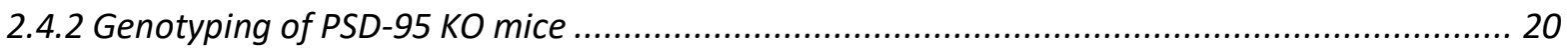

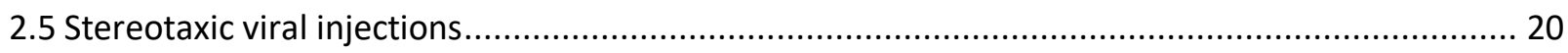

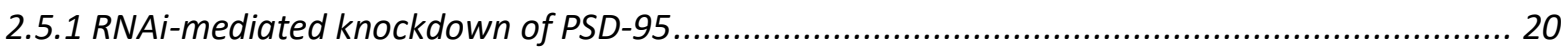

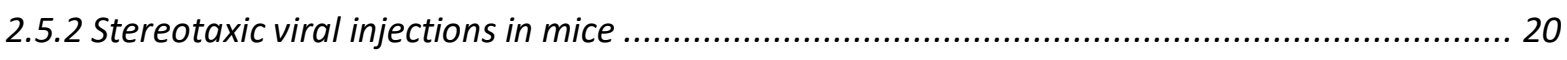

2.5.3 Imaging of viral vector injection site ......................................................................... 21

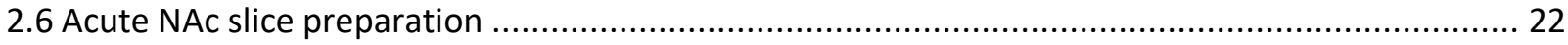

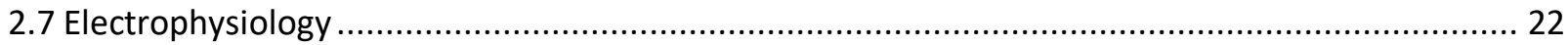




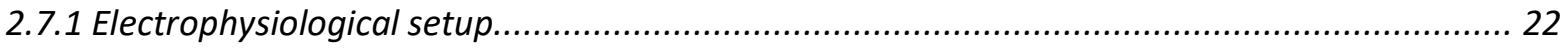

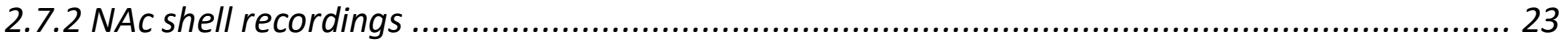

2.7.2.1 AMPAR Rectification Index - Quantifying CP-AMPAR proportion..................................... 23

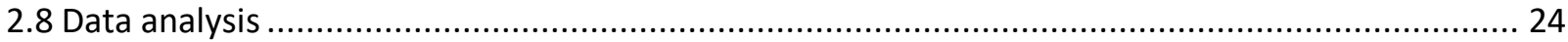

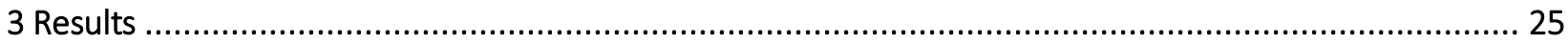

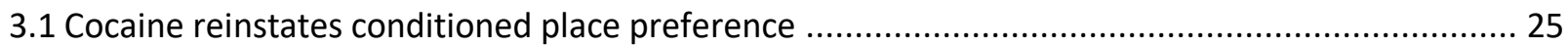

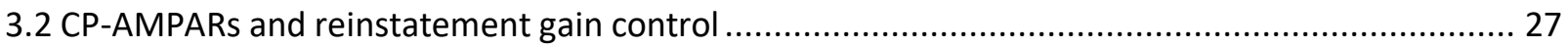

3.2.1 CP-AMPARs are increased after cocaine - CPP reinstatement ........................................... 27

3.2.2 CP-AMPARs are not required for cocaine - CPP reinstatement upon administration of a high

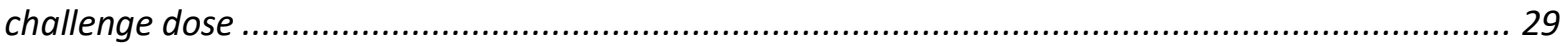

3.2.3 Low cue intensity without CP-AMPARs is insufficient for CPP reinstatement....................... 31

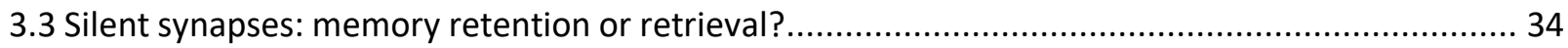

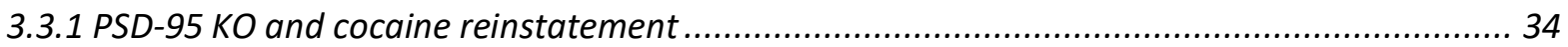

3.3.2 PSD-95 KO mice retain the CPP association after ten days of withdrawal ............................. 36

3.3.3 NAc-restricted knockdown of PSD-95 and CPP reinstatement............................................ 38

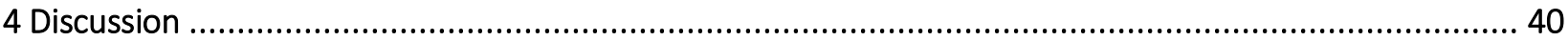

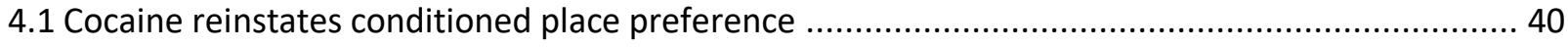

4.2 CP-AMPARs are increased after cocaine - CPP reinstatement ............................................ 42

4.3 A very low dose of cocaine is still sufficient to reinstate CPP in WT mice ................................. 43

4.4 CP-AMPARs increase a weak stimulus' gain to reawaken a cocaine-induced behaviour ............... 44

4.5 Commonalities and differences across addictive substances..................................................... 46

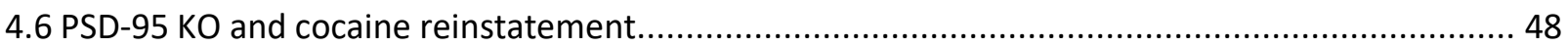

4.6.1 PSD-95 Ht and SAP102 KO transgenic mice outperform WT mice ....................................... 49

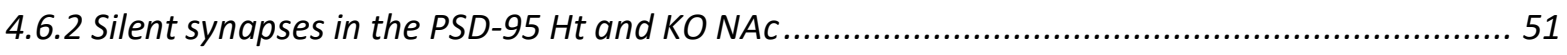

4.7 NAc-restricted knockdown of PSD-95 and CPP reinstatement.............................................. 51

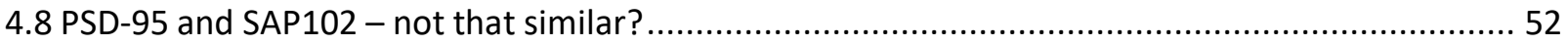

4.9 From gain control to motivation; from motivation back to addiction ...................................... 53

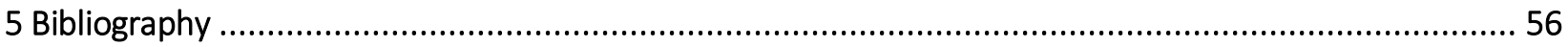

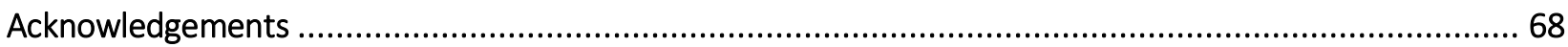




\section{Abstract}

Chronic drug use creates robust and durable memories which, even after years of abstinence, can be reawakened by drug-associated cues and trigger craving and relapse. Addictive drugs elevate extracellular dopamine levels in a key area of the brain's reward system, the nucleus accumbens (NAc). Drugs of abuse, such as cocaine, hijack plasticity mechanisms to rejuvenate and reorganise the reward circuit, thus inducing drug-seeking behaviours. One such mechanism is the generation of silent synapses in the adult NAc, synapses that lack functional AMPARs and hence do not transmit at resting potentials. Silent synapses mature over prolonged drug withdrawal. If the cocaine experience is paired with a context, this maturation will occur via recruitment of calcium-permeable, higher conductance AMPARs (CP-AMPARs). The understanding of the role of CP-AMPARs in drug-motivated behaviour remains elusive. It has been reported that CP-AMPARs are induced with drug-context associations, but are not required for long-term retention of cocaine-associated memories. However, other studies emphasise their specific role in incubation of cocaine craving, and they were found to be required for morphine-induced reinstatement.

Here, I used a mouse model of relapse by reinstating cocaine-conditioned place preference (cocaineCPP) after extinction. To study the role of silent synapses and their CP-AMPAR mediated maturation, I used a combination of pharmacological and genetic interrogations with PSD-95 and SAP102 KO mice that impair this process. In these KO mice, silent synapses are induced by cocaine, but they do not mature by CPAMPAR incorporation. Using ex vivo slice electrophysiology, I found that CP-AMPARs are increased in the WT NAc after reinstatement. My results reveal that CP-AMPARs are crucial for a low intensity cue to induce reinstatement, whereas a strong stimulus does not require their concurrent activity. I also show that impairing maturation of silent synapses, via lack of PSD-95, causes a cocaine challenge injection to abolish, rather than reinstate, the remaining preference after extinction. Additionally, since the KO has a global effect, I used an RNAi-approach to specifically target silent synapses and CP-AMPAR expression in the NAc. My preliminary results indicate no impairment in terms of high and intermediate dose-induced reinstatement.

The diverging behaviours I describe in the PSD-95 and SAP102 KO mice further support the notion that these two members of the same protein family fulfil different roles in the fate of excitatory synapses, rather than a similar, redundant function. More importantly, I show that CP-AMPARs amplify the gain of a weak cue to tip it over the threshold and trigger reinstatement. Taken together with existing knowledge, the results of this thesis suggest that CP-AMPARs gate the intensity with which addiction-driven behaviours are expressed and, thereby, may constitute major targets in the fight against addiction. 


\section{List of figures}

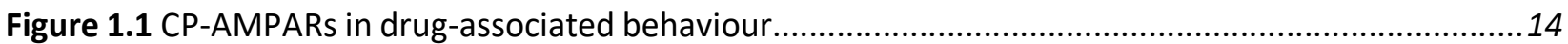

Figure 3.1 Cocaine reinstates conditioned place preference in WT mice ....................................................26

Figure 3.2 CP-AMPARs are increased after cocaine-CPP reinstatement.......................................................28

Figure 3.3 CP-AMPARs are not required for CPP reinstatement upon high challenge dose

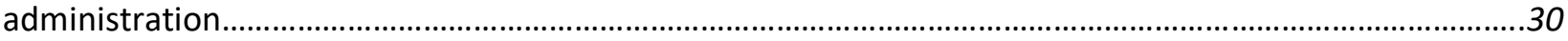

Figure 3.4 Low cue intensity without CP-AMPARs is insufficient for CPP reinstatement..............................33

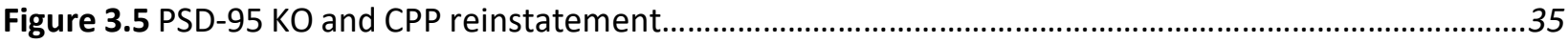

Figure 3.6 PSD-95 KO mice retain the CPP memory after 10 days of withdrawal...........................................37

Figure 3.7 NAc-restricted knockdown of PSD-95 and CPP reinstatement ...................................................39

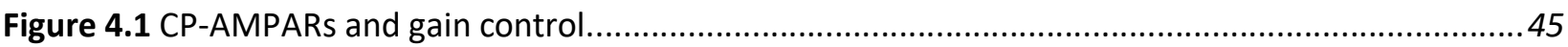




\section{Glossary}

\begin{tabular}{|c|c|}
\hline AAV & Adeno-associated virus \\
\hline aCSF & Artificial cerebrospinal fluid \\
\hline AMPARs & $\alpha$-amino-3-hydroxy-5-methylisoxasole-4-propionic acid receptors \\
\hline$B L$ & Baseline \\
\hline cef & Ceftriaxone \\
\hline CP-AMPARs & Calcium-permeable AMPA receptors \\
\hline CPP & Conditioned place preference \\
\hline CS & Conditioned Stimulus \\
\hline DAT & Dopamine transporter \\
\hline D-AP5 & APV - Amino-5-phosphonovaleric acid \\
\hline DLG-MAGUKs & Disc-large membrane-associated guanylate kinases \\
\hline EGTA & Ethylene glycol- bis(2-aminoethylether)- $N, N, N^{\prime}, N^{\prime}$ - tetraacetic acid \\
\hline EPSC & Excitatory postsynaptic current \\
\hline ext & Extinction \\
\hline GABA & $\nu$-aminobutyric acid \\
\hline GFP & Green fluorescent protein \\
\hline GK domain & Guanylate kinase domain \\
\hline GPCRs & G-protein coupled receptors \\
\hline $\mathrm{Ht}$ & Heterozygous \\
\hline i.p. & Intraperitoneal \\
\hline i.v. & Intravenous \\
\hline $\mathrm{KO}$ & Knock out \\
\hline LTD & Long-term depression \\
\hline LTP & Long-term potentiation \\
\hline mGluRs & Metabotropic glutamate receptors \\
\hline MSNs & Medium spiny neurons \\
\hline NAc & Nucleus accumbens \\
\hline NAcSh & Nucleus accumbens shell \\
\hline
\end{tabular}




\begin{tabular}{|c|c|}
\hline NMDARs & $N$-methyl-D-aspartate receptors \\
\hline PBS & Phosphate buffer saline \\
\hline PCR & Polymerase chain reaction \\
\hline PFA & Paraformaldehyde \\
\hline PPS & Place preference score \\
\hline PSD & Postsynaptic density \\
\hline PSD-95 & Postsynaptic density protein 95 \\
\hline reins & Reinstatement \\
\hline RI & Rectification index \\
\hline RT & Room temperature \\
\hline s.c. & Subcutaneous \\
\hline SAP102 & Synapse associated protein 102 \\
\hline SEM & Standard error of mean \\
\hline $\mathrm{SH} 3$ & Src homology 3 domain \\
\hline shRNA & Short-hairpin RNA \\
\hline TARP & Transmembrane AMPAR regulatory protein \\
\hline TEA-Cl & Tetraethylammonium chloride \\
\hline US & Unconditioned stimulus \\
\hline VTA & Ventral tegmental area \\
\hline WD & Withdrawal day \\
\hline WT & Wild type \\
\hline
\end{tabular}




\section{Introduction}

"Accidental drug overdose is currently the leading cause of death in the United States for those under 50. Drug overdose deaths now exceed those attributable to firearms, car accidents, homicides or HIV/AIDS."

(Drug Policy Alliance, 2020)

Drug addiction is a devastating brain disease; an acquired behavioural state where the once occasional but limited drug use gradually escalates to a habit and finally emerges as a compulsion. In spite of the detrimental consequences, such as isolation or loss of employment, the next drug exposure becomes the sole, narrowed focus of vulnerable individuals, overshadowing all other rewards in life. The chronically relapsing nature of this disease, however, is what poses the greatest challenge. Even after years of abstinence, once addicted, one remains prone to relapse. Aside from a single drug dose, relapse can also be triggered by drug-associated cues. The fact that cues are so salient is a testament to drug-related memories being durable and robust, as well as a pathological form of associative learning underlying addiction. The large impact of addiction is already observed at the cellular site of associative learning: the synapse.

The word 'synapse' originates from the Greek $\sigma u v$ (syn, meaning 'together') and $\alpha$ $\psi \iota \varsigma$ (hapsis, meaning 'touching', 'joining') and describes the connections that form between nerve cells. It is estimated that a minimum of 100 trillion synapses exist in the adult human brain, providing the framework for cognition, memory and behaviour. The ability to form new connections, or lose them; to strengthen or weaken them in response to the external world - that is the cellular basis of learning and memory.

\subsection{Synaptic transmission}

A nerve cell, or neuron, consists typically of a soma, an axon and several dendrites. Functional contacts between neurons, which allow them to communicate by passing signals to one another, are termed synapses. There are two broad categories - electrical and chemical synaptic connections. Electrical synapses are tight junctions, where rapid signal transfer occurs between cells through a cytoplasm continuum (Bennett and Zukin, 2004). The rapid bidirectional ion flow is passive; it is useful for synchronisation of neuronal populations, but also renders electrical synapses limited in terms of synaptic strength regulation (Rekling et al., 2000).

Chemical synapses constitute the vast majority of synapses in the vertebrate brain. Contrary to electrical synapses, chemical synapses do not have cytoplasmic continuity and are separated from their synaptic partner through the synaptic cleft, a 20-40 nm gap between the presynaptic (the signal-passing unit) and 
the postsynaptic (the signal-receiving unit) cell (Palay, 1956; Burns and Augustine, 1995). Once the action potential -the electrical signal travelling across the axon- reaches the presynaptic terminal, it gets converted into a chemical signal: the action potential opens voltage-gated $\mathrm{Ca}^{2+}$ channels. This $\mathrm{Ca}^{2+}$ influx triggers the fusion of synaptic vesicles with the presynaptic plasma membrane. These vesicles contain biochemical messenger molecules, called neurotransmitters, which diffuse in the synaptic cleft and, eventually, bind to neurotransmitter-gated ion channels on the postsynaptic membrane. Opening of these channels, in turn, leads to ion flow, converting the signal back to an electrical one by altering the postsynaptic cell's membrane potential. Changes in signal processing due to new experiences are incorporated by adjusting the strength of synaptic transmission. In the soma, membrane potentials summate and, once the action potential threshold is reached, a new action potential will be generated and propagated along the axon to trigger transmission to the next neuron (Scannevin and Huganir, 2000; Wojcik and Brose, 2007).

\subsection{Neurotransmitters}

Typically, one neuron only contains a single kind of neurotransmitter, which also serves as its defining characteristic. Nevertheless, each neuron is innervated by multiple cells, which in turn secrete different neurotransmitters. Hence, a single neuron can express more than one type of neurotransmitter receptor.

Neurotransmitters are biochemically diverse. One group is based on amino acids and their derivates, such as glutamate, $\gamma$-aminobutyric acid (GABA) or glycine, another one is acetylcholine and a third group consists of biogenic amines, such as dopamine, norepinephrine, serotonin or peptides (for example endorphins and other endogenous opioids). The function of a given neurotransmitter is determined by the type of postsynaptic membrane receptor it binds to - excitatory, inhibitory or modulatory:

$i$. Excitatory neurotransmitters increase the likelihood that the target neuron will fire an action potential, by binding to and opening ligand-gated cation (primarily $\mathrm{Na}^{+}$and $\mathrm{K}^{+}$) channels, thus depolarising the postsynaptic membrane. Glutamate is the most abundant excitatory neurotransmitter in the brain.

ii. Inhibitory neurotransmitters reduce the likelihood of the target neuron to fire an action potential; they bind to and open $\mathrm{Cl}^{-}$-selective channels, thus hyperpolarising the postsynaptic membrane. GABA is the principal inhibitory neurotransmitter in the developmentally mature neocortex. In the brain stem, inhibitory neurotransmission is mostly glycinergic.

iii. Modulatory neurotransmitters, or neuromodulators, bind to metabotropic receptors, subsequently acting through intracellular secondary messengers, and altering the membrane permeability and the 
metabolism of the postsynaptic neuron. Major modulatory neurotransmitters in the central nervous system include norepinephrine, dopamine, serotonin and acetylcholine. Glutamate and GABA can also have metabotropic action if binding to their metabotropic receptor subtypes.

\subsection{Glutamatergic excitatory synapse}

Neurotransmitter receptors, cell-adhesion molecules and scaffolding proteins are concentrated in a dense matrix of proteins at and beneath the opposing membrane of synaptic vesicle release, termed the postsynaptic density (PSD). A relatively thick PSD lies at the cytoplasmic surface of neuronal dendritic protrusions, called dendritic spines; this is where glutamatergic excitatory synapses are primarily formed.

Neurotransmitter receptors are categorised into ionotropic and metabotropic receptors. Ionotropic receptors are essential for fast transmission - they are ligand-gated ion channels that undergo a rapid conformational change upon ligand binding, followed by their gate opening. Metabotropic receptors, on the other hand, mediate slow or modulatory transmission - they involve intracellular signalling and secondary messenger molecules, which alter the neuronal response in a more global and sustained manner.

\subsubsection{Glutamate receptors}

In the glutamatergic excitatory synapse, glutamate binds to its respective ionotropic or metabotropic receptor. Metabotropic glutamate receptors (mGluRs) are G-protein coupled receptors (GPCRs), widely distributed over the brain and in peripheral tissues. There are eight different types of metabotropic glutamate receptors ( $\left.\mathrm{mGluR}_{1-8}\right)$, which are subdivided into three groups, according to their structure and physiological activity (Lujan et al., 1996; Cartmell and Schoepp, 2000).

Ionotropic glutamate receptors are categorised in three families, AMPA receptors, NMDA receptors and KA receptors, named after their respective agonists - $\alpha$-amino-3-hydroxy-5-methylisoxasole-4-propionic acid, $\mathrm{N}$-methyl-D-aspartate and kainate. All are non-selective, tetrameric cation channels and their subunit composition affects their properties; for example, all receptors are permeable to $\mathrm{Na}^{+}, \mathrm{K}^{+}$and, conditionally, $\mathrm{Ca}^{2+}$ (Seeburg et al., 1998). Kainate receptors are, along with AMPA receptors, referred to as non-NMDA receptors. Non-NMDA receptors are activated directly by glutamate and generate the early component of the excitatory postsynaptic current (EPSC); they are responsible for fast glutamatergic synaptic transmission (Howe et al., 1991; Stern et al., 1992). 


\subsubsection{NMDA receptors}

NMDA receptors (NMDARs) are channels with slow kinetics and mediate several forms of activitymediated plasticity. They are heterotetramers, comprising three different subunits - GluN1-3. GluN1 gene transcripts undergo RNA splicing, which results to eight different splice variants (isoforms), while GluN2 and N3 subunits are encoded by four and two different genes respectively. NMDARs consist of two obligatory GluN1 and a combination of GluN2 and/or GluN3 subunits (Traynelis et al., 2010). A higher presence of GluN2B-containing NMDARs is characteristic of nascent excitatory synapses; GluN1/GluN2B NMDARs are most abundant at birth. GluN2B NMDARs have an increased ability to activate the $\mathrm{Ca}^{2+} /$ calmodulin-dependent protein kinase II (CamKII) signalling, which is considered the major signalling protein for NMDA receptor-mediated synaptic strengthening. GluN2B NMDARs are thus more efficient in mediating activity-dependent synaptic strengthening (Halt et al., 2012). As synapses mature, the balance is shifted towards GluN2A subunits, which replace GluN2B ones, in an activity and experience-dependent manner (van Zundert et al., 2004). EPSCs of GluN2A-containing NMDARs are with faster decay times compared to those of GluN2B-containing ones (Gray et al., 2011; Paoletti, 2011).

NMDARs are $\mathrm{Ca}^{2+}, \mathrm{Na}^{+}$and $\mathrm{K}^{+}$-permeable. GluN2 subunits contain the glutamate binding site and mediate high NMDAR $\mathrm{Ca}^{2+}$ permeability and strong voltage-dependent blockade by extracellular $\mathrm{Mg}^{2+}$; GluN3 subunits mediate reduced $\mathrm{Ca}^{2+}$ permeability and $\mathrm{Mg}^{2+}$ sensitivity. Following glutamate and glycine binding and simultaneous postsynaptic depolarisation of a second neuron, $\mathrm{Mg}^{2+}$ is removed from the pore and cations can flow through the channel. Therefore, NMDARs serve as coincidence detectors of pre- and postsynaptic activity - thus, firing of two neurons (Mayer et al., 1984; Nowak et al., 1984; Stern et al., 1992; Schoepfer et al., 1994; Paoletti, 2011). $\mathrm{Ca}^{2+}$ entry following NMDAR opening initiates signalling events, which are important for modulation of synaptic strength.

\subsubsection{AMPA receptors}

AMPA receptors (AMPARs) mediate fast glutamatergic transmission, thereby generating the early component of the EPSC (reviewed by Greger et al., 2017). AMPARs are homo- or heterotetrameric, depending on the combination of four core subunits - GluA1-4 (previously known as GluR1-4) (Hollmann and Heinemann, 1994). GluA4 subunits are mostly expressed in immature hippocampal neurons and get replaced by GluA2 early in development (Zhu et al., 2000). Different subunit combinations allow for functional diversity, since each subunit contributes differently to kinetics, trafficking and ion selectivity of the receptor. For example, the GluA2 subunit undergoes RNA editing, the result of which is the substitution of a glutamine residue inside the pore with an arginine; thereby, the presence of this subunit in the receptor renders AMPARs impermeable to $\mathrm{Ca}^{2+}$ (Seeburg et al., 1998). Interestingly, there is differential 
affinity between the four subunits; GluA1 and 3 both favour GluA2 (Rossmann et al., 2011; Zhao et al., 2016). In CA1 pyramidal neurons, for instance, AMPARs are almost exclusively GluA2-containing (Lu et al., 2009). In other words, there is very strict control over GluA2-lacking, and thus calcium-permeable, AMPARs (CP-AMPARs) production (Greger et al., 2002; Greger et al., 2017). CP-AMPARs constitute a minority, albeit a very important one, and are key for synaptic plasticity and signalling (Cull-Candy et al., 2006; Lüscher and Malenka, 2011).

AMPAR function is regulated by different auxiliary subunits, in terms of gating or channel conductance. Some of them actually are connected with the core subunits early on and become integral to the AMPA receptor (Jackson and Nicoll 2011; Greger et al., 2017). One example is stargazin, a member of the transmembrane AMPAR regulatory protein (TARP) family. TARPs modify the voltage-dependent block of CP-AMPARs by endogenous polyamines, such as spermine (Soto et al., 2007; Soto et al., 2014). They also have a PDZ-binding domain, which allows them to interact with scaffolding proteins in the PSD, the disclarge (DLG-) membrane-associated guanylate kinases (MAGUKs) (Chen et al., 2000; Schnell et al., 2002).

\subsubsection{Signalling scaffolds}

Glutamate receptor clusters are found at the PSD of the postsynaptic membrane. This protein-enriched structure controls glutamate receptor trafficking and allows synaptic strength modifications during induction and maintenance of synaptic plasticity. The DLG-MAGUK family is a group of major signalling scaffold proteins at the excitatory synapse, involved in AMPAR trafficking (Bredt and Nicoll, 2003; Kim and Sheng, 2004; Xu et al., 2008).

\subsubsection{DLG-MAGUKS}

DLG-MAGUKs share a common structure - three PDZ (PSD-95/disc-large/zona occludens-1) domains, followed by one SH3 (src homology 3) and one catalytically inactive GK (guanylate kinase) domain. The DLG-MAGUK family comprises four members: PSD-95 (postsynaptic density protein 95; $95 \mathrm{kDa}$ is the molecular weight of the protein), PSD-93, SAP97 (synapse associated protein 97) and SAP102.

SAP97 is, as of now, the best characterised example of DLG-MAGUK function as signalling scaffolds with its role in regulating spike timing-dependent plasticity, which is considered as one cellular correlate of associative learning. $\beta 2$-adrenergic receptor activation leads to increased dendritic excitability, thus facilitating AP generation and back-propagation into the dendrite. These changes occur due to the inactivation of Kv1.1, a dendritic $\mathrm{K}^{+}$channel, via its endocytosis and SAP97 is the scaffold mediating this endocytosis; the interaction between Kv1.1 and the SAP97 PDZ domain is one example of the way adrenergic signalling is linked to synaptic potentiation (Liu et al., 2017). 
PSD-95 (or SAP90) is the most abundant of the DLG-MAGUK family in the PSD of the adult brain (Cho et al., 1992; Kistner et al., 1993). Initially the PDZ domain of PSD-95 was discovered to directly bind to a Cterminal motif on GluN2 subunits; this led to the hypothesis that PSD-95 partially contributes to NMDAR stabilisation at the synapse (Kornau et al., 1995; Roche et al., 2001; Sheng, 2001). PSD-95 was later also found to influence AMPAR trafficking and retention at the synapse, thereby affecting synaptic strength (Ehrlich and Malinow, 2004; Schlüter et al., 2006); contrary to NMDARs, PSD-95 interaction with AMPARs is indirect and requires stargazin (see section 1.3.1.2) (Chen et al., 2000; Schnell et al., 2002). Surprisingly, neither PSD-95 overexpression nor deletion influence NMDAR-mediated transmission at mature synapses. In contrast, PSD-95 overexpression or replacement of the endogenous protein with its major isoform, PSD95 $\alpha$, increases AMPAR function (Schnell et al., 2002; Ehrlich and Malinow, 2004; Schlüter et al., 2006). Deletion, or RNAi-mediated knockdown, of PSD-95 leads to a decrease of AMPA EPSCs and, hence, synaptic strength to 50\% of control EPSCs (Nakagawa et al., 2004; Elias et al., 2006; Schlüter et al., 2006).

PSD-93 knock out (KO) was initially linked to reduction of NMDAR cell-surface expression levels (Tao et al., 2003). Later analysis in other brain regions did not show changes in NMDAR-mediated transmission occuring upon PSD-93 loss-of-function. The same was true for basal AMPAR transmission (Carlisle et al., 2008; Krüger et al., 2013). AMPAR transmission is also unaltered in the visual cortex of PSD-93 KO mice (Favaro et al., 2018).

SAP102 regulates NMDAR function and AMPAR targeting. Contrary to PSD-95, SAP102 dominates early in development, already highly expressed by postnatal day 10 (P10). Around P10, levels of PSD-95 and -93 begin to increase until they reach adult levels at approximately P35, while SAP102 levels reduce. In an adult PSD-95 or PSD-93 KO mouse, though, SAP102 protein levels remain high; same holds true for the double KO mouse (Cuthbert et al., 2007; Bonnet et al., 2013; Favaro et al., 2018). SAP102 levels are also maintained, in case PSD-95 expression is inhibited during synaptogenesis. While the single KO of PSD-95 or SAP102 survives, double KO is lethal. Overall, in the developing mammalian brain, DLG-MAGUKs show distinct patterns of expression; SAP102 serves as a signalling scaffold during early development and its place is taken by PSD-93 and -95 in mature synapses (Bonnet et al., 2013; Huang et al., 2015a; Favaro et al., 2018).

\subsubsection{Cellular substrates of learning and memory}

Our brain has the ability to form new synaptic connections, or modify the strength of existing ones in response to past experiences or changes in the environment. This ability is termed synaptic plasticity and constitutes the cellular substrate of learning and memory. NMDAR-dependent long-term synaptic 
potentiation (LTP) and long-term synaptic depression (LTD) are two extensively studied forms of plasticity. These terms describe the strengthening -LTP- and weakening -LTD- of synaptic connections in response to repeated correlated and decorrelated activity, respectively (Dudek and Bear, 1992; Mulkey and Malenka, 1992; Malenka et al., 1989; Malinow et al., 1989). Both forms of plasticity were first discovered in the hippocampus; LTP was shown using brief high-frequency stimulation bursts (Bliss and Lømo, 1973), while LTD was induced by low-frequency stimulation (Dudek and Bear, 1992). Learning was later shown to induce LTP in vivo (Whitlock et al., 2006). LTP and LTD are accompanied by structural changes, such as PSD enlargement and dendritic spine shrinkage respectively (Yuste and Bonhoeffer, 2001; Matsuzaki et al., 2004).

LTP - NMDAR-dependent LTP is the best understood form of synaptic strengthening and a type of Hebbian plasticity. NMDARs are coincidence detectors, requiring glutamate binding and postsynaptic depolarisation. Following $\mathrm{Mg}^{2+}$-block removal, intracellular $\mathrm{Ca}^{2+}$ concentration increases and activates signalling cascades, leading to protein synthesis, changes in AMPAR trafficking, and, ultimately, to increased AMPAR numbers at the postsynaptic membrane (Malenka et al., 1989; Malinow et al., 1989; Giese et al., 1998).

Presynaptic LTP, on the other hand, has been described in the hippocampus, cerebellum and neocortex and is NMDAR-independent. In this case, activity-dependent increase in presynaptic $\mathrm{Ca}^{2+}$ concentration results in adenyl cyclase activation. Subsequent PKA activation leads to elevated glutamate release upon AP arrival (Malenka and Bear, 2004; Nicoll and Schmitz, 2005).

LTD - NMDAR-dependent LTD, in turn, results from low NMDAR activation, due to low-frequency stimulation (Dudek and Bear, 1992; Mulkey and Malenka, 1992). It leads to activation of different $\mathrm{Ca}^{2+}$-signalling cascades, compared to LTP, and dephosphorylation of AMPARs, among other substrates (Lee et al., 1998). Clathrin-dependent endocytosis of AMPARs weakens the synaptic connection (reviewed by Carroll et al., 2001).

mGluR-dependent LTD requires activation of metabotropic glutamate receptors alone, or in combination with postsynaptic $\mathrm{Ca}^{2+}$ influx, and also leads to clathrin-dependent AMPAR endocytosis (Ito, 1989).

AMPAR delivery and stabilisation at the synapse depends on PSD-95. Since, as mentioned earlier, PSD95 increases AMPAR function (Schnell et al., 2002; Ehrlich and Malinow, 2004; Schlüter et al., 2006), it was suggested that PSD-95 acts as a slot for AMPARs to be anchored to the PSD (Schnell et al., 2002; Ehrlich and Malinow, 2004). However, in PSD-95 KO mice, LTP is enhanced and LTD absent (Migaud et al., 1998), 
while PSD-95 overexpression has the opposite effect (Stein et al., 2003). The discrepancy between these results and the slot hypothesis lies in the fact that the latter would have predicted the exact opposite effect of PSD-95 on LTP and LTD. Additionally, acute knockdown of PSD-95 in hippocampal slice cultures also decreased LTD magnitude; this impairment was found to stem from the SH3 and GK domains of the PSD95 C-terminal domains. Therefore, an alternative scenario is that PSD-95 acts as a scaffold for proteinprotein interactions and orchestrates downstream signalling events: on one hand, PSD-95 contributes to AMPAR stabilisation and removal while, on the other, it independently mediates LTD (Migaud et al., 1998; Carlisle et al., 2008; Xu et al., 2008).

In sharp contrast to PSD-95 KO, which enhances LTP and impairs LTD (Migaud et al., 1998), PSD-93 KO elevates LTP induction threshold, but leaves LTD unaffected (Carlisle et al., 2008). This finding rendered the hypothesis that PSD-93 plays a role redundant to that of PSD-95 even less likely.

\subsubsection{Silent synapses}

Silent synapses are an important tool in the brain's arsenal to fine-tune and optimise existing, developing neuronal networks; silent synapses are generally regarded as a marker for early developmental stages, being highly abundant in the neonatal brain. Also called AMPA-silent, silent synapses lack stably integrated AMPARs - upon evoking of an EPSC, only NMDAR- and not AMPAR-mediated responses can be reliably detected at the postsynaptic neuron. Due to NMDARs being blocked by $\mathrm{Mg}^{2+}$ in a voltage-dependent manner, silent synapses cannot conduct at resting potentials. However, during development, silent synapses mature and convert to their full capacity of AMPAR-mediated transmission. Silent synapse levels gradually diminish by the time adulthood is reached, thereby contributing to activity- and experiencedependent circuit refinement (Durand et al., 1996; Groc et al., 2006; Huang et al., 2015a). The phenomenon of synapse unsilencing seems to be identical to LTP, as protocols conventionally used to induce LTP also lead to silent synapse maturation (Isaac et al., 1995; Liao et al., 1995; Wu et al., 1996). As an alternative to de novo generation, it is also possible to silence existing synapses by AMPAR removal (Xiao et al., 2004).

Publications describing the implication of DLG-MAGUKs in silent synapse maturation have further underlined the role of these proteins as plasticity orchestrators. PSD-95 KO mice maintain a high silent synapse percentage even in the adult stage (Béique et al., 2006; Huang et al., 2015a); AMPARs are not stably incorporated when PSD-95 is absent, thus causing a maturation deficit. This also explains why in PSD-95 KO mice, LTP is enhanced (Migaud et al., 1998; Béïque et al., 2006; Carlisle et al., 2008), as silent synapses likely serve as LTP substrates, lowering the threshold for and increasing magnitude of LTP (Isaac 
et al., 1995; Liao et al., 1995; Durand et al., 1996; Béïque et al., 2006). In the wild type (WT) visual cortex, the time window for experience-dependent circuit refinement -the critical period- is dictated by silent synapse maturation. PSD-95 knockdown after critical period closure reinstates silent synapses, thereby restoring juvenile-like plasticity (Huang et al., 2015a). Recently, PSD-93 was found to counteract PSD-95 function in promoting silent synapse maturation. PSD-93 actually inhibits the process and the two paralogs control, in an almost yin-and-yang-like manner, the fine-tuning of developing networks. In PSD-93 KO mice silent synapse fraction decline happens more rapidly, as does the critical period closure. Given the reverse effect on maturation of silent synapses observed upon KO of PSD-93 or -95, SAP102 -which is upregulated in both conditions- is unlikely to account for both of them (Favaro et al., 2018). Finally, PSD-95 KO mice were initially reported to have a learning deficit, which was later clarified as an impairment in memory retention (Migaud et al., 1998; Fitzgerald et al., 2014; Shukla et al., 2017).

\subsection{Drug addiction and synaptic plasticity - a pathological model of learning}

Drugs of abuse hijack the natural mechanisms of reward and positive reinforcement learning and memory (Dong and Nestler, 2014). Repeated administration of the drug results in tolerance and dependence. Tolerance describes the need for higher doses to keep experiencing the gratifying effect of the substance; dependence refers to the distressing withdrawal symptoms experienced upon cessation of repeated drug use. The brain interprets rewards as objects or actions possessing a positive value. Reinforcement learning describes the increased repetition of rewarding behaviours over time: sustenance, sex, and shelter are natural rewards, promoting the survival of the species. Likewise, drugs induce feelings of pleasure and desire but, in contrast, provide no evolutionary benefit. Even more so, they are valued over health and other essential elements of the affected individual's life.

Drug addiction has been conceptualised as a three-stage cycle, with different behavioural paradigms used to model each one -

i. Binge/intoxication stage; the drug-taking phase. The drug intake often increases gradually.

ii. Withdrawal/negative affect stage; lack of access to the drug leads to a negative emotional state.

iii. Preoccupation/anticipation stage; also called the craving stage. This is the part of the cycle that defines addiction as a chronic relapsing disease (Koob et al., 2009; Koob and Volkow, 2010). 


\subsubsection{Behavioural paradigms for drug-reinforcement learning}

To understand the pathophysiology dictating addiction, animal models are of crucial importance. Less complex as they may be, compared to the human condition, they do offer the potential to better control different parameters and see effects in a more straightforward and clear manner.

We will focus on conditioned place preference (CPP) and operant self-administration as relevant examples of paradigms used for studying drugs of abuse as reinforcers. CPP entails passive drug administration by the experimenter and can be considered Pavlovian in nature. The positive experience induced by the reward (unconditioned stimulus, US) is paired with certain, initially neutral, cues (conditioned stimulus, CS). Environmental stimuli that the animal is exposed to during the procedure act as the CS. Developed CS preference is measured as the increase in time spent in the context of the conditioned, drug-paired cues (Roux et al., 2003). A noteworthy detail here is that natural rewards (e.g. sucrose, water) and drugs (e.g. cocaine, morphine) both induce CPP, but have different behavioural consequences. Mice rewarded with food exhibit amplified exploratory behaviour (e.g. sniffing), as they spent time searching for the reward during the preference test in the absence of the US. This phenomenon is termed conditioned approach behaviour and reflects wanting. Conversely, drug-rewarded mice remained in close contact with the drug-associated cues throughout the test, rather than explore, demonstrating an association between the affective state and the stimuli. This conditioned affective reaction is similar to liking (Spiteri and Le Pape, 2000).

In contrast to CPP, the operant self-administration conditioning model, as the name suggests, involves contingent delivery of the positive reinforcer. Rats are most often used in this procedure and the drug is administered via the intravenous route, to induce rapid onset of the drug action. The operant, trained response, typically a nose-poke into a hole or a lever press, gets rewarded by an instant drug infusion (Gerber and Wise, 1989). Craving behaviour during drug withdrawal has also been successfully modelled by self-administration performed with rats (Grimm et al., 2001).

At this point, it is important to emphasise an important difference between CPP and self-administration: the former measures drug reward, rather than addiction per se, since the drug administration is not under the operant control of the animal. Drug craving is an important facet of human addiction that can only be modelled by self-administration protocols. CPP, instead, is useful in exploring relapse; after conditioning, extinction of the preference is caused by repeated exposures to the CS in the absence of the US, resulting in the animal learning to no longer associate the two. Afterwards, reinstatement of the conditioned 
preference is typically induced by reintroducing the rewarding stimulus - in this case, a challenge, or priming, injection of the drug.

\subsubsection{Drugs of abuse hijack the reward circuit of the brain}

A reward can be an object, action or internal physical state to which the brain attributes a positive value. Rewards are typically reinforcing, since they increase the probability of a certain behaviour to manifest, if that behaviour precedes a reward. Their influence in modifying behaviour is regarded greater than that of punishment (reviewed by Schultz, 2015).

The modulatory neurotransmitter dopamine is key in terms of reward and positive reinforcement. Dopamine concentration has been demonstrated to encode a reward prediction error - whether delivery of reward is "as expected" or not. If an animal has been trained to expect a reward and its experience has been stored in memory, prediction error equals zero; dopamine levels will not increase in response to that same reward and dopaminergic neurons will show a stable, tonic activity pattern. On the contrary, a reward not following the prediction cue, or exceeding expectations, will result in a negative (pause of dopaminergic neuron activity) or positive (bursts of activity) prediction error, respectively (Schultz et al., 1993, 1997).

The mesocorticolimbic system is the reward circuitry in the brain. Dopaminergic neurons are located, apart from substantia nigra, in the midbrain ventral tegmental area (VTA). The mesocorticolimbic dopamine pathway is formed by VTA dopaminergic projections to nucleus accumbens (NAc) in ventral striatum, prefrontal cortex, hippocampus and amygdala, while the latter regions send glutamatergic afferents back to NAc (Swanson, 1982). Simply put, prefrontal cortex provides action-outcome information and is implicated in goal representation and future planning; hippocampus is key in encoding spatial and contextual relevance; amygdala provides emotional valence (Robbins and Everitt, 1996). These inputs get integrated in the NAc; motivation facilitates the prioritisation of action plans and their realisation, via direct projections of the NAc on motor regions (Mogenson et al., 1980; French and Totterdell 2002; French and Toterdell, 2003).

Natural rewards and addictive substances increase dopamine levels in these brain areas, inducing alterations in synaptic function and plasticity (Di Chiara, 1998; Hyman et al., 2006). Cocaine, for instance, inhibits the dopamine transporter (DAT), thereby blocking dopamine reuptake and increasing the ambient dopamine concentration in the synapse (Ritz et al., 1987; Chen et al., 2006). A single non-contingent cocaine injection leads to an increased AMPA/NMDA EPSC ratio measured in VTA dopaminergic neurons 
24 hours later, which translates to the excitatory inputs onto these cells being strengthened (Ungless et al., 2001; Bellone and Lüscher, 2006).

Drug addiction has been observed to involve embryonic and developmental plasticity mechanisms, also implicated in learning and memory processes (Holt, 1931; Nestler, 2002). Therefore, the enhanced calibre of a younger brain's plasticity not only makes it more capable of forming new memories, but also more susceptible to addiction (Ehrlich et al., 2002; Wong et al., 2013). Drugs of abuse are thought to reawaken and exploit plasticity mechanisms in place to refine neuronal networks -in healthy conditions- during development in key brain areas, to create durable and robust addiction-related memories (Dong and Nestler, 2014).

\subsubsection{Cocaine induces silent synapses in the adult brain}

Silent synapses lacking AMPARs are highly abundant in the neonatal brain, and are generally regarded as a marker of early development. Their levels gradually diminish by the time adulthood is reached, thereby contributing to circuit refinement (Durand et al., 1996; Groc et al., 2006; Huang et al., 2015a). Nevertheless, silent synapses can also be re-generated post-developmentally, in the adult nucleus accumbens shell (NAcSh), upon repeated cocaine exposure (Huang et al., 2009; Lee and Dong 2011).

Initially, repeated cocaine treatment was found to increase dendritic spine density and decrease glutamatergic transmission in the NAcSh (Robinson and Kolb, 1999; Thomas et al., 2001). This paradox was partially explained by Huang and colleagues (2009) upon discovery of silent synapses in the NAc of rats that had received repeated intraperitoneal cocaine injections. The study demonstrated that these synapses are generated de novo by GluN2B-containing NMDAR insertion into new synaptic contacts; additionally, GluN2B-containing NMDAR blockade prevents the locomotor sensitisation (hyperactivity) normally induced upon acute cocaine exposure, indicating that silent synapses mediate this acute cocaine response (Brown et al., 2011).

Silent synapse levels gradually decrease during prolonged withdrawal (Huang et al., 2009). The fate of these synapses during the developmental period involves either pruning, via metabolic turnover, or maturation, via AMPAR recruitment, resulting in their stabilisation (Dong and Nestler, 2014). The fact that the aforementioned NAcSh spine density increase persists for a long time after cessation of cocaine treatment (Robinson et al., 2001), suggests that the cocaine-induced silent synapses become unsilenced during withdrawal from the drug. Therefore, it has been proposed that cocaine rejuvenates NAc excitatory synapses, via re-enrichment of GluN2B-containing NMDARs; it also generates silent synapses, granting enhanced plasticity to the region. Through their maturation, these synapses offer the potential for new, 
drug-adaptive changes and connections to be established (Lee and Dong, 2011; Dong and Nestler, 2014; Huang et al., 2015b).

The role of DLG-MAGUKs in silent synapse maturation is consistent between developmental and maladaptive plasticity. Despite their already elevated baseline levels, silent synapses in the PSD-95 KO mouse increase further following a ten-day cocaine CPP training. As expected, due to the absence of PSD95, these levels persist during withdrawal. The same pattern is observed in the SAP102 KO; silent synapses, with a basal fraction similar to WT, increase after conditioning and do not mature during withdrawal. Interestingly, neither of these proteins is required for CPP acquisition, as both KOs are able to learn the cocaine-CPP association; however, only the SAP102 KO and not the PSD-95 KO mice were able to recall the memory after 20-25 days of withdrawal (Shukla et al., 2017).

\subsubsection{CP-AMPARs in drug-associated behaviour}

The first link between cocaine and calcium permeable AMPARs (CP-AMPARs) was established when rectification and polyamine sensitivity of AMPA EPSCs, hence CP-AMPAR levels, were found to increase in the VTA upon a single cocaine injection (Bellone and Lüscher, 2006). Prolonged withdrawal from the drug in rats trained in a self-administration procedure led to CP-AMPARs increasing in the NAc, which were shown to mediate incubation of craving (Conrad et al., 2008); CP-AMPAR recruitment was later shown to only occur in operant conditioning, as passive cocaine injections in rats did not induce CP-AMPAR expression (McCutcheon et al., 2011a). mGluR1 activation via positive allosteric modulators reverses this form of plasticity, via LTD mechanisms, in VTA (Bellone and Lüscher, 2006) and NAc alike and blocks incubation of craving (McCutcheon et al., 2011b; Loweth et al., 2013; Loweth et al., 2014).

CP-AMPAR incorporation turned out to be the mechanism through which some of the cocainegenerated silent synapses mature during withdrawal after cocaine self-administration (Lee et al., 2013). This kind of unsilencing differs from the physiological maturation of glutamatergic synapses which largely integrate GluA2-containing calcium impermeable receptors, and it is possible that CP-AMPARs might only exist as an intermediate state.

In mice, silent synapses generated from a cocaine-CPP procedure were also found to mature via CPAMPAR incorporation. This result demonstrates that CP-AMPAR recruitment does not necessitate selfadministration, but rather the formation of a connection between the drug and a context, thereby raising CP-AMPARs as a signature for a drug experience-induced association. However, pharmacological CPAMPAR removal does not lessen the recall of the learned association. The difference between the PSD-95 and the SAP102 KO mice in terms of their memory retention further supports this dissociation: silent 
synapses do not mature in either case, suggesting no CP-AMPAR recruitment, but SAP102 KO mice show CPP retention (Shukla et al., 2017). A summary of these results is shown in figure 1.1.

Administration of morphine was shown to induce CP-AMPAR expression in the NAcSh, as well. Their pharmacological removal during extinction in CPP trained mice, blocked reinstatement upon a morphine challenge injection following extinction (Hearing et al., 2016). Overall, the role of CP-AMPARs is not fully understood. They are key in incubation of craving and, potentially, in reinstatement as well. On the contrary, in the SAP102 KO mouse, no CP-AMPARs exist but, nevertheless, CPP is learned and retained.

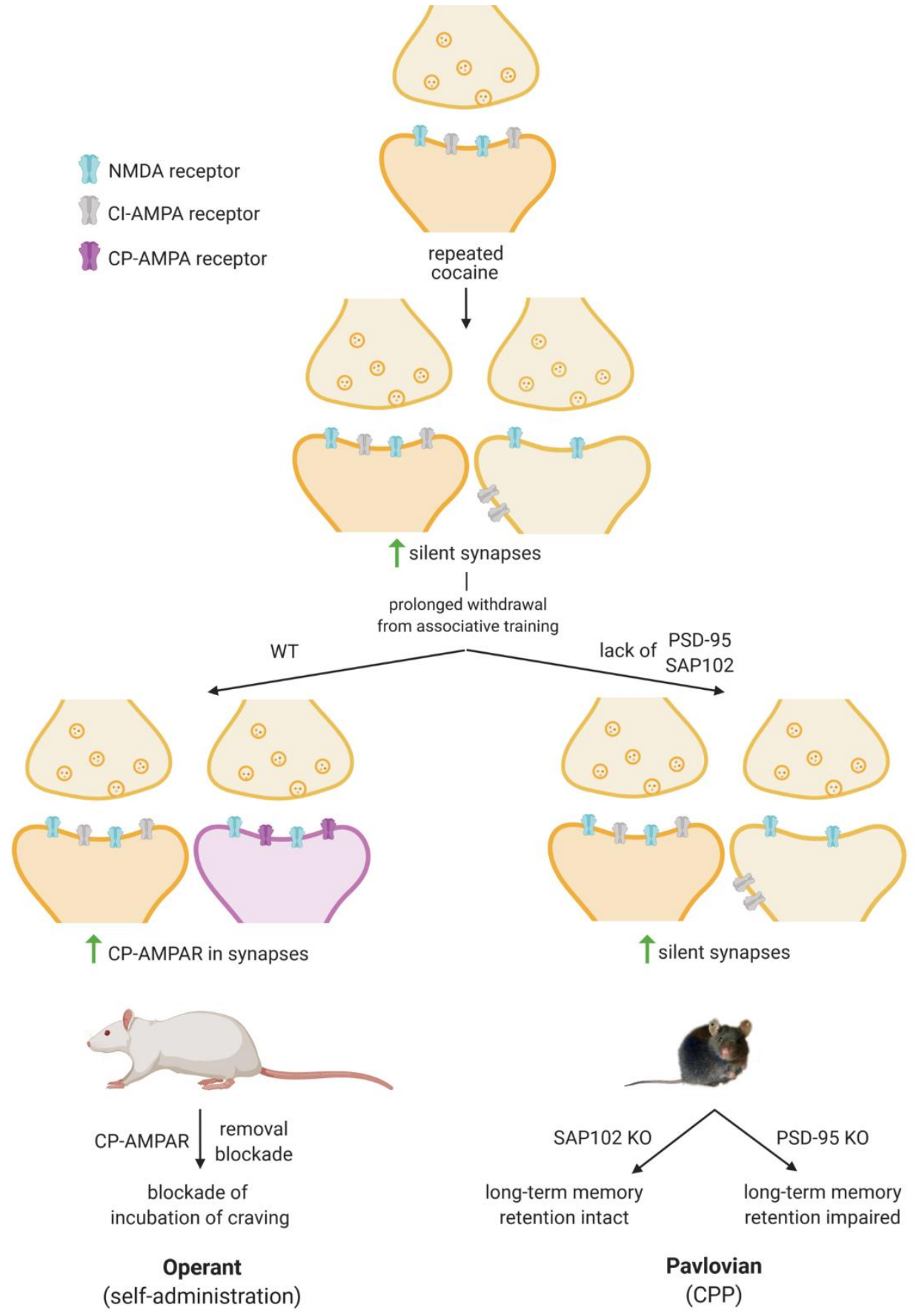

Figure 1.1: CP-AMPARs in drug-associated behaviour - Summary of data obtained from operant and classical conditioning. 


\section{Scope of this thesis}

Data from both operant and Pavlovian conditioning procedures show that CP-AMPARs are only recruited if the animal associates a cue to a trained behaviour - however, they are not involved in long-term memory coding. Blockade of CP-AMPARs in a self-administration procedure suppresses only the intensified cueinduced cocaine seeking; in a morphine-CPP procedure their removal blocks reinstatement (Conrad et al., 2008; Hearing et al., 2016; Shukla et al., 2017). Overall, the results on the role of CP-AMPARs are correlative, but provide little information in terms of their function in drug-motivated behaviours.

The question I sought to answer concerned the general role of CP-AMPARs in drug-motivated behaviours; I hypothesised that they are related to the intensity of a learned response. I first measured CP-AMPAR levels in the WT NAc upon cocaine-CPP reinstatement. I then tested PSD-95 KO and SAP102 KO mice, where silent synapses are generated but maintain their labile state, in the same behavioural paradigm. Since the KO affects all synapses, I wanted to clarify whether the changes induced specifically in the NAc are those that matter. Therefore, I used a viral vector to specifically impair silent synapse maturation and eliminate CP-AMPAR expression in the WT NAC.

Would lack of CP-AMPARs abolish reinstatement altogether, or rather alter the sensitivity, the threshold for expression of this behaviour? Is there a common thread between the addiction-relevant features that CP-AMPARs mediate? Should CP-AMPARs gate -in any way- the strength with which a cue affects the system and leads to manifestation of addiction-driven behaviours (i.e. craving and relapse), that would make them key targets to fight addiction. 


\section{Materials and Methods}

\subsection{Animal housing}

The animal housing room had a standard 12/12 light cycle with controlled temperature and humidity, while food and water were available ad libitum. Weaning of the mice took place at three weeks of age, after which males and females were separately housed. Throughout the course of experiments, mice were kept in groups of three to five animals per cage. Wild type mice of C57BL/6J background were ordered from Charles River at an age of three to four weeks, and the transgenic mice used in the study were bred in-house. All procedures were performed during the light period. Experiments were performed according to the standards of German Federal Law on Care and Use of Laboratory Animals and were approved by the local government authorities (IACUC, University of Pittsburgh and LaVes, Lower Saxony State Office for Consumer Protection and Food Safety).

\subsection{Conditioned Place Preference (CPP)}

\subsubsection{Conditioning/Training}

Conditioned place preference (CPP), a procedure used to evaluate the effect of drugs or other substances on motivation, was performed according to Roux and colleagues, with a few adjustments (Roux et al., 2003). Male wild type (WT), PSD-95 heterozygous and knock out (KO) and SAP102 KO mice were at least four weeks old at the beginning of the protocol. Prior to commencement of training sessions, the animals were habituated for four to five days to the environmental conditions of the experimental room, as well as the handling of the experimenter and the intraperitoneal injection (i.p.) procedure; to that end, during the habituation phase, the mice received sham i.p. injections daily. The needle size used was $30 \mathrm{G}$ $1 / 2^{\prime \prime}$.

The CPP apparatus consisted of two custom-made conditioning chambers, each $15 \mathrm{~cm} * 15 \mathrm{~cm}$ in size, which differed in terms of visual, tactile and olfactory cues. The walls and floor of each chamber were covered either with small black dots, or vertical black stripes on a white background (Figure 3.1A). In addition, distinct tactile cues were given by the flooring of the chamber, which featured circular, or rectangular canal-like pits of approximately $1 \mathrm{~mm}$ depth. Lastly, the scent of vanilla or cinnamon was assigned to each chamber, through a tissue soaked in scented oil inside an Eppendorf tube attached to one of the walls of each respective chamber. The tubes were kept closed, but a small hole was made at the bottom, to ensure slow and subtle diffusion of the scent in the chamber. The conditioning chambers were connected by a neutral, grey-coloured area, with guillotine trap doors on each of the two borders. 
Following the habituation phase and one day prior to conditioning, a so-called pre-test was performed, to check for a potential inherent preference of the mice to a certain chamber. For that purpose, mice were placed into the neutral area of the apparatus and recorded for 18 minutes, while having free access to both chambers. Animals that spent longer than $75 \%$ of total time in one chamber were considered biased and hence excluded from the study.

Mice were then randomly assigned to receive i.p. injections of cocaine in one, and saline (vehicle control) in the other compartment. Throughout the ten-day long training phase, the trap doors were closed to restrict each mouse to one compartment at a time and the mice received daily alternating cocaine and saline injections (see Figure 3.1A for experimental design). On the first day, each mouse received an i.p. injection of cocaine hydrochloride (20 mg/kg bodyweight, diluted in saline; Sigma, Germany) and directly placed into its assigned compartment for 20 minutes. The following day, the animal received an i.p. vehicle injection of the same volume $(0.9 \% \mathrm{NaCl}$; Braun, Germany) and was placed into the other compartment. As a result, at the end of ten days, the mice had received in total five cocaine injections in the conditioned compartment (CS+) and five saline injections in the other compartment (CS-).

On the eleventh day, no injection was given to perform the test at day 1 of withdrawal (WD1) from cocaine: the trap doors were opened and each mouse was placed into the neutral area, with free access to both compartments and, much like during the pre-test, their movement was recorded for 18 minutes. The time spent in each compartment was measured using VideoMot software (TSE systems) and a place preference score (PPS) was calculated using the following formula:

$$
P P S=\frac{\text { time in conditioned chamber }(\mathrm{sec}) * \text { total time }(\mathrm{sec})}{\text { total time }(\mathrm{sec})-\text { time in grey area }(\mathrm{sec})}
$$

PPS values range from 0 to 1080 (seconds in 18 minutes). A PPS value of 1080 means that a mouse spent the entire time in the CS+ chamber. Likewise, a score of 540 would suggest that the mouse spent exactly $50 \%$ of total recording time in CS+ and $50 \%$ in CS- chamber.

Several other parameters, such as total distance covered by the animal or number of crossings between the compartments, were measured with the software in order to further evaluate PPS reliability.

After the place preference test, animals were returned to their home cage. Mice that did not show an increase of at least 25 in their score compared to their baseline PPS measured during pre-test, were excluded from the study as non-learners. 


\subsubsection{Extinction and reinstatement of $C P P$}

Extinction and reinstatement of CPP were performed according to a recent publication, with minor modifications (Hearing et al., 2016). After WD1 test, animals were returned to their home cage and left undisturbed for 72 hours. During the six days thereafter, mice underwent extinction training: on the oddnumbered days (extD1, 3,5), trap doors were closed, and each mouse was confined in the CS+ chamber for 20 minutes and the CS- chamber for another 20 minutes. On the even-numbered days (extD2, 4, 6), trap doors were opened, and the mice could roam freely in the apparatus for 20 minutes. On the final extinction day (extD6), animal movement was recorded for 18 minutes and analysed as in pre- and WD1 test, in order to evaluate the effectiveness of the extinction training. Throughout this six-day process, mice were given sham i.p. injections each time before being placed in the apparatus. This was done to make sure that the injection itself would not be interpreted as a cue by the mice. Mice that did not show a decrease in PPS compared to WD1 were excluded from the study.

24 hours after extD6 test, CPP was reinstated by a cocaine challenge i.p. injection. Each mouse was then placed into the open apparatus and its movement were recorded for 18 minutes, to determine the PPS. Mice which were used for electrophysiological recordings were sacrificed directly after the test.

\subsection{Ceftriaxone}

Ceftriaxone is an antibiotic normally used for treating certain bacterial infections. However, it has also been shown to prevent relapse in cocaine addiction (Bechard and Knackstedt, 2019; Knackstedt et al., 2010); by increasing glutamate transporter-1 (GLT-1) expression and thereby restoring glutamate uptake, it reduces drug seeking behaviour.

For my experiments which investigated the effect of ceftriaxone in reinstatement, conditioning was performed as described above. Throughout extinction mice received six daily i.p. injections of ceftriaxone (Ceftriaxone Sodium, 400 mg/kg bodyweight, diluted in saline; Sigma-Aldrich). Reinstatement of CPP was performed with the administration of a cocaine challenge injection as described in section 2.2.2. 


\subsection{Genotyping}

\subsubsection{Genotyping of SAP102 KO mice}

The SAP102 KO mouse line used in this study was generated by Cuthbert and colleagues (Cuthbert et al., 2007). Genotype was determined by Polymerase Chain Reaction (PCR) as follows; genomic DNA was isolated either from 1-mm-long tail pieces collected from new-born mice, or ear punches taken at approximately three weeks of age, when mice were weaned from their mother. Respective samples were digested in PBND buffer (100-300 $\mu \mathrm{L}$ volume, depending on amount of tissue; see recipe below) containing 1:100 Proteinase $\mathrm{K}$ solution (ambion, ThermoFisher Scientific) at $55^{\circ} \mathrm{C}$ with constant shaking (900-1400 $\mathrm{rpm}$ ) for at least 3 hours. Proteinase $\mathrm{K}$ was then inactivated at $99^{\circ} \mathrm{C}$ for 10 minutes. $2 \mu \mathrm{L}$ of lysate were used for each PCR:

$\underline{\text { PCR mixture }}$

FastGene HotStart Ready Mix

Primer 1, $50 \mu \mathrm{M}$

Primer 2, $50 \mu \mathrm{M}$

Primer 3, $50 \mu \mathrm{M}$

$\mathrm{H}_{2} \mathrm{O}$

Lysate

\section{PCR programme}

$12.5 \mu \mathrm{L}$

$0.2 \mu \mathrm{L} \quad$ Pre-incubation

$0.2 \mu \mathrm{L} \quad$ Denaturation

$0.2 \mu \mathrm{L}$

$11.9 \mu \mathrm{L}$

$2.0 \mu \mathrm{L}$
Time - temperature

$5 \min -94^{\circ} \mathrm{C}$

$30 \mathrm{sec}-94^{\circ} \mathrm{C}$

$30 \mathrm{sec}-56^{\circ} \mathrm{C}$

$1 \mathrm{~min}-72^{\circ} \mathrm{C}$

$10 \min -72^{\circ} \mathrm{C}$

PCR products from WT and SAP102 KO alleles have 535 and 215 base pairs respectively. Bands were separated on a $1 \%$ agarose gel (Roth, Germany) in sodium tetraborate buffer ( $5 \mathrm{mM}$ sodium tetraborate decahydrate; Sigma) supplemented with MIDORI Green Xtra (Nippon Genetics Europe) (horizontal electrophoresis at 140V for 40 minutes) and visualised on a FAS-V Gel Documentation System (Nippon Genetics Europe).

Primers and solutions used for genotyping:

Primer 1 - GGTCTCTGATGAAGCAGTGATTTTT

Primer 2 - TGATGACCCATAGACAGTAGGATCA

Primer 3 - CTAAAGCGCATGCTCCAGAC

PBND lysis buffer - $10 \mathrm{mM}$ Tris, $50 \mathrm{mM} \mathrm{KCl}, 2.5 \mathrm{mM} \mathrm{MgCl} 2.6 \mathrm{H}_{2} \mathrm{O}, 0.1 \mathrm{mg} / \mathrm{ml}$ gelatin, $0.45 \%$ (v/v) Nonident P40, 0.45\% (v/v) Tween 20, pH 8.3 


\subsubsection{Genotyping of PSD-95 KO mice}

The PSD-95 KO mouse line was generated as described in previous studies (Yao et al., 2004; Abbas et al., 2009). Genotype was determined as described in paragraph 2.4 .1 with following modifications:

\section{PCR mixture}

FastGene HotStart Ready Mix

Primer $1,50 \mu \mathrm{M}$

Primer 2, $50 \mu \mathrm{M}$

$\mathrm{H}_{2} \mathrm{O}$

Lysate

$\begin{aligned} 12.5 \mu \mathrm{L} & \text { Pre-incubation } \\ 0.2 \mu \mathrm{L} & \text { Denaturation } \\ 0.2 \mu \mathrm{L} & \text { Annealing } \\ 12.1 \mu \mathrm{L} & \text { Elongation }\end{aligned}$

$2.0 \mu \mathrm{L} \quad$ Final elongation

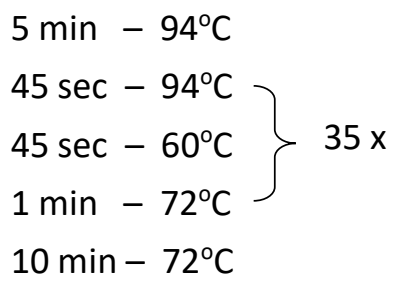

PCR products from WT and PSD-95 KO alleles have 255 and 355 base pairs respectively. Separation of the bands was done as described in paragraph 2.4.1.

Primers:

Primer 1 - CAGGTGCTGCTGGAAGAAGG

Primer 2 - CTACCCTGTGATCCAGAGCTG

\subsection{Stereotaxic viral injections}

\subsubsection{RNAi-mediated knockdown of PSD-95}

A short hairpin RNA (shRNA) construct to knockdown endogenous PSD-95 was prepared as previously described (Huang et al., 2015a). This construct was cloned into an adeno-associated viral vector (AAV) backbone, which also carried a GFP expression marker, under the control of a CAG promoter. Recombinant viruses were produced by Sandra Gebauer as described before (Suska et al., 2013).

\subsubsection{Stereotaxic viral injections in mice}

Following two to three days of painkiller administration (Metamizol; Novaminsulfon, Zentiva) mixed in the drinking water ( $375 \mathrm{mg}$ in $250 \mathrm{~mL}$ ), four- to six-week old mice were anaesthetised via i.p. injection with a mixture of Midazolam (Rotexmedica), Medetomidine (Cepetor; CP-Pharma) and Fentanyl (Rotexmedica), at a dosage of $7.0 \mathrm{mg} / \mathrm{kg}, 0.7 \mathrm{mg} / \mathrm{kg}$ and $0.07 \mathrm{mg} / \mathrm{kg}$ respectively. Throughout the course of the surgery, anaesthesia status was controlled via toe and tail pinch reflexes. If needed, anaesthesia boosters of approximately $1 / 3$ initial dosage were administered via the subcutaneous (s.c.) route. The animal's head was fixed on a stereotaxic frame (Stoelting Co., USA) and an incision was made to reveal the skull. Alignment was achieved using the bregma and lambda. The following coordinates based on the Mouse 
Brain Atlas (Franklin and Paxinos, 2008) were used to target the nucleus accumbens bilaterally: (from the bregma) +1.55 anterior-posterior (AP); \pm 0.55 medial-lateral (ML); -4.70 dorsal-ventral (DV).

Approximately $1 \mu \mathrm{L}$ of viral vector (see section 2.5.1) was injected into each hemisphere through small holes drilled in the skull (OmniDrill35, World Precision Instruments) at a rate of $0.14 \mu \mathrm{L} / \mathrm{min}$. The viral vector solution was administered via a glass micropipette attached to an injector (Nanoject II, Drummond Scientific Company) driven by a microsyringe pump controller (Micro4, World Precision Instruments, Inc.). The micropipette was left in place for 4.5 minutes to allow viral vector diffusion and then slowly retracted. In order to ensure hydration and avoid hypothermia, warm saline was administered s.c.. Following injection and suturing of the skin incision, s.c. injections of $1 \mathrm{mg} / \mathrm{kg}$ Atipamezole (Revertor, CP- Pharma) and $0.1 \mathrm{mg} / \mathrm{kg}$ Buprenorphine (Buprenovet, Bayer) were given to antagonise anaesthesia. Additionally, a s.c. injection of $5 \mathrm{mg} / \mathrm{kg}$ Carprofen (Rimadyl, Zoetis) was given as an analgesic. To promote optimal recovery, the mice were allowed to drink Metamizol-containing water for five to seven days. The behavioural experiments started at least two weeks post-op, allowing sufficient time for the expression of the viral construct in the neurons.

\subsubsection{Imaging of viral vector injection site}

After the CPP procedure was completed, it was necessary to document the success of injections, in terms of injection site and spread of viral vector expression. To that end, mice were anaesthetised with isoflurane (100\% Forene, Abbvie) and transcardially perfused with cold 0.01 M PBS followed by 4\% paraformaldehyde (PFA) solution. Brains were extracted and kept overnight in 4\% PFA solution to optimise fixation and subsequently in PBS. Next, $300 \mu \mathrm{m}$ coronal slices were cut using the Leica VT1200-S vibratome in PBS solution, mounted with Mowiol-DABCO and imaged with the Nikon SMZ18 Stereo Microscope.

Solutions:

Paraformaldehyde (PFA) solution - 1x PBS, 4\% paraformaldehyde, $1 \mathrm{~N} \mathrm{NaOH},+\mathrm{HCl}, \mathrm{pH} 6.9$

PBS - 0.137 M NaCl, 0.05 $\mathrm{M} \mathrm{Na}_{2} \mathrm{PO}_{4}, \mathrm{pH} 7.4$

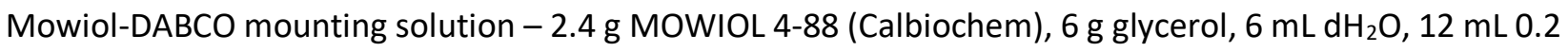
$M$ Tris [pH 8.5], $2.5 \%$ w/v DABCO (Aldrich) 


\subsection{Acute NAc slice preparation}

Mice were anaesthetised with isoflurane and decapitated. The brain was dissected and instantly submerged in ice-cold NMDG cutting buffer, bubbled with carbogen gas $\left(95 \% \mathrm{O}_{2} / 5 \% \mathrm{CO}_{2}\right)$. Coronal slices of $300 \mu \mathrm{m}$ were cut using the Leica VR1200-S vibratome. Those containing nucleus accumbens (NAc) were collected in artificial cerebrospinal fluid (aCSF), for recovery, at $35^{\circ} \mathrm{C}$ for $13-15$ minutes. Between recovery and beginning of the recording, the slices were kept in aCSF for a minimum of 30 minutes at room temperature (RT). aCSF was continuously bubbled with carbogen, both during recovery and at RT.

Solutions:

NMDG cutting buffer - 135 mM NMDG ( $N$-methyl D-glucamine, Sigma), 1 mM KCl (Sigma), $1.2 \mathrm{mM} \mathrm{KH}_{2} \mathrm{PO}_{4}$, $1.5 \mathrm{mM} \mathrm{MgCl}_{2} .6 \mathrm{H}_{2} \mathrm{O}$ (Sigma), $0.5 \mathrm{mM} \mathrm{CaCl} 2.2 \mathrm{H}_{2} \mathrm{O}, 10 \mathrm{mM}$ D-Glucose (Merck), $20 \mathrm{mM}$ choline bicarbonate (Sigma)

aCSF recovery buffer - $119 \mathrm{mM} \mathrm{NaCl}$ (Roth), $2.5 \mathrm{mM} \mathrm{KCl}$ (Sigma), $1 \mathrm{mM} \mathrm{NaH}_{2} \mathrm{PO}_{4}$ (Sigma), $26 \mathrm{mM} \mathrm{NaHCO}_{3}$ (Sigma), 20 mM D-Glucose (Merck), $1.3 \mathrm{mM} \mathrm{MgSO}_{4} .7 \mathrm{H}_{2} \mathrm{O}$ (Roth) and $2.5 \mathrm{mM} \mathrm{CaCl}_{2} .2 \mathrm{H}_{2} \mathrm{O}$ (Roth)

NMDG cutting buffer was prepared as a $3 x$ stock and kept at $4^{\circ} \mathrm{C}$. D-Glucose and choline bicarbonate were added freshly upon preparation of the working $1 x$ concentration. aCSF recovery buffer was prepared as a 10x stock and kept at RT. D-glucose, $\mathrm{NaHCO}_{3}, \mathrm{MgSO}_{4} \cdot 7 \mathrm{H}_{2} \mathrm{O}$ and $\mathrm{CaCl}_{2} \cdot 2 \mathrm{H}_{2} \mathrm{O}$ were added freshly upon preparation of the working $1 x$ concentration.

\subsection{Electrophysiology}

\subsubsection{Electrophysiological setup}

Following setup was used for all electrophysiological recordings:

ZEISS AXIO Examiner D1 microscope, 5x A-Plan air and 63x W Plan-APOCHROME water objective ELC-03XS amplifier (NPI instruments, Germany)

ITC-18 data acquisition board (HEKA)

TC-20 temperature controller (NPI instruments, Germany)

VLP-1303 PRO peristaltic pump (Voltcraft)

Hamamatsu CCD camera

ISO-FLEX stimulator (A.M.P.I., Jerusalem, Israel)

Micromanipulator SM-5 (Luigs \& Neumann, Germany)

Igor Pro 6.2 data acquisition software (Wave Metrics) 
The external solution (aCSF) was the same in composition as the recovery buffer (see above). The perfusion rate through the recording chamber was controlled by a peristaltic pump and kept stable at 2-3 $\mathrm{mL} / \mathrm{min}$. Temperature of incoming external solution and recording chamber was kept between $27-29^{\circ} \mathrm{C}$.

A micropipette puller (P-1000 and Sutter Instruments) was used to prepare borosilicate glass patch pipettes (KG-33, King Precision Glass Inc., USA) of 2.7-4.5 M 2 resistance. Following the identification of a cell of interest, the patch pipette was filled with internal solution (see below) and immersed into the bath. All recordings performed for this study were whole-cell patch clamp recordings at stable, controlled voltage (voltage clamp). Data was filtered at $3 \mathrm{kHz}$ through the amplifier.

Internal solution - 50\% w/v CsOH (Sigma), $117.5 \mathrm{mM} \mathrm{MeSO}_{3} \mathrm{H}$ (Fluka), $10 \mathrm{mM} \mathrm{HEPES} \mathrm{(Roth),} 17.75 \mathrm{mM}$ $\mathrm{CsCl}$ (Roth), $10 \mathrm{mM}$ TEA-Cl (Fluka), $0.25 \mathrm{mM}$ EGTA (Roth), $10 \mathrm{mM}$ Glucose (Merck), $2 \mathrm{mM} \mathrm{MgCl} 2.6 \mathrm{H}_{2} \mathrm{O}$ (Sigma), $5 \mathrm{mM}$ QX-314 chloride (Sigma), 4 mM Na 2 ATP (Sigma) and $0.3 \mathrm{mM} \mathrm{NaGTP} \mathrm{(Sigma);} \mathrm{pH} \mathrm{adjusted}$ to 7.0-7.3 and osmolarity adjusted to 290-293 mOsm. Throughout the recording, the internal solution was kept at $4^{\circ} \mathrm{C}$.

\subsubsection{NAc shell recordings}

Medium spiny neurons (MSNs) constitute more than 95\% of cells in the NAc shell, the rest being interneurons. All recordings were performed on MSNs; interneurons, if selected, were identified by properties such as high series resistance $(>40 \mathrm{M} \Omega$ ) as well as high spontaneous activity and were removed from the dataset. Given that NAc receives strong inhibitory input, $100 \mu \mathrm{M}$ Picrotoxin, a $\mathrm{GABA}_{\mathrm{A}}$ receptor blocker, was added to the external aCSF (Abcam, Germany). Electrical stimulation via a borosilicate 2barrel glass capillary (World Precision Instruments) filled with aCSF was used to evoke excitatory postsynaptic currents (EPSCs) in NAc MSNs. All cells were patched at a holding potential of $-60 \mathrm{mV}$. In case the series resistance of a cell showed a change of $30 \%$ or more throughout the recording, this cell was excluded during analysis.

\subsubsection{AMPAR Rectification Index - Quantifying CP-AMPAR proportion}

For this assay, it is important to record pure AMPA EPSCs, also at depolarised potentials. Hence, NMDA currents were blocked by adding $50 \mu \mathrm{M}$ D-AP5 (hello bio, UK) to the aCSF. $100 \mu \mathrm{M}$ Spermine (Roth, Germany) was added to the internal solution, in order to block CP-AMPARs in a voltage-dependent manner.

Stimulation frequency was $0.1 \mathrm{~Hz}$ and stimulation intensity was adjusted so that EPSCs of 50-300 pA amplitude were recorded. Around $25-40$ sweeps were recorded at holding potential (-60 mV), to account 
for variability in response amplitude. The cell was then depolarised to $+40 \mathrm{mV}$ and $25-40$ more sweeps were recorded. In order to verify the equilibrium potential, 5-10 sweeps were recorded at $0 \mathrm{mV}$. The AMPA response amplitude at -60 and $+40 \mathrm{mV}$ was calculated from the response peak in reference to the baseline at the respective holding potential. The following formula was used to calculate the rectification index:

$$
\text { Rectification index }(R I)=\frac{\text { AMPA EPSC }_{-60 m V}}{\text { AMPA EPSC }_{+40 m V}}
$$

\subsection{Data analysis}

All data are presented as mean \pm SEM (standard error of mean). Statistical significance is indicated as: * $p<0.05,{ }^{* *} p<0.01$ and ${ }^{* * *} p<0.001$. In the case of behavioural experiments which were repeated at different time points, data were pooled. For CPP data, repeated-measures ANOVA was followed by posthoc Bonferroni-corrected paired Student $t$-test. For electrophysiology data, values from different cells of a single animal were averaged and, afterwards, unpaired $t$-test was used to compare animals of different conditions. Each condition is shown by $\mathrm{n} / \mathrm{m}=$ number of animals/number of cells sampled. 


\section{Results}

\subsection{Cocaine reinstates conditioned place preference}

To investigate the role of silent synapses and CP-AMPARs in cocaine relapse, I used a conditioned place preference (CPP) procedure. CPP is widely used for measuring drug reward, rather than addiction per se, since the drug administration is not under the operant control of the animal. To test the extent of relapselike behaviour in mice, I performed extinction and reinstatement of CPP.

Following habituation, baseline (BL) preference testing and ten-day conditioning (for details, see section 2.2.1), mice were tested for their conditioned preference by placing them in the neutral area of the apparatus in the absence of an injection, and being given free access to both chambers (withdrawal day 1; WD1). An increased place preference score (PPS) was considered as a preference towards the cocaineassociated chamber, meaning that the animal successfully learned the association between the positive cocaine experience and the conditioned chamber, and hence was motivated to spend more time in it, even in absence of the drug. Mice were then returned to their home cage for 72 hours, and then subjected to a six-day long extinction of CPP, followed by a single reinstatement injection. A decreased PPS on extinction day 6 (extD6) compared to WD1 was considered as an extinction of the learned preference, meaning that the mice have learned to no longer associate the cocaine experience with the conditioned compartment. On day 7 , the mice were given a challenge injection of cocaine to reinstate the CPP, and their preference was tested once again (Figure 3.1A).

Wild type (WT) mice developed a strong preference towards the cocaine-associated chamber following conditioning (Figure 3.1B), as shown by an increase in the PPS (BL vs WD1: PPS $524.35 \pm 16.74$ vs $691.84 \pm$ 19.92; $\mathrm{n}=21$; paired $t$-test $p^{* * *}<0.001$ ). This preference was abolished following extinction training, with a decrease in the PPS (extD6 PPS $567.43 \pm 14.71$; paired $t$-test with WD1 $p^{* * *}<0.001$ ). Delivering an injection of cocaine 24 hours later restored the preference, with an increase in the PPS (reins PPS 684.00 \pm 26.35 ; paired $t$-test with extD6 $p^{* *}<0.01$; repeated-measures ANOVA: $\left.F_{(3,60)}=22.501, p<0.001\right)$. In order to confirm that reinstatement is specific to the challenge cocaine injection, a second WT group was injected with saline on reinstatement (reins) day and, as expected, their preference for the CS+ chamber remained similar to that measured on extinction day 6 (extD6) (BL vs WD1 vs extD6 vs reins: PPS $515.04 \pm$ 32.45 vs $765.55 \pm 23.74$ vs $604.67 \pm 44.45$ vs $589.69 \pm 44.13 ; n=8 ;$ BL vs WD1 PPS $p^{* * *}<0.001$, WD1 vs extD6 PPS $p^{* *}<0.01$ and extD6 vs reins PPS $p>0.99$, post-hoc Bonferroni-adjusted paired $t$-tests; repeated-measures ANOVA: $\left.F_{(3,21)}=15.599, p<0.001\right)$. 

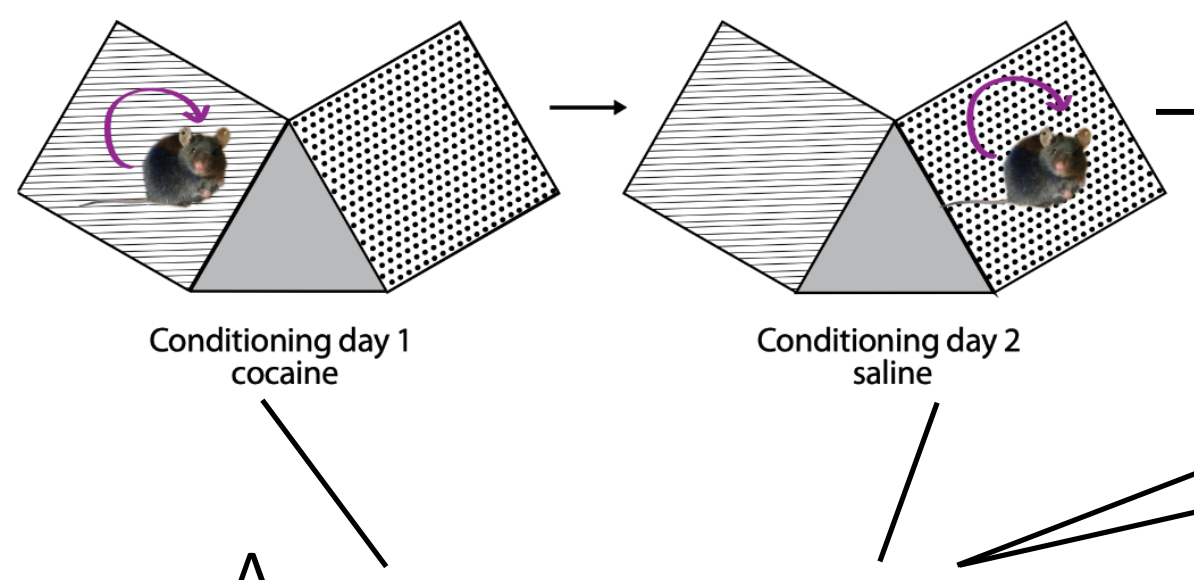

Conditioning day 2

saline

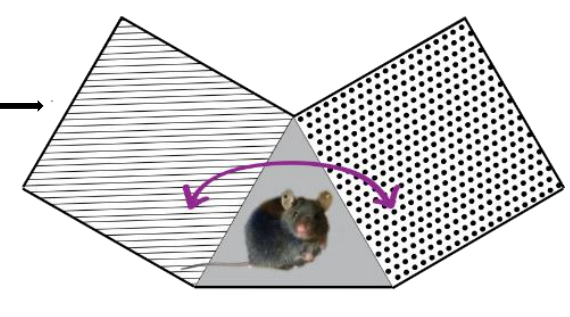

CPP test

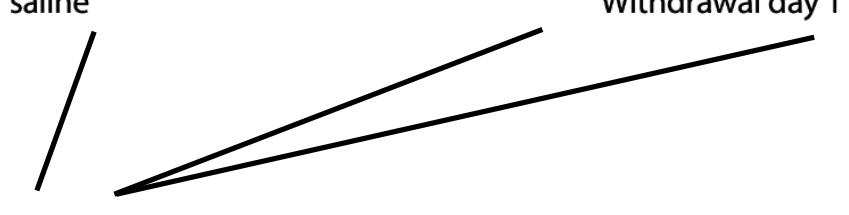

A
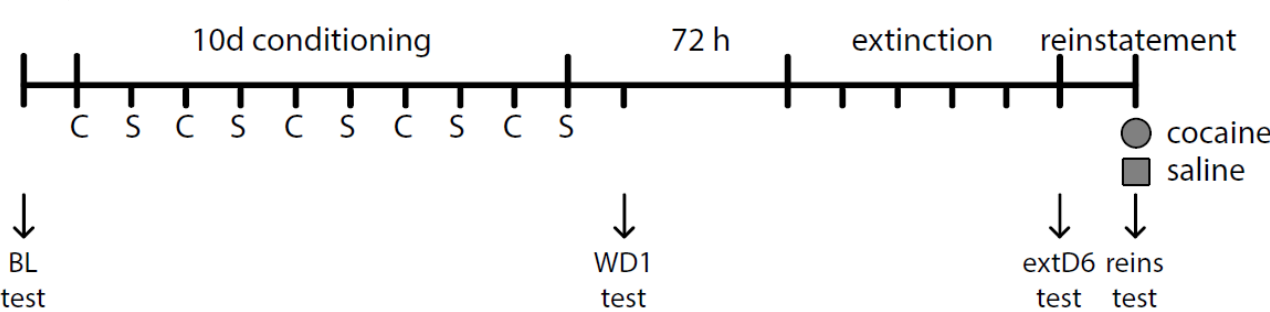

B

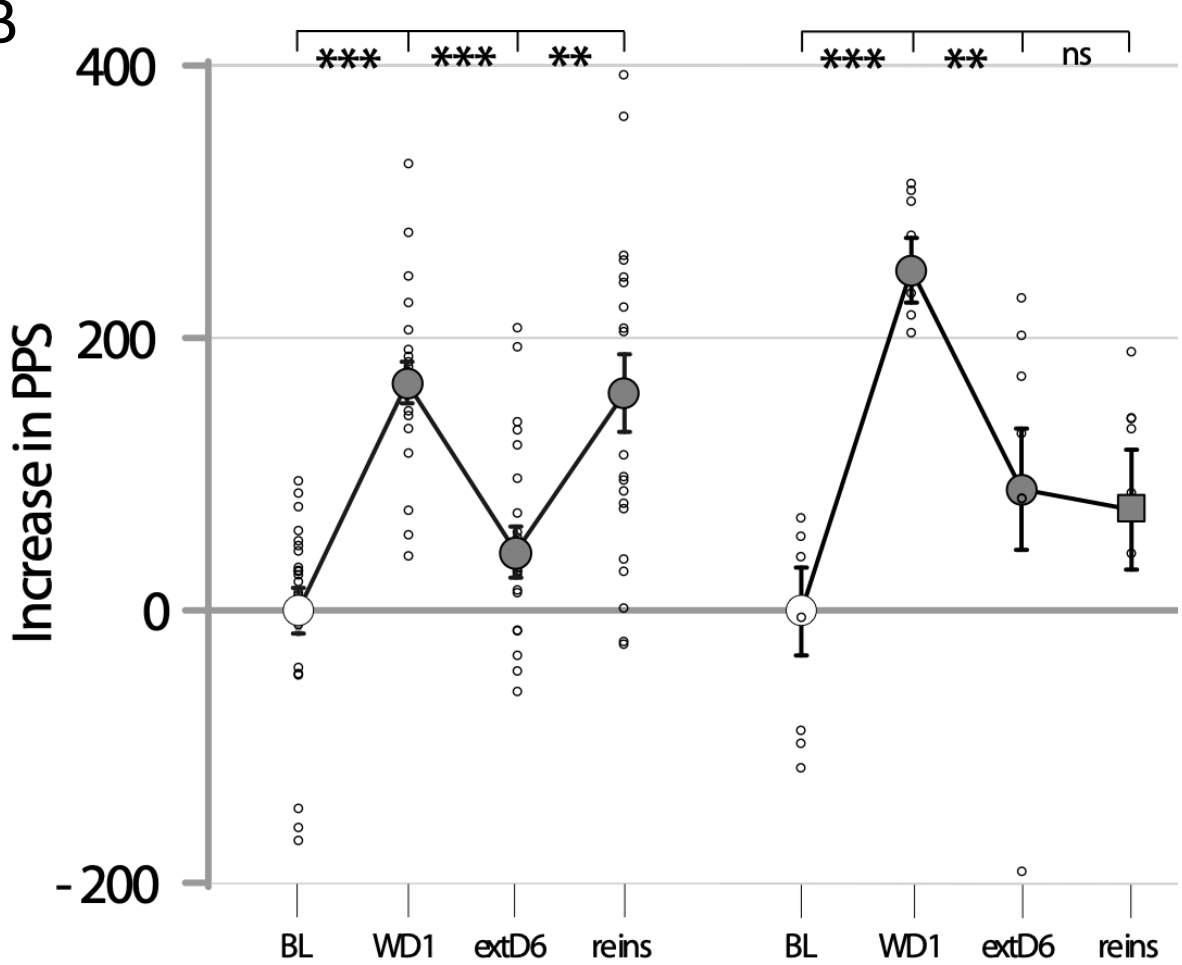

Figure 3.1: Cocaine reinstates conditioned place preference in WT mice.

(A) Schematic representation of the training and testing days of the CPP procedure and timeline of the experiment with conditioning, extinction training and reinstatement (C-cocaine, S-saline). (B) Y axis: increase in place preference score (PPS), calculated by normalising to the baseline (BL). Reinstatement of the learned preference is cocaine-specific, as seen by the control group which received a saline injection on reinstatement (reins) day. The smaller dots represent the individual performances of the mice. $\mathrm{N}=21$ and 8 mice injected with cocaine and saline on reinstatement day respectively. Data presented as mean \pm SEM. Statistical significance was assessed by within-group repeated-measures ANOVA followed by post-hoc Bonferroni-corrected paired $t$-tests. 


\subsection{CP-AMPARs and reinstatement gain control}

\subsubsection{CP-AMPARs are increased after cocaine - CPP reinstatement}

Silent synapses lacking AMPARs, an early brain development marker, can be re-generated in the adult nucleus accumbens shell (NAcSh), a key component of the reward circuitry, upon cocaine exposure (Huang et al., 2009; Lee and Dong 2011). Following cocaine withdrawal, some of these cocaine-generated silent synapses become unsilenced through the recruitment of calcium-permeable AMPARs (CP-AMPARs) which lack the GluA2 subunit (Lee et al., 2013).

Our group has previously shown that CP-AMPAR incorporation into cocaine-generated silent synapses is not related to the long-term retention of the CPP association (Shukla et al., 2017). A study with cocaine self-administration in rats demonstrated that blockade of CP-AMPAR activity prevented normal craving responses, which suggests their involvement in mediating incubation of craving (Conrad et al., 2008). Moreover, a recent CPP study with mice showed that CP-AMPAR removal blocks morphine reinstatement (Hearing et al., 2016). Based on these findings, we asked whether CP-AMPARs are involved in the intensity of a drug-related response, rather than the long-term memory coding.

The first step was to find out whether CP-AMPARs accumulate in the NAcSh synapses after reinstatement. Electrophysiological recordings analysed below were performed on medium spiny neurons (MSNs), the principal cell type (more than 95\%) of the region, with the rest being interneurons of several kinds. The MSNs were chosen at random, by visual identification initially and their identity was confirmed thereafter through their electrophysiological properties; cells with high series resistance (>40 M $\Omega$ ) or high spontaneous activity were identified as interneurons and removed from the dataset.

WT mice used for these recordings were sacrificed right after the completion of the reinstatement CPP test (Figure 3.2A). To estimate the proportion of GluA2-lacking CP-AMPARs, I recorded the rectification index (RI) from NAcSh MSNs; a higher RI suggests a higher CP-AMPAR proportion in the recorded cell. I evoked AMPA excitatory postsynaptic currents (EPSCs) at holding potentials of $-60,0$ and $+40 \mathrm{mV}$ and

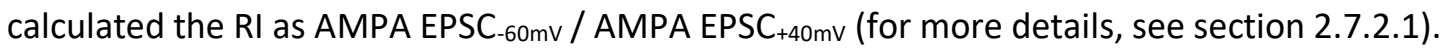

The baseline rectification index was calculated from naïve WT mice of the same age as the reinstated group (8-10 weeks old) and was observed to be $1.90 \pm 0.09(\mathrm{n} / \mathrm{m}=6 / 17)$. The rectification index measured from WT mice directly after CPP reinstatement was $2.27 \pm 0.14(\mathrm{n} / \mathrm{m}=5 / 12)$. Unpaired $t$-test comparison between animals of the two groups, revealed that this increase was statistically significant $\left(p^{*}<0.05\right)$. This result suggests that CP-AMPAR levels in the NAc are elevated following cocaine-CPP reinstatement. 
A

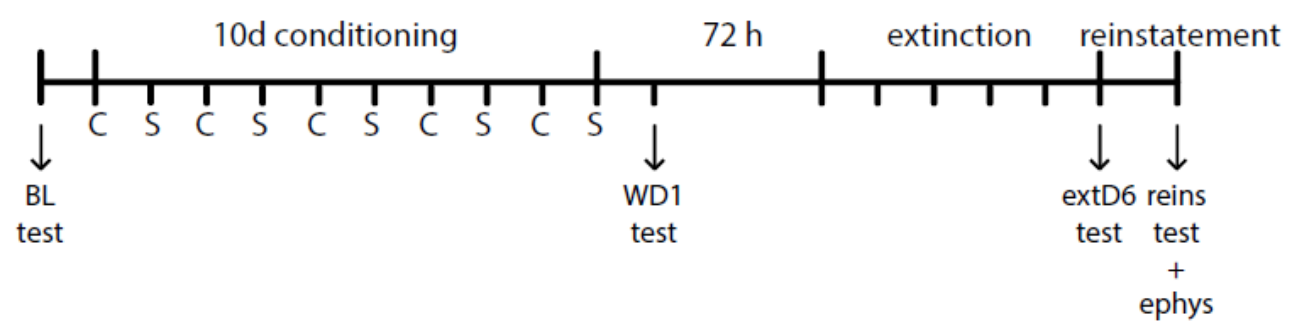

B

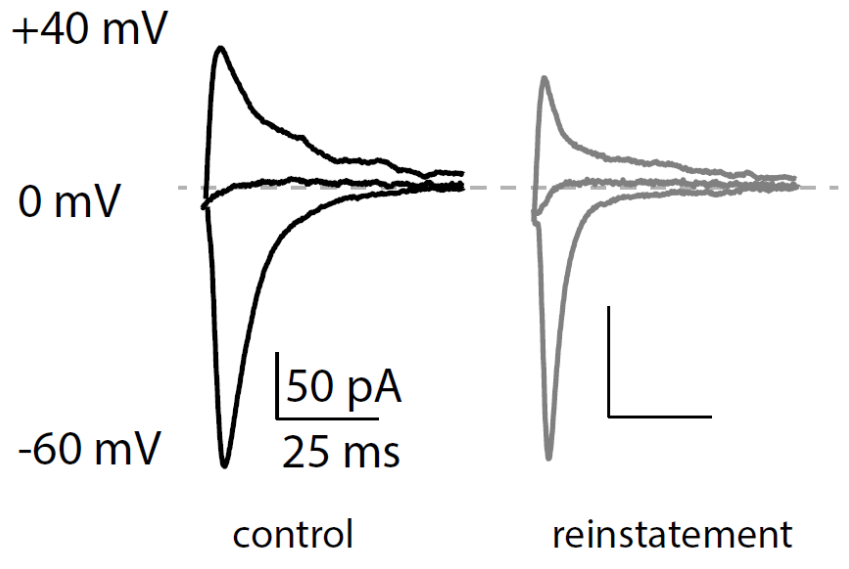

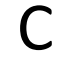

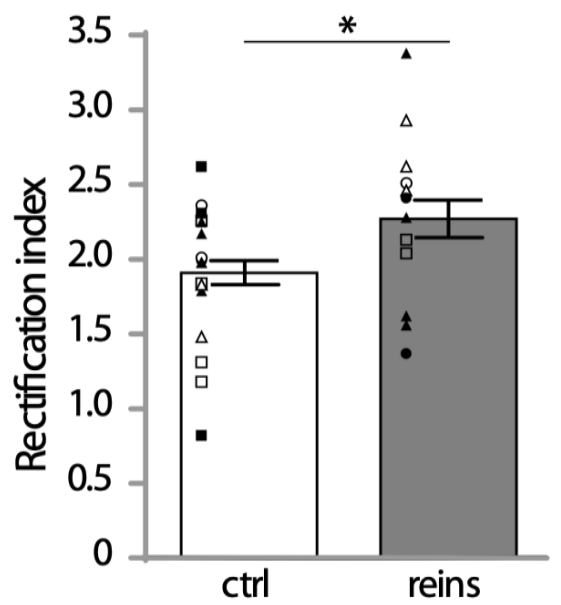

Figure 3.2: CP-AMPARs are increased after cocaine-CPP reinstatement.

(A) Timeline of the experiment with conditioning, extinction training and reinstatement (C-cocaine, S-saline); Electrophysiological (ephys) recording was performed right after the completion of the CPP test. Naïve mice of similar age were used as controls. (B) Example AMPA EPSCs evoked at $-60 \mathrm{mV}, 0 \mathrm{mV}$ and $+40 \mathrm{mV}$ during rectification index assay. (C) Rectification index, a measure of CP-AMPARs in NAcSh synapses increases after cocaine-CPP reinstatement. Each point represents a recorded cell and each animal is represented by a different shape. Data presented as mean \pm SEM. Statistical significance was assessed by unpaired $t$-test between the animals of each group.

Two cells from the reinstatement group were recorded and analysed by Alexander Engelhardt. 
3.2.2 CP-AMPARs are not required for cocaine - CPP reinstatement upon administration of a high challenge dose

After confirming that CP-AMPARs also accumulate in NAcSh upon cocaine reinstatement, the next step was testing whether correlation also means causality. To that end, I tested whether CP-AMPAR presence and/or activity is required for reinstatement, implementing a pharmacological and a genetic approach. Ceftriaxone is an antibiotic that was reported to block morphine reinstatement by restoring CP-AMPAR expression to baseline levels (Hearing et al., 2016), while SAP102 knock out (KO) mice were shown to not incorporate CP-AMPARs during silent synapse maturation upon cocaine withdrawal (Shukla et al., 2017).

WT mice developed a strong preference towards the cocaine-associated chamber following conditioning (BL vs WD1: PPS $530.50 \pm 18.66$ vs $687.36 \pm 19.24 ; \mathrm{n}=15$; paired $t$-test $p^{* * *}<0.001$; repeated-measures ANOVA: $\left.F_{(3,42)}=22.088, p<0.001\right)$. The animals then received six daily injections of ceftriaxone during extinction training (Figure 3.3A), which led to the expected decrease in preference (extD6 PPS $583.27 \pm$ 15.76; paired $t$-test with WD1 $p^{* * *}<0.001$ ). In contrast to the blockade of morphine reinstatement in the study by Hearing and colleagues (2016), cocaine reinstatement in the present study was not impaired by ceftriaxone, as seen by the increased PPS following a cocaine challenge injection (reins PPS 663.57 \pm 23.13 ; paired $t$-test with extD6 $\left.p^{*}<0.05\right)$. Similarly, no change on cocaine reinstatement was seen following deletion of SAP102. SAP102 KO mice were also able to learn the association, and the conditioned preference was strongly reinstated following successful extinction (BL vs WD1 vs extD6 vs rein: PPS 441.90 \pm 25.83 vs $818.94 \pm 34.52$ vs $403.47 \pm 80.37$ vs $731.87 \pm 72.38 ; n=10 ; B L$ vs WD1 PPS $p^{* * *}<0.001 ;$ WD1 vs extD6 PPS $p^{* * *}<0.001$; extD6 vs rein PPS $p^{* * *}<0.001$, post-hoc Bonferroni-adjusted paired $t$-tests; repeated-measures ANOVA: $\left.F_{(3,27)}=23.172, p<0.001\right)$. Taken together, these results suggest that $\mathrm{CP}$ AMPARs are not required for cocaine-CPP reinstatement, when a relatively high dose of cocaine is used as the priming cue (Figure 3.3B). 


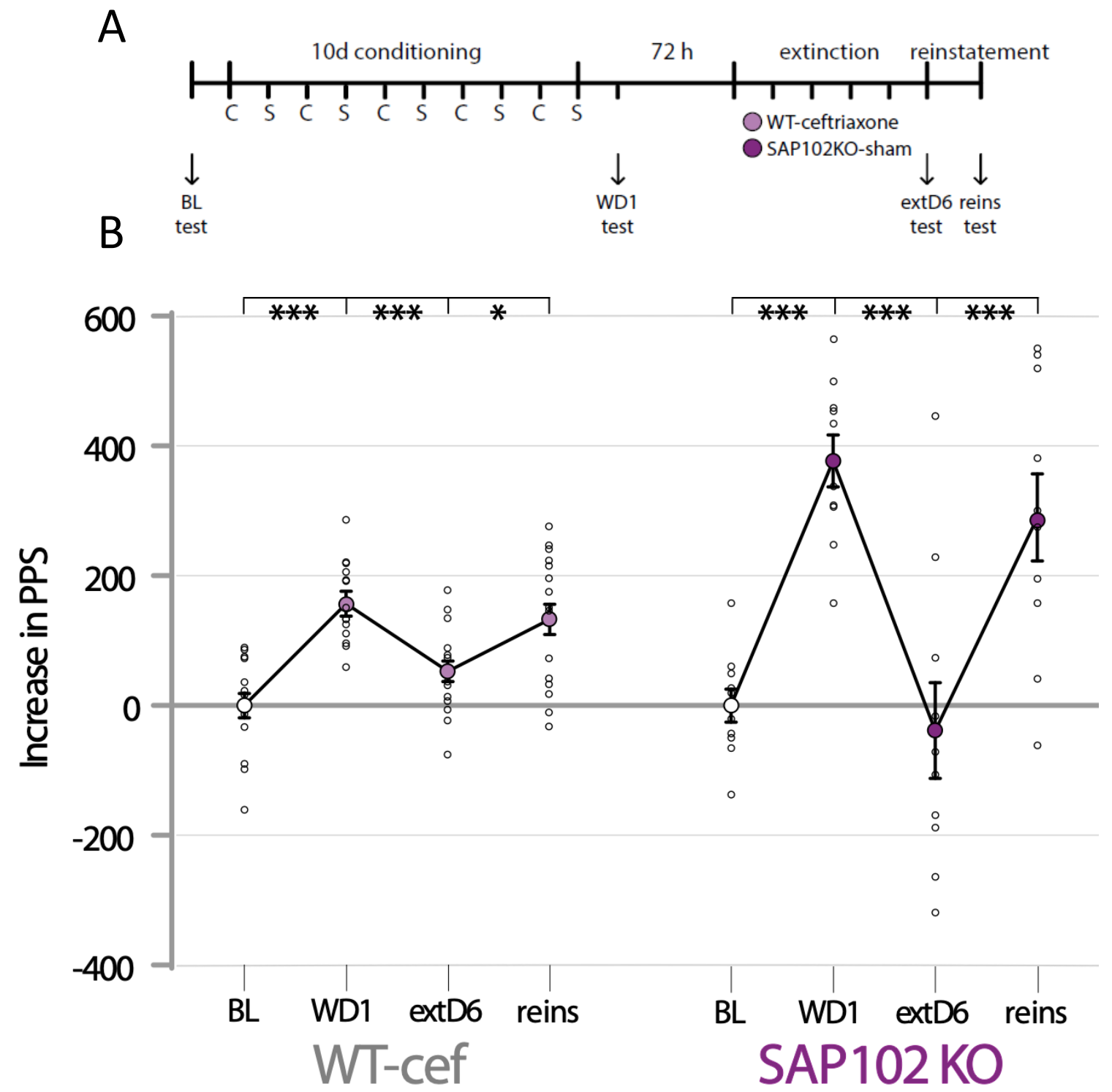

Figure 3.3: CP-AMPARs are not required for cocaine-CPP reinstatement upon high challenge dose administration.

(A) Timeline of the experiment with conditioning, extinction training and reinstatement (C-cocaine, S-saline). WT group received six daily ceftriaxone i.p. injections during extinction training. SAP102 KO group received sham i.p. injections. (B) Y axis: increase in place preference score (PPS) calculated by normalising to the baseline (BL) score prior to commencement of the training. Extinction and reinstatement were not impaired in either group. The smaller dots represent the individual performances of the mice. $\mathrm{N}=15$ and 10 mice for WT-cef and SAP102 KO respectively. Data presented as mean \pm SEM. Statistical significance was assessed by within-group repeated-measures ANOVA followed by post-hoc Bonferroni-corrected paired $t$-tests. 


\subsubsection{Low cue intensity without CP-AMPARs is insufficient for CPP reinstatement}

For the aforementioned experiments, I used the same dose of cocaine for reinstatement as for establishing the conditioned preference during the ten-day training $(20 \mathrm{mg} / \mathrm{kg})$. Since CP-AMPARs are not required for reinstatement, the possibility remained that their importance lies in regulating the threshold for reinstatement: if the cue (cocaine challenge injection) is sufficiently strong, the drug-induced response will always be reinstated. However, if the stimulus is too weak to successfully reinstate the response, it is possible that the concurrent activity of CP-AMPARs in the NAc may serve to tip it over the threshold.

I first investigated in WT mice whether a cue of lower intensity has an effect on performance during reinstatement.

I compared the original reinstatement dose of $20 \mathrm{mg} / \mathrm{kg}$ to 5 and $2 \mathrm{mg} / \mathrm{kg}$. Mice that were trained with $20 \mathrm{mg} / \mathrm{kg}$ and received an i.p. injection of $5 \mathrm{mg} / \mathrm{kg}$ cocaine on reinstatement day learned the association and reinstated preference similarly as when given $20 \mathrm{mg} / \mathrm{kg}$ as a challenge injection (BL vs WD1 vs extD6 vs rein: PPS $502.36 \pm 24.73$ vs $687.13 \pm 15.78$ vs $596.93 \pm 20.77$ vs $680.24 \pm 31.19 ; n=8 ;$ BL vs WD1 PPS

$p^{* * *}<0.001$; WD1 vs extD6 PPS $p^{* * *}<0.001$; extD6 vs rein PPS $p^{* * *}<0.001$, post-hoc Bonferroniadjusted paired $t$-tests; repeated-measures ANOVA: $\left.F_{(3,24)}=20.548, p<0.001\right)$. Likewise, a cocaine dose of $2 \mathrm{mg} / \mathrm{kg}$ was also sufficient to reinstate CPP (BL vs WD1 vs extD6 vs rein: PPS $521.45 \pm 19.10$ vs $709.63 \pm$ 22.79 vs $553.53 \pm 20.22$ vs $616.19 \pm 25.30 ; n=12 ; B L$ vs WD1 PPS $p^{* * *}<0.001 ;$ vs extD6 PPS $p^{* * *}<0.001$; extD6 vs rein PPS $p^{* * *}<0.001$, post-hoc Bonferroni-adjusted paired $t$-tests; repeated-measures ANOVA: $\left.F_{(3,33)}=18.958, p<0.001\right)$ (Figure 3.4A). Upon normalising the reinstatement PPS to that of extinction day 6 , there is a clear dose-dependency descriptively, but this difference is not statistically significant (oneway ANOVA: $F_{(2,39)}=1.011, p=0.373$, unpaired $t$-test between 20 and $2 \mathrm{mg} / \mathrm{kg}$ cocaine as a challenge dose $p=0.141)$ (Figure 3.4B).

Since a dose of $2 \mathrm{mg} / \mathrm{kg}$ cocaine (i.e. as low as $10 \%$ of the original training amount) was sufficient to reinstate CPP in WT mice, I proceeded to repeat the experiments described in section 3.2 .1 with $2 \mathrm{mg} / \mathrm{kg}$ cocaine as the challenge injection. Both WT mice receiving ceftriaxone and the SAP102 KO group learned the association, as expected, with the latter again showing pronounced conditioning (WT; repeatedmeasures ANOVA: $F_{(3,39)}=22.822, p<0.001 ; \mathrm{BL}$ vs WD1: PPS 509.26 \pm 20.44 vs 703.45. $\pm 13.82 ; \mathrm{n}=14$; paired $t$-test $p^{* * *}<0.001$. SAP102 KO; repeated-measures ANOVA: $F_{(3,30)}=21.461, p<0.001 ; \mathrm{BL}$ vs WD1: PPS $455.09 \pm 29.51$ vs $807.60 \pm 16.65 ; \mathrm{n}=11$; paired $t$-test $p^{* * *}<0.001$ ). Extinction was similarly successful: ceftriaxone administration throughout the six days of training did not affect the performance of the WT group, while SAP102 KO mice again showed pronounced extinction (WT extD6 PPS $603.16 \pm$ 
19.51; paired $t$-test with WD1 $p^{* * *}<0.001$. SAP102 KO extD6 PPS $524.02 \pm 38.62$; paired $t$-test with WD1 $\left.p^{* * *}<0.001\right)$. In sharp contrast to WT mice, $2 \mathrm{mg} / \mathrm{kg}$ of cocaine failed to reinstate the preference of the ceftriaxone-treated WT mice (reins PPS $605.57 \pm 19.23$; paired $t$-test with extD6 $p>0.99$ ). This dose was also insufficient for the SAP102 KO mice (reins PPS $520.61 \pm 61.63$; paired $t$-test with extD6 $p>0.99$ ) (Figure 3.4C). Additionally, I calculated the increase in PPS from extinction day 6 to reinstatement day with 2 $\mathrm{mg} / \mathrm{kg}$ cocaine and compared it to that of the respective $20 \mathrm{mg} / \mathrm{kg}$-reinstated groups. In both ceftriaxonetreated WT (Figure 3.4D) and SAP102 KO mice (Figure 3.4E), the increase in PPS was much stronger for the $20 \mathrm{mg} / \mathrm{kg}$ as compared to the $2 \mathrm{mg} / \mathrm{kg}$ cocaine challenge dose (unpaired $t$-test between 20 and $2 \mathrm{mg} / \mathrm{kg}$ cocaine as a challenge dose: WT-cef $p<0.05$; SAP102 KO $p<0.001$ ), indicating that CP-AMPARs are necessary for a weak stimulus to induce cocaine-CPP reinstatement. 

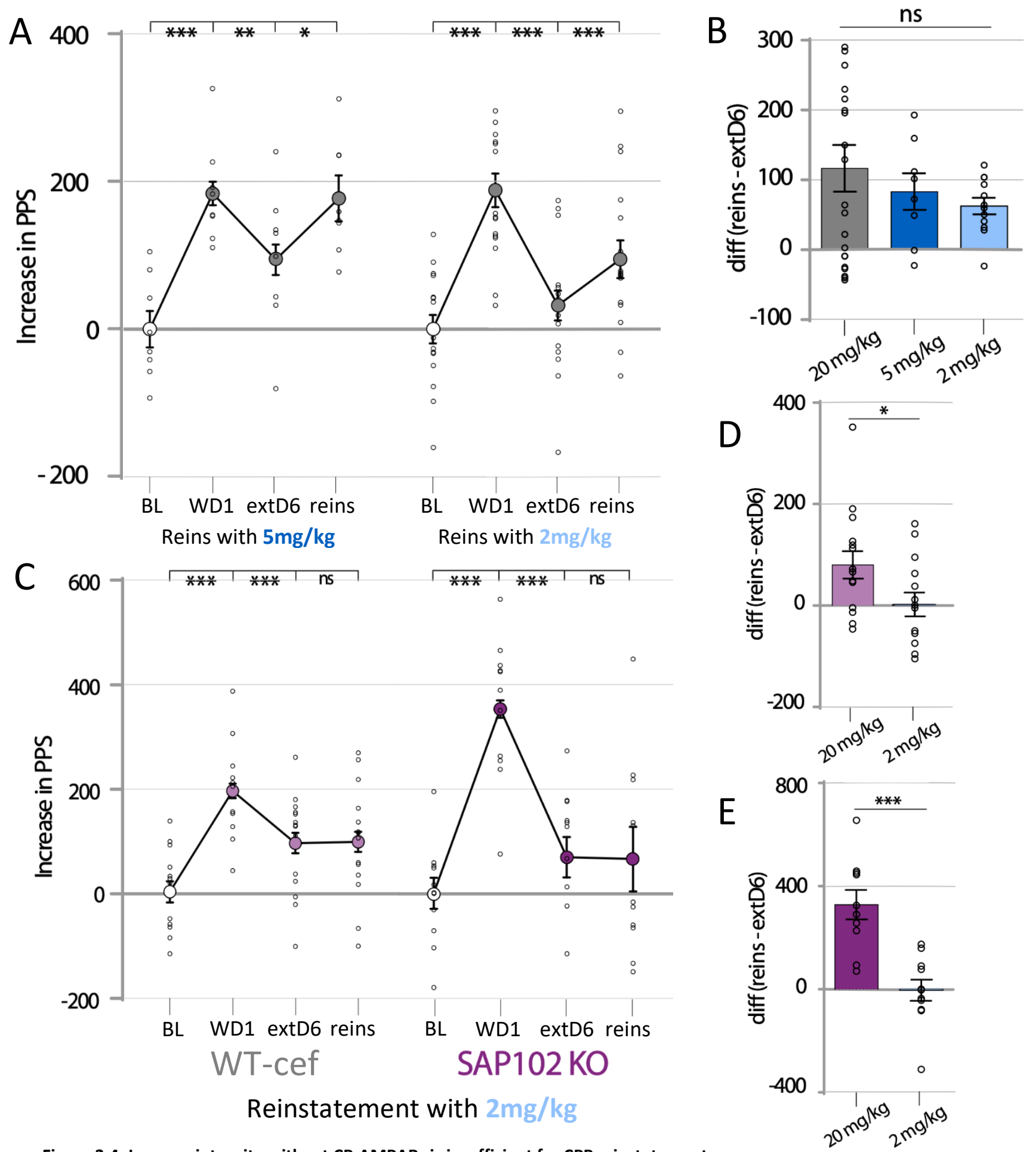

Figure 3.4: Low cue intensity without CP-AMPARs is insufficient for CPP reinstatement.

(A), (C) $Y$ axis: increase in place preference score (PPS) calculated by normalising to the baseline (BL) score. (A) Challenge injections of $5 \mathrm{mg} / \mathrm{kg}$ and $2 \mathrm{mg} / \mathrm{kg}$ cocaine were enough to reinstate CPP. $\mathrm{N}=8$ and 12 mice for $5 \mathrm{mg} / \mathrm{kg}(\mathrm{rein})$ and $2 \mathrm{mg} / \mathrm{kg}(\mathrm{rein})$ respectively. (C) Challenge injection of $2 \mathrm{mg} / \mathrm{kg}$ cocaine does not suffice to reinstate CPP in ceftriaxone-treated WT or SAP102 KO mice. $\mathrm{N}=14$ and 11 mice for WT-cef and SAP102 KO respectively. (B), (D), (E) PPS on reinstatement day was normalised to PPS of extinction day 6 to check for a potential dependency between doses and PPS increase. (B) In WT control mice, the PPS increase following reinstatement did not significantly differ between different cocaine challenge doses (one-way ANOVA). High $(20 \mathrm{mg} / \mathrm{kg})$ and low $(2 \mathrm{mg} / \mathrm{kg})$ challenge dose are compared in terms of reinstatement strength induced in WT-cef (D) and SAP102 KO mice (E). Unpaired $t$-test between the two doses reveals a significant difference (WT-cef group $p^{*}<0.05$, SAP102 KO group $\left.p^{* * *}<0.001\right)$. Data presented as mean \pm SEM. The smaller dots represent the mice individual performances. Statistical significance was assessed by within-group repeated-measures ANOVA followed by post-hoc Bonferroni-corrected paired $t$-tests $(\mathbf{A}, \mathbf{C})$, or one-way ANOVA (B) and independent $t$-test $(\mathbf{D}, \mathrm{E})$ respectively. 


\subsection{Silent synapses: memory retention or retrieval?}

\subsubsection{PSD-95 KO and cocaine reinstatement}

Postsynaptic density protein 95 (PSD-95) has been shown to play a key role in the maturation of silent synapses. Our group and others have previously demonstrated that adult PSD-95 KO mice have a higher baseline number of silent synapses than WTs (Béique et al., 2006; Huang et al., 2015a). Using the CPP procedure, these mice were found to have an impaired long-term retention of cocaine-associated memories, since they were able to learn the association, but did not retain it after 20-25 days of withdrawal. In contrast, WT mice retain the memory after 40-45 days of withdrawal. We demonstrated that the already elevated silent synapse levels of the PSD-95 KO mouse increase further following exposure to cocaine. Additionally, we found that these levels persist throughout prolonged withdrawal, contrary to the silent synapse maturation observed in the WT. Interestingly, a targeted knockdown of PSD-95 in the NAc of adult mice induced silent synapses at the cellular level, but did not reproduce the PSD-95 KO behavioural phenotype observed in the CPP procedure, as the mice retained the cocaine-associated memory after 20 days of withdrawal (Shukla et al., 2017).

I asked whether the impairment of long-term memory that is observed in the PSD-95 KO mice actually reflects an impairment of memory storage, or rather memory retrieval. In other words, since silent synapse maturation in the NAc is not part of long-term memory retention, I hypothesised that it could be linked to successful memory recovery following exposure to a cue. To that end, I tested PSD-95 KO mice in the CPP reinstatement assay. As described previously, the mice underwent a ten-day long training with $20 \mathrm{mg} / \mathrm{kg}$ cocaine, followed by a six-day long extinction training with sham injections and reinstatement with a 20 $\mathrm{mg} / \mathrm{kg}$ dose (Figure 3.5A). WT and heterozygous $(\mathrm{Ht})$ littermate animals were used as controls. As in figure $3.5 B$, both control groups showed successful extinction and reinstatement (in grey WT: BL vs WD1 vs extD6 vs rein: PPS $425.71 \pm 39.96$ vs $721.84 \pm 33.07$ vs $503.74 \pm 54.96$ vs $668.39 \pm 44.00 ; n=7 ;$ BL vs WD1 PPS

$p^{* *}<0.01$; WD1 vs extD6 PPS $p^{*}<0.05$; extD6 vs rein PPS $p^{*}<0.05$, post-hoc Bonferroni-adjusted paired $t$-tests; repeated-measures ANOVA: $F_{(3,24)}=13.278, p<0.001$. In light green Ht: BL vs WD1 vs extD6 vs rein: PPS $442.18 \pm 31.79$ vs $704.43 \pm 37.78$ vs $366.93 \pm 45.92$ vs $804.81 \pm 52.50 ; n=11 ;$ BL vs WD1 PPS $p^{* * *}<$ 0.001; WD1 vs extD6 PPS $p^{* * *}<0.001$; extD6 vs rein PPS $p^{* * *}<0.001$, post-hoc Bonferroni-adjusted paired $t$-tests; repeated-measures ANOVA: $\left.F_{(3,30)}=23.909, p<0.001\right)$. In contrast, CPP was not reinstated in PSD-95 KO mice (shown in green) after a cocaine challenge injection following extinction. Even more so, these mice entirely lost their preference upon cocaine administration (BL vs WD1 vs extD6 vs rein: PPS $476.82 \pm 22.70$ vs $886.79 \pm 23.61$ vs $722.81 \pm 73.35$ vs $515.06 \pm 28.16 ; n=17 ;$ BL vs WD1 PPS $p^{* * *<0.001 ;}$ WD1 vs extD6 PPS $p^{*}<0.05$; extD6 vs rein PPS $p^{*}<0.05$, post-hoc Bonferroni-adjusted paired $t$-tests; 
repeated-measures ANOVA: $\left.F_{(3,45)}=22.406, p<0.001\right)$. To ensure that this effect was specific to cocaine, I treated an additional group of KO mice with saline during reinstatement as a further control. This group showed no significant difference in their performance between reinstatement and the final day of the extinction procedure (BL vs WD1 vs extD6 vs rein: PPS $415.76 \pm 19.78$ vs $790.25 \pm 56.98$ vs $720.64 \pm 73.43$ vs $628.67 \pm 111.43 ; n=11 ;$ BL vs WD1 PPS $p^{* * *}<0.001 ;$ WD1 vs extD6 PPS $p>0.99 ;$ extD6 vs rein PPS $p>$ 0.99, post-hoc Bonferroni-adjusted paired $t$-tests; repeated-measures ANOVA: $\left.F_{(3,27)}=4.712, p<0.01\right)$.
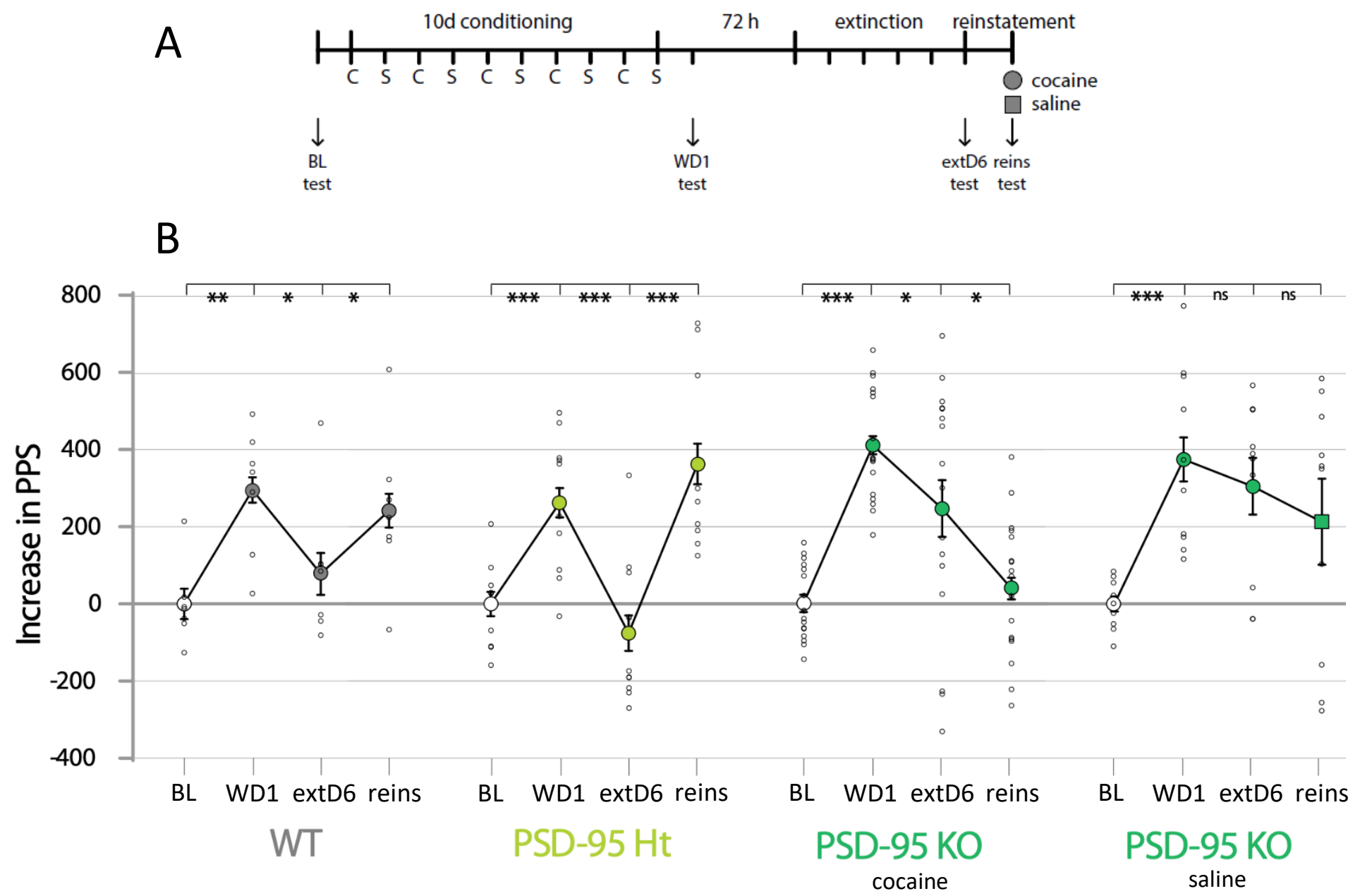

Figure 3.5: PSD-95 KO and cocaine reinstatement.

(A) Timeline of the experiment with conditioning, extinction training and reinstatement (C-cocaine, S-saline). (B) Y axis: increase in place preference score (PPS) calculated by normalising to the baseline (BL) score prior to commencement of the training. WT and heterozygous $(\mathrm{Ht})$ littermates showed successful extinction and reinstatement. In contrast, CPP was not reinstated in PSD-95 KO animals, but the mice rather seemed to entirely lose the preference. This effect was cocaine-specific since KOs treated with saline during reinstatement maintained a similar performance as on extinction day $6 . N=7,11,17$ and 11 mice for WT, Ht, KO-rein cocaine $_{\text {and KO-rein }}$ saline respectively. Data presented as mean $\pm \mathrm{SEM}$. Statistical significance was assessed by within-group repeated-measures ANOVA followed by post-hoc Bonferroni-corrected paired $t$-tests. 


\subsubsection{PSD-95 KO mice retain the CPP association after ten days of withdrawal}

As mentioned above, PSD-95 KOs have been shown to lose their learned preference following 25 days of withdrawal (Shukla et al., 2017). The day of reinstatement in the extinction/reinstatement protocol coincides with withdrawal day (WD) 10. To confirm that the observed loss of preference was not simply due to an accelerated weakening of the memory over time, I also tested their memory on WD10.

For this set of experiments, conditioning and WD1 preference testing were performed as previously described. However, over the following days, the mice were left undisturbed in their home cage and then tested for preference on WD10 (Figure 3.6A). WT and heterozygous ( $\mathrm{Ht}$ ) littermate animals were used as controls. WT littermates learned and remembered the association after ten days. Their WD10 PPS, albeit visibly lower than WD1, remained significantly increased compared to BL (BL vs WD1 vs WD10: PPS 467.80 \pm 49.54 vs $733.88 \pm 34.55$ vs $597.64 \pm 64.05 ; n=8 ;$ BL vs WD1 PPS $p^{* * *}<0.001 ;$ BL vs WD10 PPS $p^{* *}<$ 0.01 , post-hoc Bonferroni-adjusted paired $t$-tests; repeated-measures ANOVA: $\left.F_{(2,14)}=26.720, p<0.001\right)$. PSD-95 Ht animals also successfully learned and remembered the preference for the cocaine-paired chamber (BL vs WD1 vs WD10: PPS $493.51 \pm 27.01$ vs $684.28 \pm 34.54$ vs $650.12 \pm 54.54 ; n=15 ;$ BL vs WD1 PPS $p^{* * *}<0.001 ;$ BL vs WD10 PPS $p^{*}<0.05$, post-hoc Bonferroni-adjusted paired $t$-tests; repeatedmeasures ANOVA: $\left.F_{(2,28)}=8.532, p<0.001\right)$. Finally, as seen by the increase compared to BL, PSD-95 KO mice also retained the learned preference ten days into withdrawal (BL vs WD1 vs WD10: PPS $430.49 \pm$ 30.78 vs $817.51 \pm 45.48$ vs $706.58 \pm 51.29 ; \mathrm{n}=11 ;$ BL vs WD1 PPS $p^{* * *}<0.001 ;$ BL vs WD10 PPS $p^{* *}<0.01$ post-hoc Bonferroni-adjusted paired $t$-tests; repeated-measures ANOVA: $F_{(2,20)}=16.411, p<0.001$ ) (Figure 3.6B). This result confirmed that the loss of preference observed on reinstatement day was due to the cocaine injection itself, rather than an accelerated memory loss in the PSD95-KO mice. 
A

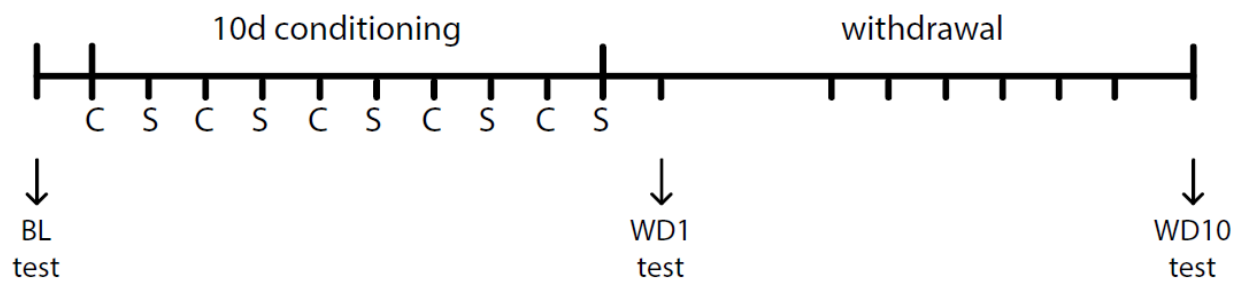

B

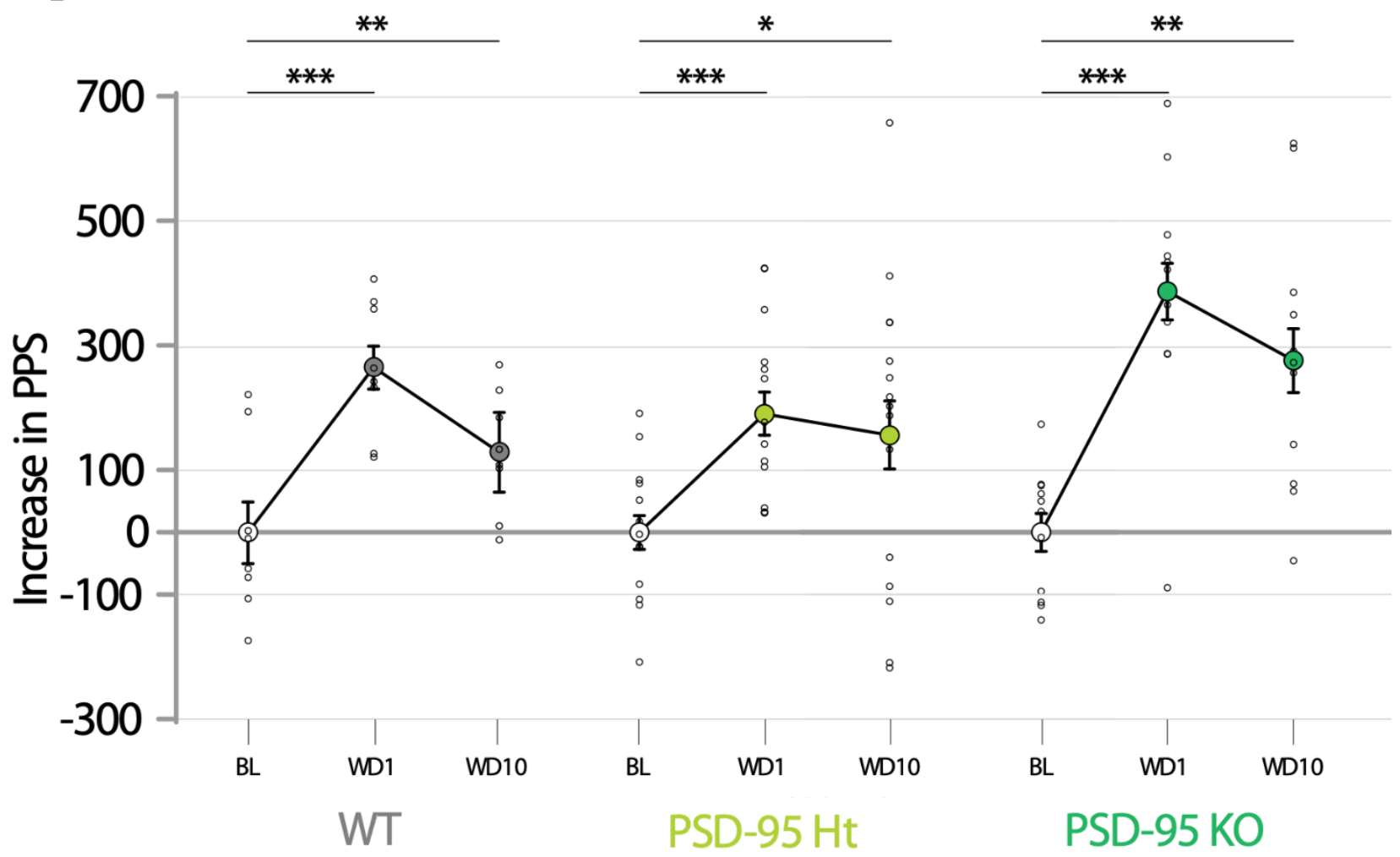

Figure 3.6: PSD-95 KO mice retain the CPP memory after 10 days of withdrawal.

(A) Timeline of the experiment with conditioning and withdrawal days (C-cocaine, S-saline). (B) Y axis: increase in place preference score (PPS) calculated by normalising to the baseline (BL) score prior to commencement of the training. PSD-95 $\mathrm{WT}, \mathrm{Ht}$ and KO mice learn and remember the CPP association after 10 days of withdrawal. $\mathrm{N}=8,15$ and $11 \mathrm{mice}$ for WT, Ht and KO respectively. Data presented as mean \pm SEM. Statistical significance was assessed by within-group repeatedmeasures ANOVA followed by post-hoc Bonferroni-corrected paired $t$-tests.

Majority of the data for this experiment were generated and analysed by Isabel Heise. Five Ht mice were trained by Max Krause; analysis was done by Myrto Panopoulou. All experiments were performed under the supervision of M. Panopoulou. 


\subsubsection{NAc-restricted knockdown of PSD-95 and CPP reinstatement}

Targeted knockdown of PSD-95 in the NAc successfully induced silent synapses and prevented their maturation, namely by CP-AMPAR incorporation, during withdrawal (Shukla et al., 2017). Hence, this manipulation can successfully reproduce the cellular characteristics of PSD-95 KO NAc cells.

So far, the approaches described were systemic - a genetic complete knock out of different proteins, or a systemic antibiotic injection. To target NAcSh silent synapses and CP-AMPARs specifically and dissect their role in extinction and reinstatement, I used an RNAi approach to knockdown PSD-95. An shRNA against PSD-95 (sh95) packaged into an AAV8 vector, along with a GFP marker, was injected into the NAc of adult WT mice. Following a two-week recovery period, the mice were subjected to the CPP conditioning, extinction and reinstatement procedure, as previously described (Figure 3.7A). Upon completion of the protocol, the mice were transcardially perfused, and the success of the manipulation was evaluated by a post-hoc analysis of GFP fluorescence in NAc brain slices (Figure 3.7C). If the GFP signal was very weak, did not cover the entire region, or was restricted to one hemisphere, the mouse was excluded from the dataset. I began with the usual, high-dose challenge injection $(20 \mathrm{mg} / \mathrm{kg})$; WT control data from figure 3.1B are shown again for the sake of comparison. After applying the exclusion criterion explained above, sh95injected WT mice were found to learn the cocaine-paired association successfully, but only showed a trend towards successful extinction and reinstatement of the preference (BL vs WD1 vs extD6 vs rein: PPS 523.76 \pm 12.57 vs $646.95 \pm 14.19$ vs $591.15 \pm 27.54$ vs $679.80 \pm 18.02 ; n=7 ; B L$ vs WD1 PPS $p^{* * *}<0.001 ;$ WD1 vs extD6 PPS $p=0.09$; extD6 vs rein PPS $p=0.07$, post-hoc Bonferroni-adjusted paired $t$-tests; repeatedmeasures ANOVA: $\left.F_{(3,18)}=20.878, p<0.001\right)$. However, on an individual basis, six out of seven mice showed cocaine reinstatement following extinction, and the overall average was largely skewed by the results of a single mouse. Therefore, with the preliminary results pointing towards successful reinstatement with 20 $\mathrm{mg} / \mathrm{kg}$, even after knockdown of PSD-95, I repeated the experiments using a $5 \mathrm{mg} / \mathrm{kg}$ dose of cocaine to reinstate CPP. In this case the sh95-injected mice learned the association and showed a significant decrease in their preference after extinction training. There was an increase in PPS after the $5 \mathrm{mg} / \mathrm{kg}$ challenge injection on average, but it was not significant, possibly due to animal variability (BL vs WD1 vs extD6 vs rein: PPS $450.13 \pm 20.60$ vs $727.58 \pm 17.54$ vs $626.54 \pm 20.06$ vs $690.92 \pm 39.54 ; n=7 ;$ BL vs WD1 PPS $p^{* * *}<0.001$; WD1 vs extD6 PPS $p^{* *}<0.01$; extD6 vs rein PPS $p=0.42$, post-hoc Bonferroni-adjusted

paired $t$-tests; repeated-measures ANOVA: $F_{(3,18)}=25.869, p<0.001$ ) (Figure 3.7B). Overall, these preliminary results suggest that WT mice show reinstatement even after NAc-restricted knockdown of PSD-95, as they descriptively show an increase with 20 and $5 \mathrm{mg} / \mathrm{kg}$ challenge doses of cocaine. However, the dataset is small. 
A

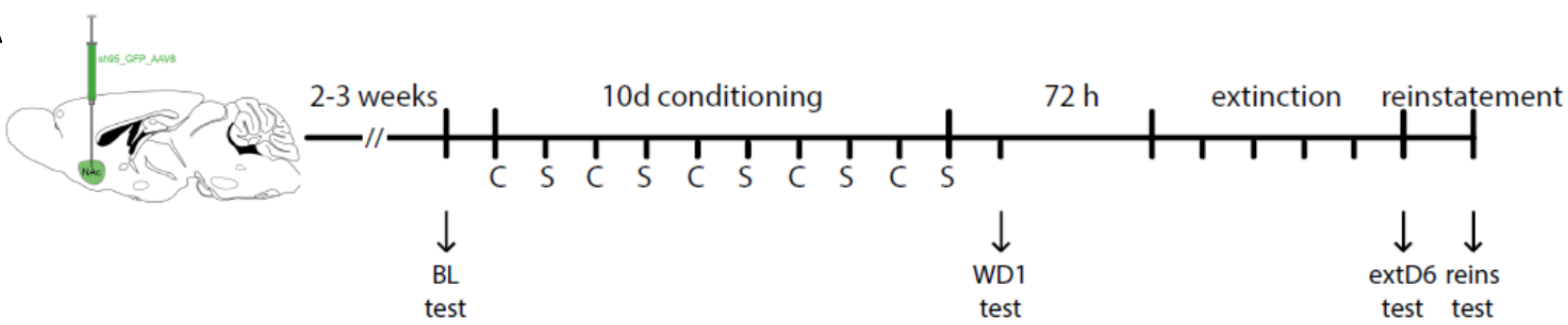

B

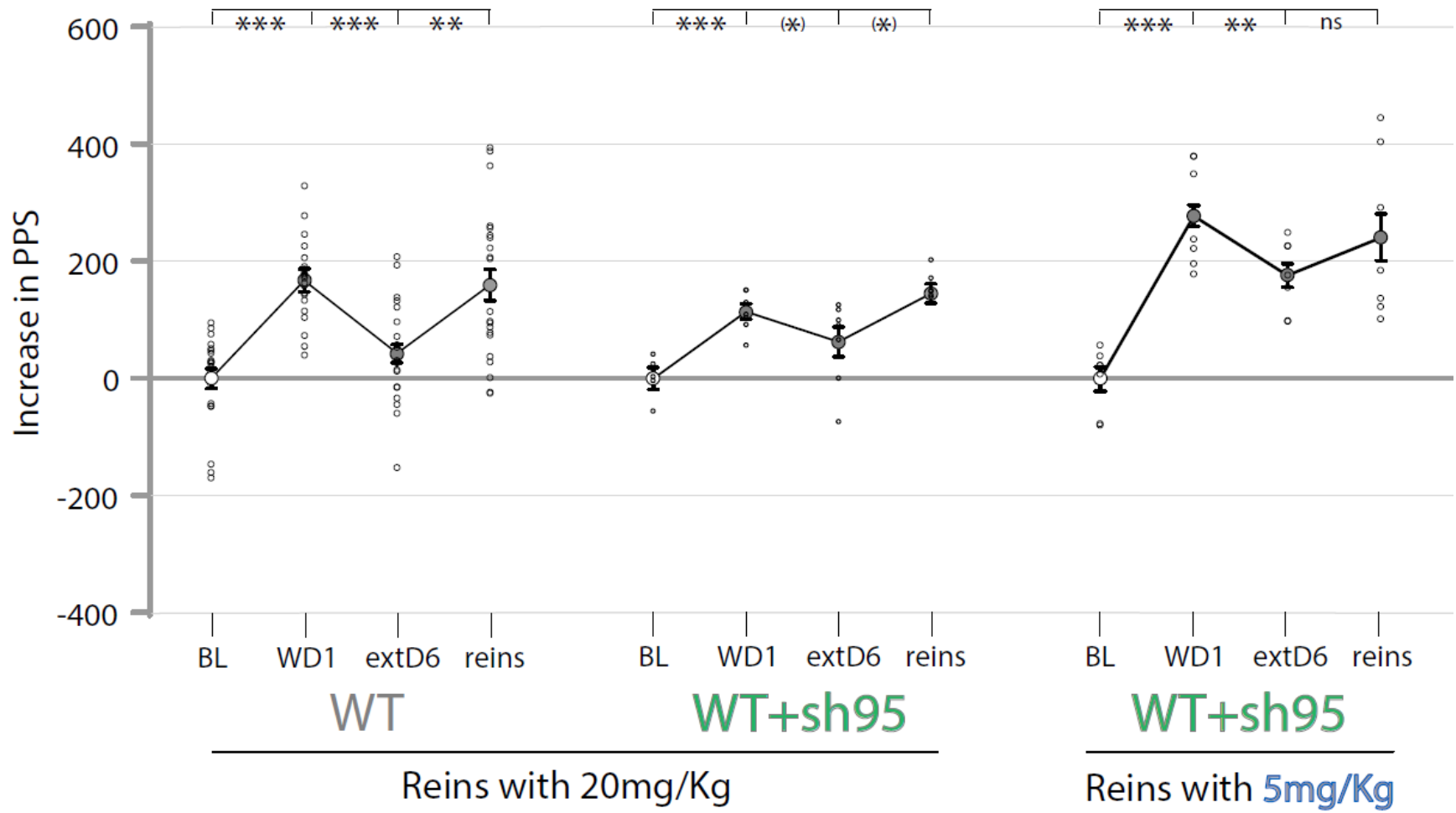

C
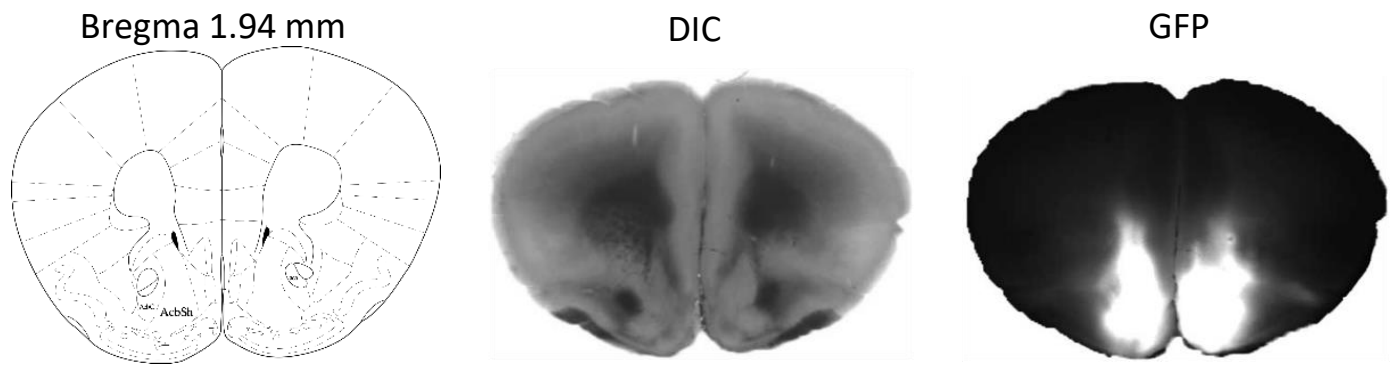

Figure 3.7: NAc-restricted knockdown of PSD-95 and CPP reinstatement.

(A) Timeline of the AAV8 injection targeting the NAc followed by CPP training, extinction and reinstatement (C-cocaine, Ssaline). (B) Y axis: increase in place preference score (PPS) calculated by normalising to the baseline (BL) score prior to commencement of the training. WT control data from Fig. 3.1 have been shown again for the sake of comparison. Taken together, data from both WT+sh95 groups suggest that PSD-95 knockdown did not affect extinction. PPS upon reinstatement with $20 \mathrm{mg} / \mathrm{kg}$ showed a trend $(0.05<p<0.1)$ towards an increase; a challenge dose of $5 \mathrm{mg} / \mathrm{kg}$ did not cause a significant increase. $\mathrm{N}=7$ mice for each condition. Data presented as mean \pm SEM. Statistical significance was assessed by within-group repeated-measures ANOVA followed by post-hoc Bonferroni-corrected paired $t$-tests. (C) Schematic image of a NAccontaining coronal slice, light (DIC) and fluorescent (GFP) images showing the expression site of the AAV8 in NAc shell. Both schematic images in this figure are from Mouse Brain Atlas (Franklin and Paxinos, 2008). 


\section{Discussion}

Relapse risk, even after years of abstinence, remains high for vulnerable individuals. Drug-associated cues can reawaken the robust and durable memories, formed by chronic drug use, and trigger intense craving and relapse. Addictive drugs, like natural rewards, act by increasing dopamine transmission in the NAc, a key region in the reward system. Cocaine and other drugs of abuse cause maladaptive plasticity in the brain's reward pathways to reorganise the circuit and induce drug-seeking behaviour. This is achieved through plasticity mechanisms, normally occurring when circuit refinement and optimisation are required (Hyman et al., 2006; Lee and Dong et al., 2011; Dong and Nestler, 2014). One such mechanism is the generation of silent synapses, important substrates for developmental plasticity, in the adult NAc shell (Huang et al., 2009). Studies on rodents have demonstrated that pairing of the cocaine experience to a context leads to silent synapse maturation via CP-AMPAR recruitment during withdrawal (Lee et al., 2013); this holds true for both operant (McCutcheon et al., 2011a) and non-contingent (Shukla et al., 2017) administration of cocaine. CP-AMPARs mediate incubation of cocaine craving (Conrad et al., 2008; McCutcheon et al., 2011b) but their removal does not impair long-term retention of the cocaineassociated memory (Shukla et al., 2017).

In this study, I modelled relapse by using reinstatement of the preference learned during a cocaine-CPP procedure after extinction. I discovered that CP-AMPARs control the threshold for induction of reinstatement by a challenge (priming) cocaine injection: a high cocaine dose, i.e. a strong cue, will always reinstate the learned preference, even when CP-AMPARs are absent. A low cocaine dose, however, requires CP-AMPAR activity to reawaken the trained response, after its extinction. Additionally, I demonstrated that impairing silent synapse maturation, via lack of scaffolding protein PSD-95, affects reinstatement in an unexpected manner: not only was CPP not reinstated after a challenge injection, but, even more so, cocaine administration abolished the remaining preference of the mice (i.e. scores similar to baseline were measured) after extinction.

\subsection{Cocaine reinstates conditioned place preference}

Results described in section 3.1 and figure 3.1 clearly show that the learned preference gets reinstated specifically by cocaine. Mice initially learn to associate the cocaine experience with the conditioned chamber: they spend more time in that chamber, resulting in an increased PPS. This preference decreases following six daily extinction sessions, only to increase again 24 hours later, if the mice receive a cocaine challenge injection. The fact that CPP gets reinstated underlines that extinction must not be equated with forgetting; the originally learned association is not destroyed or unlearned. The term extinction describes 
the performance loss observed when the unconditioned stimulus (US, the reinforcer) is no longer paired with the conditioned stimulus (CS, the Pavlovian signal) (Mueller and Stewart, 2000; Bouton, 2002). This happens when the animal is repeatedly exposed to the CS in the absence of the US - in our case, the chamber and cocaine, respectively. It has already been proposed that extinction, rather than causing forgetting, works by teaching the animal something new - that the reward is no longer present in the CS context. This memory is stored along with, or on top of, the initial association (Bouton, 2002).

Extinction and reinstatement of CPP have been extensively studied, in rats and mice alike. It has been demonstrated, for example, that repeated CS exposures cannot be too far apart from each other: when rats were tested at a frequency of two weeks or more, CPP was not extinguished and persisted for up to six weeks (Mueller and Stewart, 2000). The results of this thesis, as well as a publication on morphine-CPP, show that six consecutive days are enough to cause extinction of the robust trained preference (Hearing et al., 2016). Timing is also key for reinstatement: mice were still vulnerable to a cocaine challenge injection two weeks after extinction, further suggesting that the memory trace remains present. Nevertheless, after a total of four weeks, the same cue was not sufficient to reinstate CPP (Itzhak and Martin, 2002). This, of course, raises the question whether this time-dependent impairment in reinstatement suggests that the original memory trace is gone if the mouse is not re-exposed to cocaine for four weeks after extinction; in humans, year-long abstinence does not guarantee protection from relapse (Hunt et al., 1971; O'Brien, 2005). When rats are trained to self-administer cocaine, a challenge dose is sufficient to reinstate lever pressing, even after 60 days of withdrawal (Lutgen et al., 2014); this result shows how robust the effect of a single dose can be, though this study used an operant procedure in rats and did not include extinction training.

A large body of studies suggests that a range of cues can serve as priming stimuli for the memory trace to induce reinstatement. In the aforementioned mouse CPP study, reinstatement within the two-week frame was not cocaine-specific, as other psychostimulants also reinstated CPP (Itzhak and Martin, 2002). Aside from addictive substances, stress has been majorly implemented as a reinstatement-inducing factor (Mantsch et al., 2016). Electric foot shocks reinstated cocaine seeking in self-administering rats four to six weeks after extinction training (Shaham et al., 2000). The same stimulus reinstated morphine-CPP in rats after nine days of extinction (Wang et al., 2000). Stress induced by a forced-swim test reinstated cocaineCPP in mice, following extinction of preference due to extinction training (Kreiblich and Blendy, 2004; Redila and Chavkin, 2008), or due to prolonged -21 days after conditioning- withdrawal (Carey et al., 2007). Overall, more evidence is available concerning the endurance of the memory over time -withdrawal-, rather than the long-term effect of extinction training, in terms of reinstatement induction. 


\subsection{CP-AMPARs are increased after cocaine - CPP reinstatement}

To calculate the proportion of CP-AMPARs, I measured the rectification index of NAcSh MSNs immediately after the cocaine challenge injection and the $18 \mathrm{~min}$-long CPP test. As shown in figure 3.2, the rectification index after reinstatement is increased compared to baseline levels measured in naïve mice of similar age. This suggests that reinstatement might induce CP-AMPAR increase in the NAcSh MSNs. Reinstatement day, in the procedure I implemented, coincides with WD10; this means that I found CPAMPARs to be significantly increased at an earlier time point, compared to a study which elucidated the kinetics of CP-AMPAR recruitment during withdrawal from CPP training in mice (Shukla et al., 2017).

Until recently, CP-AMPARs had mostly been measured in adult rats that had undergone cocaine selfadministration training and prolonged withdrawal; elevated CP-AMPARs were not measured earlier than WD 30-35 (Conrad et al., 2008; McCutcheon et al., 2011a; Lee et al., 2013) and these levels then persisted even after 70 days of withdrawal (Wolf and Tseng, 2012). It was also suggested that an operant procedure is required to induce CP-AMPAR recruitment over withdrawal in rats (McCutcheon et al., 2011a). Shukla and colleagues revealed rather recently the maturation time course of silent synapses generated in the NAcSh after ten days of CPP training. Increased silent synapses return to baseline levels by WD20, and remain stable all the way to WD40. CP-AMPAR accumulation follows a complementary pattern; levels begin to gradually increase around WD10 and become significantly different from baseline levels on WD20. By WD30, CP-AMPAR levels peak (Shukla et al., 2017). While results from this study suggested that CPAMPAR incorporation into cocaine-generated silent synapses is a signature of the association between the drug experience and a context (CPP), another study had previously shown that ten daily passive cocaine injections also lead to an increased rectification index on WD35 (Mameli et al., 2009). Overall, there is no consensus in the field as to which procedure is needed for recruiting CP-AMPARs to maturing silent synapses during withdrawal. This could be attributed to interspecies differences between rats and mice, slight protocol variations, or possibly both.

My findings and those of Shukla and colleagues are not necessarily at odds with each other, since the additional re-exposures to the context throughout the extinction phase of my procedure might have led to an acceleration of CP-AMPAR incorporation. Interestingly, I found that the number of CP-AMPARs on reinstatement day was actually higher than on WD10 but, still, lower than their peak amount on WD30. This further supports the idea that extinction and reinstatement accelerate CP-AMPAR recruitment, which takes place during cocaine withdrawal. Nonetheless, my data only show the presence of CP-AMPARs; they do not provide information on whether it is extinction or reinstatement that causes this change. 
Ideally, I would like to repeat this experiment and measure CP-AMPAR levels pre-reinstatement; that is, 24 hours after the last extinction session, but omitting the cocaine administration and the CPP test. This would provide insight into the effect of extinction on CP-AMPARs and help us further understand the mechanism of reinstatement- how does the canvas on which the challenge injection acts look like, and how does cocaine affect the existing picture? Measuring silent synapse levels at the same two time points (pre- and post-reinstatement) would reveal whether and, if so, how extinction training affects their maturation. Hearing and colleagues showed that five daily morphine injections led, after 10-14 days of withdrawal, to increased CP-AMPARs in NAc; this plasticity was reversed when the mice received ceftriaxone for seven to ten days following passive morphine exposure. They then proceeded to administer ceftriaxone during CPP extinction training and observed reinstatement blockade. However, CP-AMPARs were not measured in the context of behaviour (Hearing et al., 2016). It would, therefore, be of value to measure CP-AMPAR levels pre-reinstatement, following ceftriaxone administration during extinction. It is important to confirm that ceftriaxone removes CP-AMPARs in our procedure.

\subsection{A very low dose of cocaine is still sufficient to reinstate CPP in WT mice}

Results in figures $3.4 \mathrm{~A}$ and $\mathrm{B}$ show that three different doses of cocaine $(20,5$ and $2 \mathrm{mg} / \mathrm{kg})$ are all sufficient to reinstate CPP in WT mice that were trained with $20 \mathrm{mg} / \mathrm{kg}$. Even though the mice descriptively respond less strongly to lower doses, the difference is not statistically significant.

Throughout the literature, a large spectrum of doses has been used to induce robust CPP in mice ranging from 2 all the way up to $50 \mathrm{mg} / \mathrm{kg}$ (Medvedev et al., 2005; Maldonado et al., 2006; Ribeiro Do Couto et al., 2009; Conrad et al., 2013; Hildebrand and Lasek, 2014). The picture becomes less clear with $1 \mathrm{mg} / \mathrm{kg}$ cocaine, as one study reports it to be sufficient (Cunningham et al., 1999) and another showed that such a low dose is effective only in the case of socially defeated mice (Montagud-Romero et al., 2016). Therefore, all three doses that I used to induce reinstatement are well within the range used for conditioning.

In the cases where CPP was reinstated following extinction the challenge injection was typically no less than half of the amount used for conditioning (Itzhak and Martin, 2002; Maldonado et al., 2006; Ribeiro Do Couto et al., 2009; Conrad et al., 2013). To my knowledge, this is the first time that a dose as low as $10 \%$ of the original training amount has been shown to reinstate CPP in mice and a confirmation that even a very low drug dose can trigger relapse. 


\subsection{CP-AMPARs increase a weak stimulus' gain to reawaken a cocaine-induced behaviour}

To test the role of CP-AMPARs in reinstatement, I implemented a pharmacological and a genetic approach (results summarised in figure 4.1). First, I removed NAC CP-AMPARs in WT mice by administering ceftriaxone daily during extinction; this was previously undertaken in a morphine-CPP study (Hearing et al., 2016). Second, I utilised SAP102 KO mice; these animals were previously shown to learn and retain the cocaine-CPP association, despite not expressing CP-AMPARs following drug withdrawal (Shukla et al., 2017). Results in figure 3.3 demonstrate that a strong cue, i.e. a high-dose challenge injection, does not require CP-AMPAR activity to reinstate CPP. To test whether sensitivity in terms of cue strength, rather than reinstatement per se, was affected by lack of CP-AMPARs, I used the lowest dose which successfully reinstated CPP in WT mice. This time, as shown in figure 3.4C, $2 \mathrm{mg} / \mathrm{kg}$ were not enough to reinstate CPP in ceftriaxone-treated WT, or SAP102 KO mice.

CP-AMPAR insertion increases synaptic strength and can lead to circuit remodelling. Since it was shown that a single cocaine injection can increase CP-AMPAR levels in the VTA (Bellone and Lüscher, 2006), it has been of great interest to the field to comprehend their role in drug-motivated behaviours - drug seeking and craving, for example. Grimm and colleagues were the first to successfully model human craving behaviour during withdrawal in a rat self-administration procedure and establish the term incubation of craving. Essentially, rats were trained to press a lever and receive i.v. cocaine injections in the presence of two cues- a tone and a light. At varying withdrawal time points, rats were presented with the drugassociated cues and the lever, which no longer rewarded them with the drug. The later this test took place

during withdrawal, the more craving developed and the more intense the lever pressing became; deprivation of cocaine for 60 days caused the maximal response (Grimm et al., 2001). This result mirrored clinical observations, wherein vulnerability of human addicts to environmental cues previously associated with cocaine, gradually escalates throughout withdrawal (Gawin and Kleber, 1986). Cocaine selfadministration studies demonstrated later on that CP-AMPAR incorporation mediates silent synapse maturation as well as incubation of craving over prolonged withdrawal (Conrad et al., 2008; McCutcheon et al., 2011a; Lee et al., 2013). Shukla and colleagues established CP-AMPARs as a signature for cocainecontext association, showing that they accumulate in NAc after a non-operant procedure, as well. Nevertheless, pharmacological CP-AMPAR removal did not impair CPP retention (Shukla et al., 2017). 
Hearing and colleagues showed that CP-AMPAR removal, using ceftriaxone throughout extinction, blocks CPP reinstatement by morphine (Hearing et al., 2016). My results suggest that this finding also

NMDA receptor

Cl-AMPA receptor

CP-AMPA receptor
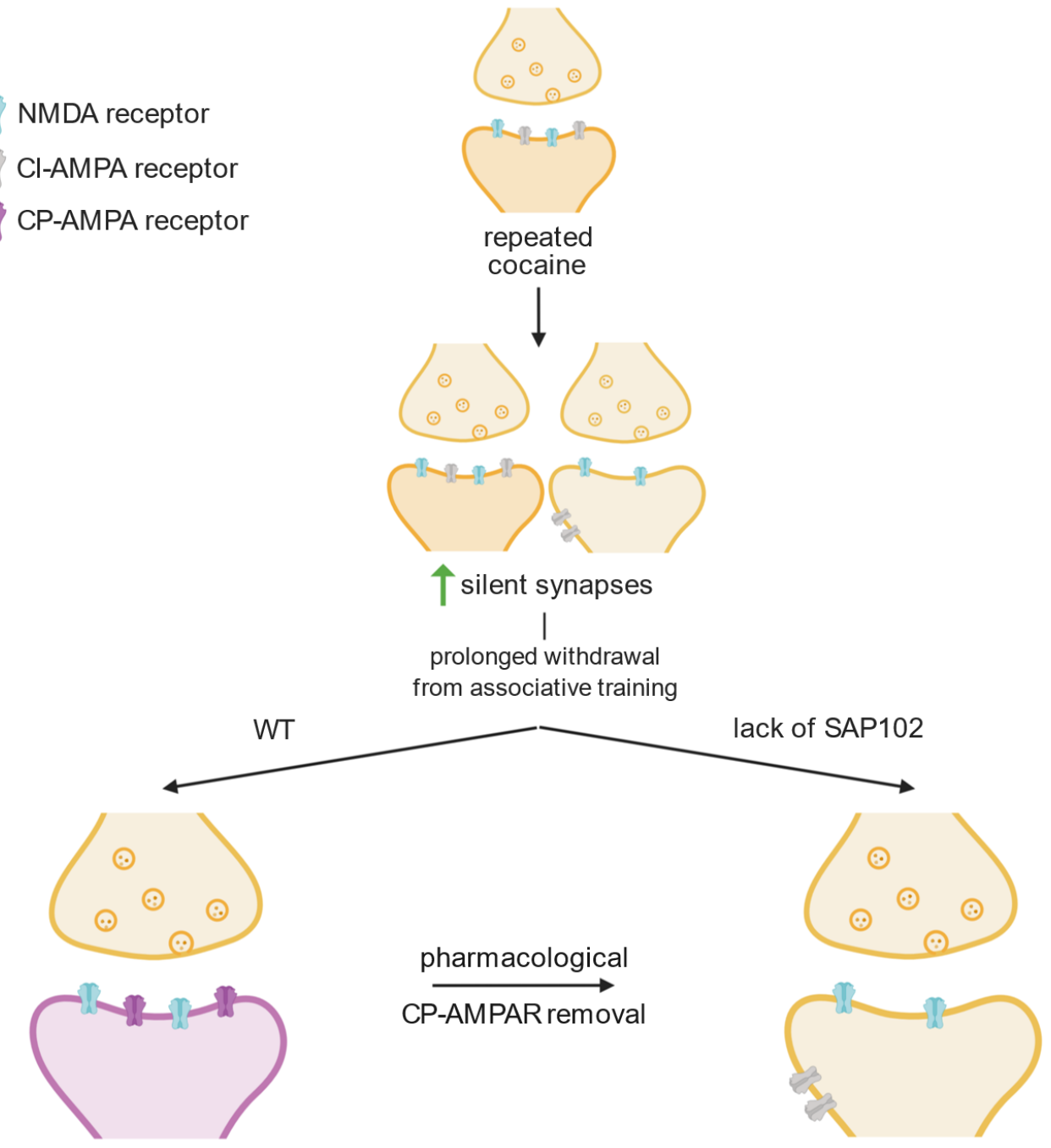

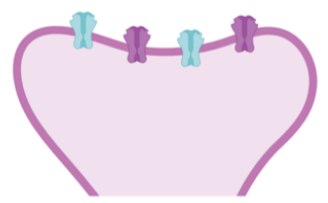

CP-AMPAR recruitment no CP-AMPAR recruitment

\section{Pavlovian \\ (CPP)}

high dose

low dose

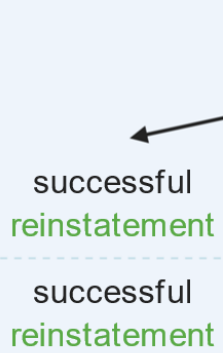

challenge injection following extinction

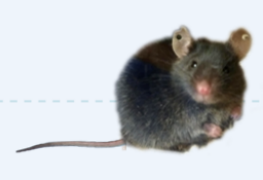

association

intact

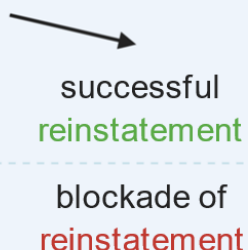

CP-AMPARs: - control the threshold of a challenge cocaine injection to induce reinstatement.

- amplify the gain of a weak challenge injection to tip it over the threshold and induce reinstatement. - control the intensity with which a trained response is expressed.

Figure 4.1: CP-AMPARs and gain control - Schematic representation of the results. 


\section{Discussion}

applies, in part, to cocaine. I showed that CP-AMPARs are only required for a weak cue to induce reinstatement. In a way, this finding brings together knowledge gained from operant and non-contingent procedures; in both cases, CP-AMPARs control the intensity with which a trained response is expressed. In the case of self-administration, this is rather clear with incubation of craving: the trained response, be that lever pressing or nose-poking, intensifies the longer the rat is denied drug access. For CPP, the trained response is simply choosing the conditioned chamber and spending more time in it; with extinction, this response becomes masked by the new association learned by the animal. A very strong cue will reawaken the initial drug-motivated behaviour, regardless of CP-AMPARs; if said cue is too weak to induce reinstatement, concurrent NAC CP-AMPAR activity is required to tip it over the threshold. In other words, CP-AMPARs are involved in more than one facet of addiction; not only do they mediate craving behaviour in rats, but they also facilitate relapse-like behaviour in mice. By controlling the threshold for reinstatement, CP-AMPARs may gate the ability of not just a low drug dose, but potentially any given cue, to induce relapse. As previously discussed, not only cocaine, but also other psychostimulants and different stressors are sufficient to reinstate cocaine-CPP in mice, or drug seeking in rats (Itzhak and Martin, 2002; Mantsch et al., 2016). It certainly is an exciting concept and would be very interesting to investigate whether these factors are as effective in inducing craving and relapse, if CP-AMPARs are removed or blocked.

\subsection{Commonalities and differences across addictive substances}

Silent synapses, an important substrate for developmental plasticity, are generated due to repeated cocaine exposure in the adult NAc shell (Huang et al., 2009). To broaden the scope further, silent synapses were recently detected in rodents upon exposure to other addictive substances. Synapses lacking functional AMPARs were generated after alcohol conditioning in the dentate gyrus, an area which releases dopamine in the NAc when stimulated (Tritschler et al., 2017). Interestingly, silent synapse levels in this study correlated with manifestation of addictive behaviours, rather than alcohol training per se. Moreover, acamprosate, a drug used to limit alcohol consumption in humans prevented their generation (Beroun et al., 2018). Chronic nicotine also increases silent synapse levels in dorsolateral striatal MSNs (Xia et al., 2017). Taken together, these studies suggest that, apart from dopamine increase in the reward circuit, silent synapse generation is a common denominator among drugs of abuse. On the other hand, each of these studies looked at a different brain region; it is not clear whether cocaine, for example, also generates silent synapses in other areas, besides the NAc.

The findings discussed in previous paragraphs on CPP reinstatement were primarily obtained from cocaine studies. Though varying cocaine doses have successfully induced CPP in mice (Medvedev et al., 
2005; Maldonado et al., 2006; Ribeiro Do Couto et al., 2009; Conrad et al., 2013; Hildebrand and Lasek, 2014), including those I used for training and reinstatement, CPP throughout the literature has been mostly reinstated with doses not lower than half of the original training amount (Itzhak and Martin, 2002; Maldonado et al., 2006; Ribeiro Do Couto et al., 2009; Conrad et al., 2013). My results suggest that the threshold - at least for WT mice - lies even lower: 10\% of the dose used for conditioning is enough of a cue to reinstate CPP, provided that CP-AMPARs are present. On the other hand, Hearing and colleagues were the only ones mentioned so far who used morphine; in their case, CP-AMPAR removal via ceftriaxone was reported to block reinstatement, without dose dependency. It may very well be that the dose used in this study was a low one. Moreover, the effects of cocaine, a stimulant, should not be equated with those of morphine, an opiate.

A recent study compared the effects of cocaine and morphine on different MSN subtypes in the NAc (Graziane et al., 2016). Depending on the type of dopamine receptor they express, MSNs are categorised in type 1 (D1R-MSNs) and 2 (D2R-MSNs) (Gerfen et al., 1990). These subpopulations in the NAc have been suggested to function in a distinct and often antagonistic manner; D1R-MSNs are thought to drive the reinforcing effects of addictive substances (Lobo and Nestler, 2011). On the contrary, D2R-MSN activation and inhibition mediates place aversion and makes conditioned responses more resistant to change, respectively (Smith et al., 2013). Upon comparing the effect of repeated passive cocaine and morphine injections in the NAc, Graziane and colleagues found that even though the net circuit effect is similar, in that the glutamatergic input to D1R compared to D2R-MSNs is increased, the two drugs achieve it differently. Passive exposure of rats to cocaine generates de novo silent synapses in D1 cells which, over withdrawal, are stabilised resulting in elevated D1 EPSC amplitude; morphine results in AMPAR removal from, and thus silencing of, existing synapses in D2 cells, which subsequently get pruned. Prevention of AMPAR internalisation disrupts morphine-CPP. Simply put, cocaine strengthens excitatory inputs to D1RMSNs -the drivers- and morphine weakens those to D2R-MSNs -the brakes- (Graziane et al., 2016).

In line with Graziane and colleagues, Hearing and colleagues reported reduced D2R signalling after five daily i.p. injections of morphine and 10-14 days of withdrawal. However, they additionally observed transmission at D1R MSNs to be enhanced (Hearing et al., 2016). Strengthened AMPAR-mediated transmission, specifically in D1R cells, has been previously shown for cocaine (Pascoli et al., 2012). It is not known whether these changes occur upon morphine- or cocaine-induced associative learning, or whether the two subtypes continue to serve opposing functions in the long run. Cocaine-CPP induces silent synapses in the NAcSh of mice, which incorporate CP-AMPARs during withdrawal. Therefore, cocaine-CPP 
induces the formation and strengthening of new connections, though it is not clear whether a difference exists between D1R- and D2R MSNs (Shukla et al., 2017).

Overall, it becomes apparent that converging mechanisms, namely silent synapse generation, are utilised by many addictive substances, though each drug induces distinct physical and emotional effects. Nonetheless, since different studies have -so far- each focused on a particular brain region, it is not yet known whether the described effect for each substance might be broader.

\subsection{PSD-95 KO and cocaine reinstatement}

To understand the role of silent synapses in relapse, I tested PSD-95 KO mice in the reinstatement protocol; in this case, cocaine-generated silent synapses do not mature during withdrawal but, contrary to the SAP102 KO, memory retention after 20-25 days is impaired (Shukla et al., 2017). The result shown in figure 3.5 was surprising. Not only did cocaine fail to induce reinstatement, but the administration of the $20 \mathrm{mg} / \mathrm{kg}$ challenge dose actually had the opposite effect: the mice entirely lost their preference which, for most animals, returned to baseline ( $\sim 50 \%)$ levels.

To ensure that this behaviour was not relevant to the transgenic line itself, I included not just WT, but also heterozygous $(\mathrm{Ht})$ littermates in my controls. Both groups showed successful extinction and reinstatement. Next, to confirm that this effect was cocaine-specific, I administered saline i.p. to PSD-95 KO mice, instead of cocaine, on reinstatement day. The difference in performance between extinction day 6 and reinstatement was not significant, confirming that the loss of preference was caused by cocaine and not by the injection itself. A final control experiment was performed in order to rule out the possibility that the effect I was observing was a matter of time; reinstatement day coincides with WD10. PSD-95 KOs show no preference on WD20-25 (Shukla et al., 2017), yet we did not know when these mice actually begin to forget. Experiments presented in figure 3.6 show that, if PSD-95 KO mice are left undisturbed in their home cage after WD1, the CPP memory remains intact at least until WD10. This result confirmed that loss of preference on reinstatement day did not mirror a memory impairment.

Overall, this demonstrates that the striking effect of cocaine on PSD-95 KO mice, which have undergone extinction, is both drug- and procedure-specific. I also observed that the extinction training itself was not as effective in PSD-95 KO mice, as can be seen in the saline group in figure 3.5. However, this impairment was only descriptive and not statistically significant. It is possible that the very robust learned preference of the PSD-95 KO (briefly discussed below, in 4.6.1) resists extinction due to the mice choosing the conditioned chamber out of habit, rather than learning the new association. Nevertheless, this does not 
explain the effect of cocaine 24 hours later. Why does the preference largely persist for six days only to be abolished when the reward gets reintroduced?

It has been known for some time that recall of a drug-associated memory causes its temporary destabilisation (Lee et al., 2005). During this time, the memory is liable to disruption before it is reconsolidated and becomes stable once again. A recent study demonstrated that cue re-exposure during an extinction session re-silences cocaine-generated silent synapses in a rat self-administration procedure. CP-AMPARs that had been incorporated into these synapses during withdrawal were temporarily removed and, during that $\sim$ six-hour-long time window, it was possible to weaken the drug-associated memory (Wright et al., 2020). It is, therefore, plausible that the cocaine-generated silent synapses in the PSD-95 $\mathrm{KO}$, which are anyway in a labile state due to impaired maturation, are even more vulnerable during repeated context re-exposure. Reintroduction of a cue as potent as cocaine could erase the unstable memory trace.

Alternatively, the preference of the PSD-95 KO could remain intact after a cocaine challenge injection, but become temporarily masked during reinstatement due to drug-induced hyperactivity. Hence, it would be of great interest to measure CPP in PSD-95 KO both 24 hours and one week after reinstatement. Should CPP be detected one day after a challenge injection, it would indicate that the phenomenon I described is a by-product of hyperactivity. However, if CPP remains on the same levels throughout, it could be an exciting hint towards long-lasting eradication of an otherwise robust drug association. WT control experiments would be required to elucidate this, since there are two scenarios which should be investigated: if preference levels after a week following reinstatement are close to those measured after extinction, it would mean that the new association learned during extinction is still intact; the cocaine challenge injection only temporarily uncovers the initial one. Otherwise, preference remaining high would suggest that reinstatement has long lasting effects that require additional extinction training to be counteracted.

\subsubsection{PSD-95 Ht and SAP102 KO transgenic mice outperform WT mice}

Performance of different mice tested shown in figures 3.3-3.5 suggest that different transgenic mice outperform WTs in terms of CPP acquisition (WD1; figure 3.5: PSD-95 KO group shows a much higher PPS increase compared to the WT littermates), extinction (extD6; figure 3.5 PSD-95 Ht group shows pronounced extinction), or both (figures 3.3 and 3.4; SAP102 KO group outperforms WT). Since extinction is essentially a form of learning, these results suggest that the transgenic mice used in this study are better learners. 


\section{Discussion}

Mice lacking PSD-95 have higher baseline silent synapse levels, which facilitates synaptic enhancement and - potentially - learning. This is supported, for example, by cocaine-CPP procedure, where PSD-95 KOs acquire CPP not only better than WTs, but also faster; a shorter conditioning period will induce CPP in PSD95 KO but not in WT mice (Shukla et al., 2017). However, in other behavioural paradigms, such as fear conditioning or visual water task, PSD-95 KOs perform similar to WT mice (Fitzgerald et al., 2014; Huang et al., 2015a), while one study reported impaired spatial learning (Migaud et al., 1998). Mice carrying a heterozygous deletion of the gene encoding PSD-95 have been less studied, although a recent publication reported PSD-95 Ht mice to show enhanced performance in certain learning paradigms. Interestingly, LTP was enhanced in PSD-95 Ht hippocampal slices, similarly to but less pronounced than what has been observed in the PSD-95 KO (Migaud et al., 1998; Horner et al., 2018). Taken together, these findings suggest that the PSD-95 Ht animals only partially share the electrophysiological characteristics of the KO, which endows them with enhanced learning flexibility.

Alternatively, decreased activity and curiosity could explain the more extreme scores observed in the PSD-95 Ht group. This interpretation concerns the way that different rewards affect manifestation of CPP. CPP, by definition, means that the animal spends more time in the conditioned chamber. Natural rewards (e.g. sucrose) increase PPS by amplifying exploratory behaviour, meaning that the animal makes more transitions (visits) of the same duration to the conditioned chamber. Drugs, conversely, achieve the same behavioural output by increasing the time spent in close contact with the drug-associated cues. Therefore, drug-rewarded mice pay longer visits to the conditioned chamber, making fewer transitions between compartments (Spiteri and Le Pape, 2000). PSD-95 Ht mice were reported to be slightly hypoactive in the aforementioned publication (Horner et al., 2018). In another study on social behaviour, PSD-95 Hts were less exploratory and did not exhibit increased interest when an unfamiliar mouse was introduced (KruegerBurg et al., 2016). Therefore, slightly decreased activity and curiosity, could enhance the conditioned affective reaction induced by cocaine-CPP.

There is less evidence available for the SAP102 KO mice, however either or both of these alternatives could apply. Their activity and curiosity levels have not been characterised; to distinguish between the two, the open field and the novel object recognition test can be implemented, respectively (Hall, 1934; Berlyne, 1950; Walsh and Cummins, 1976; Ennaceur and Delacour, 1988). Moreover, a slightly increased baseline level of silent synapses was measured in the adult NAc, similar to but not as pronounced as in the PSD-95 KO (Shukla et al., 2017). 


\subsubsection{Silent synapses in the PSD-95 Ht and KO NAC}

Shukla and colleagues demonstrated the time course of silent synapses generation in NAcSh in a cocaineCPP procedure over 45 days of withdrawal. Silent synapse levels peak on WD1, while CP-AMPARs are incorporated gradually, peaking on WD30. Given that the PSD-95 KO memory defect was observed on WD20, this was the relevant point to make the aforementioned measurements in this group (Shukla et al., 2017).

Results obtained in the context of this thesis now show that PSD-95 KO mice still retain the association on WD10; the memory loss begins somewhere between WD10 and WD20. Measuring silent synapse levels and CP-AMPARs on WD10 could prove informative; CP-AMPAR incorporation could be facilitated by a protein other than PSD-95 in an accelerated but transient manner. Same holds true for the PSD-95 Ht mice, who followed WT patterns, even though extinction and reinstatement of CPP were amplified. From an electrophysiological perspective, however, PSD-95 Ht mice seem to resemble PSD-95 KO in that they exhibit enhanced LTP, albeit more mildly (Migaud et al., 1998; Horner et al., 2018). Measuring silent synapse levels from baseline, to WD1, to long-term withdrawal and their fate in these - genetically, behaviourally and electrophysiologically - 'intermediate' mice, might help us gain a deeper understanding of these synapses' role in drug-motivated behaviours.

\subsection{NAc-restricted knockdown of PSD-95 and CPP reinstatement}

Results discussed in section 4.4 shed light on the role of NAC CP-AMPARs in drug-motivated behaviour; however, both approaches were systemic - a complete genetic protein knock-out, or a systemic antibiotic injection. To delineate the role of CP-AMPARs specifically in the NAc, I did an RNAi-mediated NAcrestricted knockdown of PSD-95 using a viral vector. This manipulation has been shown to induce silent synapses and prevent their maturation (Shukla et al., 2017). Data shown in figure 3.7 are merely preliminary due to small sample size but they suggest that PSD-95 knock-down does not impair extinction or reinstatement with 20 and $5 \mathrm{mg} / \mathrm{kg}$ challenge doses of cocaine.

It is necessary to repeat these experiments. Both knockdown groups show a PPS increase descriptively upon reinstatement, which will most likely become significant when more mice are tested. The next step would be to perform an injection control; it remains to be confirmed that neither the surgery itself nor the viral vector have an effect on the behaviour of the animals. A proper control would be a viral vector expressing an shRNA for luciferase, a control with an effective shRNA against a protein not present in mice, and a GFP expression marker under the control of a CAG promoter (was used as a control in Shukla et al., 2017). 
Following the same rationale, the next step would be to reinstate CPP with $2 \mathrm{mg} / \mathrm{kg}$ since this is the dose where WT mice still succeed, but SAP102 KO and ceftriaxone-treated WT mice do not show reinstatement. However, at this level one might be looking at rather slight differences which could be masked, for instance, by less effective extinction due to animal variability (see difference in extinction performance between the two WT groups in figure 3.4A). To circumvent this problem, the PSD-95 Ht mouse could be of value; these mice already have half of the normally-expressed PSD-95 levels, making it possible for the RNAi-mediated knockdown to more fully abolish PSD-95 expression. Furthermore, the pronounced extinction of the PSD-95 Ht would allow us to see and evaluate changes in reinstatement more precisely.

\subsection{PSD-95 and SAP102 - not that similar?}

DLG-MAGUKs are signalling scaffold proteins, with an instrumental role in AMPAR trafficking at the excitatory synapse (Bredt and Nicoll, 2003; Kim and Sheng, 2004; Xu et al., 2008). They display distinct expression patterns throughout development and it has been proposed that SAP102 can functionally compensate for the lack of PSD-95, as its expression is significantly upregulated in the PSD-95 KO mouse (Elias et al., 2006; Cuthbert et al., 2017; Bonnet et al., 2013). In this thesis, I used KO mice for PSD-95 and SAP102, to manipulate synaptic states and observe behavioural effects. As discussed above, results acquired for these groups were interesting and far from similar.

In contrast to the proposed redundancy, a recent study suggested that PSD-95 and SAP102 influence synaptic properties independently, requiring different AMPAR auxiliary subunits (Liu et al., 2018). As previously discussed, Shukla and colleagues compared WT to PSD-95 KO and SAP102 KO mice and found that a lack of PSD-95, but not SAP102, leads to an increased basal silent synapse fraction in the adult NAc. Though silent synapses are generated following cocaine-CPP training in all genotypes, for the PSD-95 and SAP102 KO mice they persist throughout withdrawal. From a cellular perspective, PSD-95 and SAP102 KO phenotypes differ from WT, since they lack CP-AMPAR recruitment. Nevertheless, even though both mice are able to acquire CPP, only SAP102 KOs maintain it after 20 days, similarly to the WTs (Shukla et al., 2017).

Genotype differences are also observed during the extinction-reinstatement procedure used in the present study. Performance of SAP102 KO mice resembles that of WTs, provided that the challenge cocaine dose is sufficiently high to trigger reinstatement. Conversely, extinction training is clearly less effective in the PSD-95 KO group, since the decrease in preference was either small (figure 3.5, PSD-95 KO cocaine-reinstatement) or not significant (figure 3.5, PSD-95 KO saline-reinstatement). During reinstatement, behaviours deviate even further, as the high challenge dose $(20 \mathrm{mg} / \mathrm{kg})$, which successfully 
reinstates CPP in SAP102 KOs, causes PSD-95 KOs to lose their preference. My results are thus consistent with other studies that propose a differential role for PSD-95 and SAP102 in the fate of excitatory synapses, in developmental and maladaptive plasticity alike. I believe the reinstatement threshold experiment with PSD-95 Ht mice would be immensely informative. These mice show pronounced extinction, much like the SAP102 KOs; therefore, effects of different doses on reinstatement strength could be detected accurately. Will $2 \mathrm{mg} / \mathrm{kg}$ be enough for the PSD-95 Ht, as for the WT, or will these mice really mirror SAP102 KO behaviour?

Since the PSD-95 Ht mice express half the WT protein levels, it is likely that a similar proportion of cocaine-generated silent synapses mature via CP-AMPAR recruitment; this would be straightforward to determine by measuring RI upon reinstatement. If PSD-95 Ht CP-AMPAR levels are between those of the WT -cocaine-generated synapses are unsilenced- and the SAP102 KO -silent synapses do not mature-, comparison of reinstatement thresholds between SAP102 KO and PSD-95 Ht mice is a key experiment; should the same challenge injection induce reinstatement only in the PSD-95 Ht, but not in the SAP102 $\mathrm{KO}$, this result would constitute a quantitative link between CP-AMPAR levels and the minimum stimulus intensity required, the threshold, to induce reinstatement.

\subsection{From gain control to motivation; from motivation back to addiction}

Among the things I learned during my thesis is that CP-AMPARs act as amplifiers of a weak challenge cue, tipping it over the threshold needed to induce reinstatement. Since the procedure is non-contingent, I did not study craving or addiction per se. Instead, I used reinstatement to model relapse, a component of addiction.

The NAc is a key region of the reward circuitry, where emotion and motivation facilitate the prioritisation of action plans and their ultimate realisation as actions (Mogenson et al., 1980). CP-AMPARs in the NAC could be a cellular correlate for the motivation to express a drug-associated behaviour. Their singlechannel conductance is higher than that of normal, $\mathrm{Ca}^{2+}$-impermeable AMPARs (Ozawa et al., 1991), meaning that the cocaine-generated synapses become functionally predominant in the network upon their maturation (Ma et al., 2016). In other words, CP-AMPAR-containing synapses have a higher synaptic weight in neurons, thus enhancing the salience of their inputs.

However, it remains unclear in which cells or synapses in the NAC CP-AMPARs are actually expressed. The two subpopulations of MSNs, D1R and D2R expressing, have possibly antagonistic functions, with D1 typically considered as the driver and D2 as the brake (Lobo and Nestler, 2011). Therefore, if CP-AMPARs were selectively expressed in the D1R population, they could amplify their effect in facilitating action 
induction. Initially, repeated passive cocaine injections were reported to induce silent synapses in different NAc subtypes (Brown et al., 2011). Graziane and colleagues later clarified that there is a synaptic weight increase in D1 compared to D2, meaning that different NAc MSN subpopulations are not affected in the same way by passive cocaine exposure (Graziane et al., 2016). CP-AMPAR recruitment necessitates associative learning; only if the animal associates the drug experience to a context, will silent synapses mature by incorporating CP-AMPARs over withdrawal (McCutcheon et al., 2011a; Shukla et al., 2017). Therefore, it is likely that D1 strengthening observed by Graziane and colleagues is mediated by maturation of the newly generated silent synapses by normal, $\mathrm{Ca}^{2+}$-impermeable AMPARs. Investigating the effect of operant and classical conditioning on D1R MSN inputs is important; should CP-AMPARs be found only in these driver cells, it would take the findings of the current study a step further. The role of CP-AMPARs as cue amplifiers could be mediated specifically by D1R MSNs, the cells thought to facilitate action. This postulate could explain how CP-AMPARs could lower the threshold for induction of reinstatement.

The environment can also influence susceptibility to addiction. This link is confirmed by a plethora of studies. An enriched environment supports brain recovery from a disease. It has also been shown to prevent establishment of drug intake and seeking (Smith et al., 1997; Nithianantharajah and Hannan, 2006; Stairs and Bardo, 2009; Gipson et al., 2011). Interestingly, environmental enrichment was recently shown to have conditional anti-relapse effects. Upon LTD-induced transient re-silencing of matured cocainegenerated silent synapses, via CP-AMPAR internalisation, environmental enrichment promoted the insertion of non-CP-AMPARs. The subsequent circuit remodelling led to a long-term reduction in incubation of craving (Ma et al., 2016). If environmental enrichment, a positive factor, promotes the insertion of $\mathrm{Ca}^{2+}$-impermeable AMPARs and reduces craving, it is plausible that stress, a negative factor, increases susceptibility to relapse by promoting CP-AMPAR recruitment.

Stressed, isolated rats display increased sensitivity to the stimulating and the reinforcing effects of cocaine and amphetamine (Smith et al., 1997). Likewise, if a mouse is subjected to isolation after successful CPP acquisition, or to social defeat prior to receiving the challenge injection, vulnerability to reinstatement is enhanced. On the contrary, juvenile adolescent mice living in crowded conditions were immune to reinstatement by a cocaine challenge injection, as were adult male mice that were sharing a cage with a female (Ribeiro Do Couto et al., 2009). Young adult female rats that exercised regularly for six weeks between CPP acquisition and extinction training, were protected against stress-induced reinstatement (Robison et al., 2018). Lastly, most rats trained to self-administer cocaine will cease to seek the drug, if punishment becomes associated with its delivery. Facing negative consequences is enough for the animals 
to control their craving. However, this is not the case for $\sim 20 \%$ of the rats. These rats will even ignore electric foot shocks, as long as the drug is signalled to be available (Kasanetz et al., 2010). Taken together, these studies show how stress makes animals more prone to drug seeking and how the absence of stress, or stress relieving conditions, protect them.

Experimentally proven facts in rodents often hold true for humans. Positive factors, such as social contacts and activity, can be protective for us, too. On the contrary, negative life factors, such as loss of employment, can contribute to vulnerability (Compton et al., 2014; Lee et al., 2015). People who feel stuck, who lack novel stimuli in their environment and who feel their life has become too stale and predictable, may resort to drugs as a substitute to a natural drive and new experiences that would engage the reward system (Baker et al., 1987; Everitt and Robbins, 2005; Hyman et al., 2006; reviewed by Köpetz et al., 2013; Dossey, 2019). Similar to rats (Kasanetz et al., 2010), most people will be able to control drug use once they are made aware of its effect on their life and the risk to lose what they deem important. For few, compulsive seeking and craving the next dose will, unfortunately, overshadow the dire consequences.

Rewiring induced by drugs is much more effective in producing durable memories and robust behaviours, compared to natural rewards. Without CP-AMPARs, drug-induced synapses lose their increased synaptic weight and impact (Ozawa et al., 1991; Ma et al., 2016). Results of this thesis suggest that CP-AMPARs control the intensity with which drug-motivated behaviours are expressed. Targeting CPAMPARs in drug-generated silent synapses may, thus, bring us a step closer to understanding and fighting addiction. 


\section{Bibliography}

Abbas, A.I., Yadav, P.N., Yao, W.D., Arbuckle, M.I., Grant, S.G.N., Caron, M.G., and Roth, B.L. (2009). PSD95 is essential for hallucinogen and atypical antipsychotic drug actions at serotonin receptors. J. Neurosci. 29, 7124-7136.

Baker, T.B., Morse, E., Sherman, J.E. (1987) The motivation to use drugs: A psychobiological analysis of urges. In: Rivers, PC., editor. The Nebraska symposium on motivation: Alcohol use and abuse. Lincoln: University of Nebraska Press, 257-323.

Bechard, A.R., and Knackstedt, L.A. (2019). The effects of Pavlovian cue extinction and ceftriaxone on cocaine relapse after abstinence. Drug Alcohol Depend. 197, 83-86.

Béïque, J.-C., Lin, D.-T., Kang, M.-G., Aizawa, H., Takamiya, K., and Huganir, R.L. (2006). Synapse-specific regulation of AMPA receptor function by PSD-95. Proc. Natl. Acad. Sci. 103, 19535-19540.

Bellone, C., and Lüscher, C. (2006). Cocaine triggered AMPA receptor redistribution is reversed in vivo by mGluR-dependent long-term depression. Nat. Neurosci. 9, 636-641.

Bennett, M.V.L., and Zukin, R.S. (2004). Electrical Coupling and Neuronal Synchronization in the Mammalian Brain. Neuron 41, 495-511.

Berlyne, D. (1950). Novelty and curiosity as determinants of exploratory behavior. Br. J. Psychol. 41, 6880.

Beroun, A., Nalberczak-Skóra, M., Harda, Z., Piechota, M., Ziółkowska, M., Cały, A., Pagano, R. and Radwanska, K. (2018). Generation of silent synapses in dentate gyrus correlates with development of alcohol addiction. Neuropsychopharmacology 43, 1989-1999.

Bliss, T.V.P., and Lømo, T. (1973). Long-lasting potentiation of synaptic transmission in the dentate area of the anaesthetized rabbit following stimulation of the perforant path. J. Physiol. 232, 331-356.

Bonnet, S.A.D., Akad, D.S., Samaddar, T., Liu, Y., Huang, X., Dong, Y., and Schlüter, O.M. (2013). Synaptic state-dependent functional interplay between postsynaptic density- 95 and synapse-associated protein 102. J. Neurosci. 33, 13398-13409.

Bouton, M.E. (2002). Context, ambiguity, and unlearning: sources of relapse after behavioral extinction. Biol. Psychiatry 52, 976-986.

Bredt, D.S. and Nicoll, R.A. (2003). AMPA Receptor Trafficking at Excitatory Synapses. Neuron 40, 361-379.

Brown, T.E., Lee, B.R., Mu, P., Ferguson, D., Dietz, D., Ohnishi, Y.N., Lin, Y., Suska, A., Ishikawa, M., Huang, Y.H., et al. (2011). A silent synapse-based mechanism for cocaine-induced locomotor sensitization. J. Neurosci. 31, 8163-8174.

Burns, M.E., and Augustine, G.J. (1995). Synaptic structure and function: Dynamic organization yields architectural precision. Cell 83, 187-194. 
Carey, A.N., Borozny, K., Aldrich, J.V., McLaughlin, J.P. (2007). Reinstatement of cocaine place-conditioning prevented by the peptide kappa-opioid receptor antagonist arodyn. Eur. J. Pharmacol. 569, 84-89.

Carlisle, H.J., Fink, A.E., Grant, S.G.N. \& O'dell, T.J. (2008). Opposing effects of PSD-93 and PSD-95 on longterm potentiation and spike timing-dependent plasticity. J. Physiol. 586, 5885-5900.

Carroll, R. C., Beattie, E. C., von Zastrow, M. and Malenka, R. C. (2001). Role of AMPA receptor endocytosis in synaptic plasticity. Nature Rev. Neurosci. 2, 315-324.

Cartmell, J., and Schoepp, D.D. (2000). Regulation of Neurotransmitter Release by Metabotropic Glutamate Receptors. J. Neurochem. 75, 889-907.

Chen, L., Chetkovich, D.M., Petralia, R.S., Sweeney, N.T., Kawasaki, Y., Wenthold, R.J., Bredt, D.S., and Nicoll, R.A. (2000). Stargazin regulates synaptic targeting of AMPA receptors by two distinct mechanisms. Nature 408, 936-943.

Chen, R., Tilley, M.R., Wei, H., Zhou, F., Zhou, F.-M., Ching, S., Quan, N., Stephens, R.L., Hill, E.R., Nottoli, T., et al. (2006). Abolished cocaine reward in mice with a cocaine-insensitive dopamine transporter. Proc. Natl. Acad. Sci. 103, 9333-9338.

Cho, K.-O., Hunt, C.A., and Kennedy, M.B. (1992). The rat brain postsynaptic density fraction contains a homolog of the drosophila discs-large tumor suppressor protein. Neuron 9, 929-942.

Compton, W.M., Gfroerer, J., Conway, K.P., Finger, M.S. (2014). Unemployment and substance outcomes in the United States 2002-2010. Drug Alcohol Depend. 142, 350-353.

Conrad, K. L., Louderback, K. M., Milano, E. J., \& Winder, D. G. (2013). Assessment of the impact of pattern of cocaine dosing schedule during conditioning and reconditioning on magnitude of cocaine CPP, extinction, and reinstatement. Psychopharmacology 227, 109-116.

Conrad, K.L., Tseng, K.Y., Uejima, J.L., Reimers, J.M., Heng, L.-J., Shaham, Y., Marinelli, M., and Wolf, M.E. (2008). Formation of accumbens GluR2-lacking AMPA receptors mediates incubation of cocaine craving. Nature 454, 118-121.

Cunningham, C.L., Dickinson, S.D., Grahame, N.J., Okorn, D.M., McMullin, C.S. (1999). Genetic differences in cocaine-induced conditioned place preference in mice depend on conditioning trial duration. Psychopharmacology (Berl) 146, 73-80.

Cuthbert, P.C., Stanford, L.E., Coba, M.P., Ainge, J.A., Fink, A.E., Opazo, P., Delgado, J.Y., Komiyama, N.H., O'Dell, T.J., and Grant, S.G.N. (2007). Synapse-associated protein 102/dlgh3 couples the NMDA receptor to specific plasticity pathways and learning strategies. J. Neurosci. 27, 2673-2682.

Di Chiara, G. (1998). A motivational learning hypothesis of the role of mesolimbic dopamine in compulsive drug use. J. Psychopharmacol. 12, 54-67.

Dong, Y., and Nestler, E.J. (2014). The neural rejuvenation hypothesis of cocaine addiction. Trends Pharmacol. Sci. 35, 374-383. 
Dossey, L. (2019). Deaths of despair. Explore (NY) 15, 1-6.

Drug Policy Alliance (2020). Drug Overdose | Drug Policy Alliance. http://www.drugpolicy.org/issues/drugoverdose

Dudek, S.M., and Bear, M.F. (1992). Homosynaptic long-term depression in area CA1 of hippocampus and effects of N-methyl-D-aspartate receptor blockade. Proc. Natl. Acad. Sci. U.S.A. 89, 4363-4367.

Durand, G.M., Kovalchuk, Y., and Konnerth, A. (1996). Long-term potentiation and functional synapse induction in developing hippocampus. Nature 381, 71-75.

Ehrlich, M.E., et al. (2002). Periadolescent mice show enhanced DeltaFosB upregulation in response to cocaine and amphetamine. J. Neurosci. 22, 9155-9159.

Ehrlich, I., and Malinow, R. (2004). Postsynaptic Density 95 controls AMPA Receptor Incorporation during Long-Term Potentiation and Experience-Driven Synaptic Plasticity. J. Neurosci. 24, 916-927.

Elias, G.M., Funke, L., Stein, V., Grant, S.G., Bredt, D.S., and Nicoll, R.A. (2006). Synapse-Specific and Developmentally Regulated Targeting of AMPA Receptors by a Family of MAGUK Scaffolding Proteins. Neuron 52, 307-320.

Ennaceur, A., Delacour, J. (1988). A new one-trial test for neurobiological studies of memory in rats. 1: Behavioral-data. Behav. Brain Res. 31, 47-59.

Everitt, B.J., and Robbins, T.W. (2005). Neural systems of reinforcement for drug addiction: from actions to habits to compulsion. Nat. Neurosci. 8, 1481-1489.

Favaro, P.D., Huang, X., Hosang, L., Stodieck, S., Cui, L., Liu, Y.Z., Engelhardt, K.A., Schmitz, F., Dong, Y., Löwel, S., et al. (2018). An opposing function of paralogs in balancing developmental synapse maturation. PLoS Biol 16: e2006838.

Fitzgerald, P.J., Pinard, C.R., Camp, M.C., Feyder, M., Sah, A., Bergstrom, H.C., Graybeal, C., Liu, Y., Schlüter, O.M., Grant, S.G., et al. (2014). Durable fear memories require PSD-95. Mol. Psychiatry 20, 901-912.

French, S.J., and Totterdell, S. (2002). Hippocampal and prefrontal cortical inputs monosynaptically converge with individual projection neurons of the nucleus accumbens. J. Comp. Neurol. 446, 151-165.

French, S.J., and Totterdell, S. (2003). Individual nucleus accumbens-projection neurons receive both basolateral amygdala and ventral subicular afferents in rats. Neuroscience 119, 19-31.

Gawin, F.H. and Kleber, H.D. (1986). Abstinence symptomatology and psychiatric diagnosis in cocaine abusers. Clinical observations. Arch. Gen. Psychiatry 43, 107-113.

Gerfen, C.R., Engber, T.M., Mahan, L.C., Susel, Z., Chase, T.N., Monsma, F.J. Jr., Sibley, D.R. (1990). D1 and D2 dopamine receptor-regulated gene expression of striatonigral and striatopallidal neurons. Science 250, 1429-1432. 
Giese K.P., Storm J.F., Reuter D., Fedorov N.B., Shao L.R., Leicher T., Pongs O., Silva A.J. (1998). Reduced K+ channel inactivation, spike broadening, and after-hyperpolarization in Kvbeta1.1 deficient mice with impaired learning. Learning and Memory 5, 257-73.

Gipson, C.D., Beckmann, J.S., El-Maraghi, S., Marusich, J.A., Bardo, M.T. (2011). Effect of environmental enrichment on escalation of cocaine self-administration in rats. Psychopharmacology (Berl). 214, 557-566.

Gray, J. A., Shi, Y., Usui, H., During, M. J., Sakimura, K., \& Nicoll, R. A. (2011). Distinct modes of AMPA receptor suppression at developing synapses by GluN2A and GluN2B: single-cell NMDA receptor subunit deletion in vivo. Neuron 71(6), 1085-1101.

Graziane, N., Sun, S., Wright, W., Jang, D., Liu, Z., Huang, Y.H., Nestler, E.J., Wang, Y.T., Schlüter, O.M and Dong, Y. (2016). Opposing mechanisms mediate morphine- and cocaine-induced generation of silent synapses. Nat. Neurosci. 19, 915-925.

Greger, I.H., Watson, J.F., and Cull-Candy, S.G. (2017). Structural and Functional Architecture of AMPAType Glutamate Receptors and Their Auxiliary Proteins. Neuron 94, 713-730.

Grimm, J.W., Hope, B.T., Wise, R.A., and Shaham, Y. (2001). Neuroadaptation: Incubation of cocaine craving after withdrawal. Nature 412, 141-142.

Groc, L., Gustafsson, B., and Hanse, E. (2006). AMPA signalling in nascent glutamatergic synapses: there and not there! Trends Neurosci. 29, 132-139.

Hall, C.S. (1934). Emotional behavior in the rat: defecation and urination as measures of individual differences in emotionality. J. Comp. Psychol. 18, 385-403.

Halt, A.R., et al. (2012). CaMKII binding to GluN2B is critical during memory consolidation. The EMBO journal 31, 1203-1216.

Hearing, M.C., Jedynak, J., Ebner, S.R., Ingebretson, A., Asp, A.J., Fischer, R.A., Schmidt, C., Larson, E.B., and Thomas, M.J. (2016). Reversal of morphine-induced cell-type-specific synaptic plasticity in the nucleus accumbens shell blocks reinstatement. Proc. Natl. Acad. Sci. U.S.A. 113, 757-762.

Hilderbrand, E.R. and Lasek, A.W. (2014). Sex differences in cocaine conditioned place preference in C57BL/6J mice. Neuroreport 25, 105-109.

Hollmann, M., and Heinemann, S. (1994). Cloned Glutamate Receptors. Annu. Rev. Neurosci. 17, 31-108.

Holt, E.B. (1931). Animal drive and the learning process. Edwin Holt.

Horner, A.E., McLaughlin, C.L., Afinowi, N.O., Bussey, T.J., Saksida, L.M., Komiyama, N.H., Grant, S.G.N. and Kopanitsa, M.V. (2018). Enhanced cognition and dysregulated hippocampal synaptic physiology in mice with a heterozygous deletion of PSD-95. Eur. J. Neurosci. 47, 164-176.

Howe, J. R., Cull-Candy, S. G., \& Colquhoun, D. (1991). Currents through single glutamate receptor channels in outside-out patches from rat cerebellar granule cells. J. Physiol. 432, 143-202. 
Huang, X., Stodieck, S.K., Goetze, B., Cui, L., Wong, M.H., Wenzel, C., Hosang, L., Dong, Y., Löwel, S., and Schlüter, O.M. (2015a). Progressive maturation of silent synapses governs the duration of a critical period. Proc. Natl. Acad. Sci. U.S.A. 112, E3131-E3140.

Huang, Y.H., Lin, Y., Mu, P., Lee, B.R., Brown, T.E., Wayman, G., Marie, H., Liu, W., Yan, Z., Sorg, B.A., et al. (2009). Report In Vivo Cocaine Experience Generates Silent Synapses. Neuron 63, 40-47.

Huang, Y.H., Schlüter, O.M., and Dong, Y. (2015b). Silent Synapses Speak Up Updates of the Neural Rejuvenation Hypothesis of Drug Addiction. The Neuroscientist 21, 451-9.

Hyman, S.E., Malenka, R.C., and Nestler, E.J. (2006). NEURAL MECHANISMS OF ADDICTION: The Role of Reward-Related Learning and Memory. Annu. Rev. Neurosci. 29, 565-598.

Hunt, W.A., Barnett, L.W., Branch, L.G. (1971). Relapse rates in addiction programs. J. Clin. Psychol. 27, 455-456.

Isaac, J.T.R., Nicoll, R.A., and Malenka, R.C. (1995). Evidence for silent synapses: Implications for the expression of LTP. Neuron 15, 427-434.

Ito, M. (1989). Long-Term Depression. Annu. Rev. Neurosci. 12, 85-102.

Itzhak, Y., and Martin, J. L. (2002). Cocaine-induced Conditioned Place Preference in Mice: Induction, Extinction and Reinstatement by Related Psychostimulants. Neuropsychopharmacology 26, 130-134.

Jackson, A.C., and Nicoll, R.A. (2011). The expanding social network of ionotropic glutamate receptors: TARPs and other transmembrane auxiliary subunits. Neuron 70, 178-199.

Kasanetz, F., Deroche-Gamonet, V., Berson N., Balado, E., Lafoucarde, M., Manzoni, O., Piazza, P.V. (2010). Transition to addiction is associated with a persistent impairment in synaptic plasticity. Science $328,1709-$ 1712.

Kim, E., and Sheng, M. (2004). PDZ domain proteins of synapses. Nat. Rev. Neurosci. 5, 771-781.

Kistner, U., Wenzel, B.M., Veh, R.W., Cases-Langhoff, C., Garner, A.M., Appeltauer, U., Voss, B., Gundelfinger, E.D., and Garner, C.C. (1993). SAP90, a rat presynaptic protein related to the product of the Drosophila tumor suppressor gene dlg-A. J. Biol. Chem. 268, 4580-4583.

Knackstedt, L.A., Melendez, R.I., and Kalivas, P.W. (2010). Ceftriaxone Restores Glutamate Homeostasis and Prevents Relapse to Cocaine Seeking. BPS 67, 81-84.

Koob G.F., Lloyd G.K., Mason B.J. (2009). Development of pharmacotherapies foe drug addiction: a Rosetta Stone approach. Nat. Rev. Drug. Discov. 8, 500-515.

Koob, G.F., and Volkow, N.D. (2009). Neurocircuitry of Addiction. Neuropsychopharmacology 35, 217-238.

Köpetz, C.E., Lejuez, C.W., Wiers, R.W., Kruglanski, A.W. (2013). Motivation and Self-Regulation in Addiction: A Call for Convergence. Perspect. Psychol. Sci. 8, 3-24. 
Kornau, H.C., Schenker, L.T., Kennedy, M.B., and Seeburg, P.H. (1995). Domain interaction between NMDA receptor subunits and the postsynaptic density protein PSD-95. Science 269, 1737-1740.

Kreibich, A.S., Blendy, J.A. (2004). cAMP response element-binding protein is required for stress but not cocaine-induced reinstatement. J. Neurosci. 24, 6686-6692.

Krueger-Burg, D., Winkler, D., Mitkovski, M., Daher, F., Ronnenberg, A., Schlüter, O.M., Dere, E. and Ehrenreich, H. (2016). The SocioBox: A Novel Paradigm to Assess Complex Social Recognition in Male Mice. Front. Behav. Neurosci. 10: 151.

Krüger, J.M., Favaro, P.D., Liu, M., Kitlinska, A., Huang, X., Raabe, M., Akad, D.S., Liu, Y., Urlaub, H., Dong, Y., Xu, W. \& Schluter, O.M. (2013). Differential Roles of Postsynaptic Density-93 Isoforms in Regulating Synaptic Transmission. J. Neurosci. 33, 15504-15517.

Lee, B.R., and Dong, Y. (2011). Cocaine-induced metaplasticity in the nucleus accumbens: Silent synapse and beyond. Neuropharmacology 61, 1060-1069.

Lee, B.R., Ma, Y., Huang, Y.H., Wang, X., Otaka, M., Ishikawa, M., Neumann, P.A., Graziane, N.M., Brown, T.E., Suska, A., et al. (2013). Maturation of silent synapses in amygdala-accumbens projection contributes to incubation of cocaine craving. Nat. Publ. Gr. 16, 1644-1651.

Lee, H.-K., Kameyama, K., Huganir, R.L., and Bear, M.F. (1998). NMDA Induces Long-Term Synaptic Depression and Dephosphorylation of the GluR1 Subunit of AMPA Receptors in Hippocampus. Neuron 21, 1151-1162.

Lee, J.L.C., Di Ciano, P., Thomas, K.L. and Everitt, B.J. (2005). Disrupting Reconsolidation of Drug Memories Reduces Cocaine-Seeking Behavior. Neuron 47, 795-801.

Lee, J.O., Hill, K.G., Hartigan, L.A., et al. (2015). Unemployment and substance use problems among young adults: Does childhood low socioeconomic status exacerbate the effect?. Soc. Sci. Med. 143, 36-44.

Liao, D., Hessler, N.A., and Malinow, R. (1995). Activation of postsynaptically silent synapses during pairinginduced LTP in CA1 region of hippocampal slice. Nature 375, 400-404.

Liu, M., Shi, R., Hwang, H., Han, K.S., Wong, M.H., Ren, X., Lewis, L.D., Brown, E.N., Xu, W. (2018). SAP102 regulates synaptic AMPAR function through a CNIH-2-dependent mechanism. J. Neurophysiol. 120, 15781586.

Liu, Y., Cui, L., Schwarz, M.K., Dong, Y., and Schlüter, O.M. (2017). Adrenergic Gate Release for Spike Timing-Dependent Synaptic Potentiation. Neuron 93, 394-408.

Lobo, M.K. and Nestler, E.J. (2011). The striatal balancing act in drug addiction: distinct roles of direct and indirect pathway medium spiny neurons. Front. Neuroanat. 5, 5-41.

Loweth, J.A., Scheyer, A.F., Milovanovic, M., Lacrosse, A.L., Flores-barrera, E., Werner, C.T., Li, X., Ford, K.A., Le, T., Olive, M.F., et al. (2014). Synaptic depression via mGluR1 positive allosteric modulation suppresses cue-induced cocaine craving. Nat. Publ. Gr. 17, 73-80. 
Loweth, J.A., Tseng, K.Y., and Wolf, M.E. (2013). Using metabotropic glutamate receptors to modulate cocaine' s synaptic and behavioral effects : mGluR1 finds a niche. Curr. Opin. Neurobiol. 23, 500-506.

Lu, W., Shi, Y., Jackson, A.C., Bjorgan, K., During, M.J., Sprengel, R., Seeburg, P.H., and Nicoll, R.A. (2009). Subunit composition of synaptic AMPA receptors revealed by a single-cell genetic approach. Neuron 62 , 254-268.

Lujan, R., Nusser, Z., Roberts, J.D., Shigemoto, R., and Somogyi, P. (1996). Perisynaptic location of metabotropic glutamate receptors mGluR1 and mGluR5 on dendrites and dendritic spines in the rat hippocampus. Eur. J. Neurosci. 8, 1488-1500.

Lutgen, V., Kong, L., Kau, K.S., Madayag, A., Matsch, J.R. and Baker, D.A. (2014). Time course of cocaine0induced behavioural and neurochemical plasticity. Addict. Biol. 19, 529-538.

Lüscher, C., and Malenka, R.C. (2011). Drug-Evoked Synaptic Plasticity in Addiction: From Molecular Changes to Circuit Remodeling. Neuron 69, 650-663.

Ma, Y.-Y., Wang, X., Huang, Y., Marie, H., Nestler, E.J., Schlüter, O.M. and Dong, Y. (2016). Re-silencing of silent synapses unmasks anti-relapse effects of environmental enrichment. Proc. Natl. Acad. Sci. U.S.A. 113, 5089-5094.

Maldonado, C., Rodríguez-Arias, M., Castillo, A., Aguilar, M.A., Miñarro, J. (2006). Gamma-hydroxybutyric acid affects the acquisition and reinstatement of cocaine-induced conditioned place preference in mice. Behavioural Pharmacology 17, 119-131.

Malenka R.C., Kauer J.A., Perkel D.J., Mauk M.D., Kelly P.T., Nicoll R.A., Waxham M.N. (1989). An essential role for postsynaptic calmodulin and protein kinase activity in long-term potentiation. Nature 340, 554-7.

Malenka, R.C. and Bear, M.F. (2004). LTP and LTD: an embarrassment of riches. Neuron 44, 5-21.

Malinow R., Schulman H., Tsien R.W. (1989). Inhibition of postsynaptic PKC or CaMKII blocks induction but not expression of LTP. Science 245, 862-6.

Mameli, M., Halbout, B., Creton, C., Engblom, D., Parkitna, J.R., Spanagel, R., and Lüscher, C. (2009). Cocaine-evoked synaptic plasticity: persistence in the VTA triggers adaptations in the NAc. Nat. Neurosci. $12,1036-1041$.

Mantsch, J.R., Baker, D.A., Funk, D., Lê, A.D. and Shaham, Y. (2016). Stress-induced reinstatement of drug seeking: 20 years of progress. Neuropsychopharmacology 41, 335-356.

Matsuzaki, M., Honkura, N., Ellis-Davies, G.C.R., and Kasai, H. (2004). Structural basis of long-term potentiation in single dendritic spines. Nature 429, 761-766.

Mayer, M.L., Westbrook, G.L., and Guthrie, P.B. (1984). Voltage-dependent block by Mg2+ of NMDA responses in spinal cord neurones. Nature 309, 261-263.

McCutcheon, J.E., Loweth, J.A., Ford, K.A., Marinelli, M., Wolf, M.E., and Tseng, K.Y. (2011b). Group I mGluR Activation Reverses Cocaine-Induced Accumulation of Calcium-Permeable AMPA Receptors in Nucleus 
Accumbens Synapses via a Protein Kinase C-Dependent Mechanism. J. Neurosci. 31, 14536-14541.

McCutcheon, J.E., Wang, X., Tseng, K.Y., Wolf, M.E., and Marinelli, M. (2011a). Calcium-Permeable AMPA Receptors Are Present in Nucleus Accumbens Synapses after Prolonged Withdrawal from Cocaine SelfAdministration But Not Experimenter-Administered Cocaine. J. Neurosci. 31, 5737-5743.

Medvedev, I.O., Gainetdinov, R.R., Sotnikova, T.D., Bohn, L.M., Caron, M.G. and Dykstra, L.A. (2005). Characterization of conditioned place preference to cocaine in congenic dopamine transporter knockout female mice. Psychopharmacology 180, 408-413.

Migaud, M., Charlesworth, P., Dempster, M., Webster, L.C., Watabe, A.M., Makhinson, M., He, Y., Ramsay, M.F., Morris, R.G.M., Morrison, J.H., et al. (1998). Enhanced long-term potentiation and impaired learning in mice with mutant postsynaptic density-95 protein. Nature 396, 433-439.

Mogenson, G.J., Jones, D.L., and Yim, C.Y. (1980). From motivation to action: Functional interface between the limbic system and the motor system. Prog. Neurobiol. 14, 69-97.

Montagud-Romero, S., Reguilon, M.D., Roger-Sanchez, C., Pascual, M., Aguilar, M.A., Guerri, C., Miñarro, J., Rodríguez-Arias, M. (2016). Role of dopamine neurotransmission in the long-term effects of repeated social defeat on the conditioned rewarding effects of cocaine. Prog. Neuropsychopharmacol. Biol. Psychiatry 71, 144-54.

Mueller, D., Stewart, J. (2000). Cocaine-induced conditioned place preference: reinstatement by priming injections of cocaine after extinction. Behavioural Brain Research 115, 39-47.

Mulkey, R.M., and Malenka, R.C. (1992). Mechanisms underlying induction of homosynaptic long-term depression in area CA1 of the hippocampus. Neuron 9, 967-975.

Nakagawa, T., Futai, K., Lashuel, H.A., Lo, I., Okamoto, K., Walz, T., Hayashi, Y., Sheng, M. (2004). Quaternary structure, protein dynamics, and synaptic function of SAP97 controlled by L27 domain interactions. Neuron 44, 453-467.

Nestler, E.J. (2002). Common molecular and cellular substrates of addiction and memory. Neurobiology of learning and memory 78, 637-647.

Nicoll, R.A. and Schmitz, D. (2005). Synaptic plasticity at hippocampal mossy fibre synapses. Nature Rev. Neurosci. 6, 863-876.

Nithianantharajah, J. and Hannan, A.J. (2006). Enriched environments, experience-dependent plasticity and disorders of the nervous system. Nature Reviews Neuroscience 7, 697-709.

Nowak, L., Bregestovski, P., Ascher, P., Herbet, A., and Prochiantz, A. (1984). Magnesium gates glutamateactivated channels in mouse central neurones. Nature 307, 462-465.

O'Brien, C.P. (2005). Anticraving medications for relapse prevention: a possible new class of psychoactive medications. Am. J. Psychiatry 162, 1423-1431.

Ozawa, S., lino, M., Tsuzuki, K. (1991). Two types of kainate response in cultured rat hippocampal neurons. 
J. Neurophysiol. 66, 2-11.

Palay, S.L. (1956). Synapses in the Central Nervous System. J. Biophys. Biochem. Cytol. 2, 193-202.

Paoletti, P. (2011). Molecular basis of NMDA receptor functional diversity. Eur. J. Neurosci. 33, 1351-1365.

Pascoli, V., Turiault, M. and Lüscher, C. (2012). Reversal of cocaine-evoked synaptic potentiation resets drug-induced adaptive behaviour. Nature 481, 71-75.

Redila, V.A., Chavkin, C. (2008). Stress-induced reinstatement of cocaine seeking is mediated by the kappa opioid system. Psychopharmacology (Berl). 200, 59-70.

Rekling, J.C., Shao, X.M., and Feldman, J.L. (2000). Electrical coupling and excitatory synaptic transmission between rhythmogenic respiratory neurons in the preBötzinger complex. J. Neurosci. Off. J. Soc. Neurosci. 20, RC113.

Ribeiro Do Couto, B., Aguilar, M.A., Lluch, J., Rodríguez-Arias, M., Miñarro, J. (2009). Social experiences affect reinstatement of cocaine-induced place preference in mice. Psychopharmacology 207, 485-498.

Ritz, M.C., Lamb, R.J., Goldberg, S.R., and Kuhar, M.J. (1987). Cocaine receptors on dopamine transporters are related to self-administration of cocaine. Science $237,1219-1223$.

Robbins, T.W., and Everitt, B.J. (1996). Neurobehavioural mechanisms of reward and motivation. Curr. Opin. Neurobiol. 6, 228-236.

Robison, L.S., Alessi, L. and Thanos, P.K. (2018). Chronic forced exercise inhibits stress-induced reinstatement of cocaine conditioned place preference. Behav. Brain Res. 353, 176-184.

Roche, K.W., Standley, S., McCallum, J., Dune Ly, C., Ehlers, M.D., and Wenthold, R.J. (2001). Molecular determinants of NMDA receptor internalization. Nat. Neurosci. 4, 794-802.

Rossmann, M., Sukumaran, M., Penn, A.C., Veprintsev, D.B., Babu, M.M., and Greger, I.H. (2011). Subunitselective $\mathrm{N}$-terminal domain associations organize the formation of AMPA receptor heteromers. EMBO J. $30,959-971$.

Roux, S., Froger, C., Porsolt, R.D., Valverde, O., and Maldonado, R. (2003). Place Preference Test in Rodents. Curr. Protoc. Neurosci. 22, 9.15.1-9.15.14.

Scannevin, R.H., and Huganir, R.L. (2000). Postsynaptic organisation and regulation of excitatory synapses. Nat. Rev. Neurosci. 1, 133-141.

Schlüter, O.M., Xu, W., and Malenka, R.C. (2006). Alternative N-Terminal Domains of PSD-95 and SAP97 Govern Activity-Dependent Regulation of Synaptic AMPA Receptor Function. Neuron 51, 99-111.

Schnell, E., Sizemore, M., Karimzadegan, S., Chen, L., Bredt, D.S., and Nicoll, R.A. (2002). Direct interactions between PSD-95 and stargazin control synaptic AMPA receptor number. Proc. Natl. Acad. Sci. U.S.A. 99, 13902-13907. 
Schoepfer, R., Monyer, H., Sommer, B., Wisden, W., Sprengel, R., Kuner, T., Lomeli, H., Herb, A., Kohler, M., Burnashev, N., \& et al. (1994). Molecular biology of glutamate receptors. Prog. Neurobiol. 42(2), 353357.

Schultz, W. (2015). Neuronal reward and decision signals: from theories to data. Physiol. Rev. 95, 853-951.

Schultz, W., Apicella, P. \& Ljungberg, T. (1993). Responses of monkey dopamine neurons to reward and conditioned stimuli during successive steps of learning a delayed response task. J. Neurosci. 13, 900-913.

Schultz, W., Dayan, P., and Montague, P.R. (1997). A neural substrate of prediction and reward. Science 275, 1593-1599.

Seeburg, P.H., Higuchi, M., and Sprengel, R. (1998). RNA editing of brain glutamate receptor channels: mechanism and physiology. Brain Res. Rev. 26, 217-229.

Shaham, Y., Erb, S., Stewart, J. (2000). Stress-induced relapse to heroin and cocaine seeking in rats: a review. Brain. Res. Rev. 33, 13-33.

Sheng, M. (2001). Molecular organization of the postsynaptic specialization. Proc. Natl. Acad. Sci. 98, 70587061.

Shukla, A., Beroun, A., Panopoulou, M., Neumann, P.A., Grant, S.G.N., Olive, M.F., Dong, Y., and Schlüter, O.M. (2017). Calcium-permeable AMPA receptors and silent synapses in cocaine-conditioned place preference. EMBO J. 36, 458-474.

Smith, J.K., Neill, J.C. and Costall, B. (1997). Post-weaning housing conditions influence the behavioural effects of cocaine and d-amphetamine. Psychopharmacology 131, 23-33.

Smith, R.J., Lobo, M.K., Spencer, S., Kalivas, P.W. (2013). Cocaine-induced adaptations in D1 and D2 accumbens projection neurons (a dichotomy not necessarily synonymous with direct and indirect pathways). Curr. Opin. Neurobiol. 23, 546-552.

Soto, D., Coombs, I.D., Gratacós-Batlle, E., Farrant, M., and Cull-Candy, S.G. (2014). Molecular mechanisms contributing to TARP regulation of channel conductance and polyamine block of calcium-permeable AMPA receptors. J. Neurosci. 34, 11673-11683.

Soto, D., Coombs, I.D., Kelly, L., Farrant, M., and Cull-Candy, S.G. (2007). Stargazin attenuates intracellular polyamine block of calcium-permeable AMPA receptors. Nat. Neurosci. 10, 1260-1267.

Spiteri, T., and Le Pape, G. (2000). What is learned during place preference conditioning ? A comparison of food- and morphine-induced reward. Psychobiology 28, 367-382.

Stairs, D.J., Bardo, M.T. (2009). Neurobehavioral effects of environmental enrichment and drug abuse vulnerability. Pharmacol. Biochem. Behav. 92, 377-382.

Stein, V., House, D.R.C., Bredt, D.S., and Nicoll, R.A. (2003). Postsynaptic Density-95 Mimics and Occludes Hippocampal Long-Term Potentiation and Enhances Long-Term Depression. J. Neurosci. 23, 5503-5506. 
Stern, P., Edwards, F.A., and Sakmann, B. (1992). Fast and slow components of unitary EPSCs on stellate cells elicited by focal stimulation in slices of rat visual cortex. J. Physiol. 449, 247-278.

Suska, A., Lee, B.R., Huang, Y.H., Dong, Y., and Schlüter, O.M. (2013). Selective presynaptic enhancement of the prefrontal cortex to nucleus accumbens pathway by cocaine. Proc. Natl. Acad. Sci. U.S.A. 110, 713718.

Swanson, L.W. (1982). The projections of the ventral tegmental area and adjacent regions: a combined fluorescent retrograde tracer and immunofluorescence study in the rat. Brain. Res. Bull. 9, 321-353.

Tao, Y.X., Rumbaugh, G., Wang, G.D., Petralia, R.S., Zhao, C., Kauer, F.W., Tao, F., Zhuo, M., Wenthold, R.J., Raja, S.N., Huganir, R.L., Bredt, D.S., Johns, R.A. (2003). Impaired NMDA receptor-mediated postsynaptic function and blunted NMDA receptor-dependent persistent pain in mice lacking postsynaptic density-93 protein. The Journal of Neuroscience 23, 6703-12.

Thomas, M.J., Beurrier, C., Bonci, A., and Malenka, R.C. (2001). Long-term depression in the nucleus accumbens: a neural correlate of behavioral sensitization to cocaine. Nat. Neurosci. 4, 1217-1223.

Traynelis, S.F., Wollmuth, L.P., McBain, C.J., Menniti, F.S., Vance, K.M., Ogden, K.K., Hansen, K.B., Yuan, H., Myers, S.J., and Dingledine, R. (2010). Glutamate Receptor Ion Channels: Structure, Regulation, and Function. Pharmacol. Rev. 62, 405-496.

Tritschler, L., Kheirbek, M.A., Dantec, Y. Le, Mendez-David, I., Guilloux, J.P., Faye, C., Doan, J., Pham, T.H., Hen, R., David, D.J., Gardier, A.M. (2018). Optogenetic activation of granule cells in the dorsal dentate gyrus enhances dopaminergic neurotransmission in the Nucleus Accumbens. Neurosci. Res. 134, 56-60.

Ungless, M.A., Whistler, J.L., Malenka, R.C., and Bonci, A. (2001). Single cocaine exposure in vivo induces long-term potentiation in dopamine neurons. Nature 411, 583-587.

van Zundert, B., Yoshii, A., Constantine-Paton, M. (2004). Receptor compartmentalization and trafficking at glutamate synapses: a developmental proposal. Trends Neurosci. 27, 428-437.

Walsh, R.N., Cummins, R.A. (1976). The open field test: a critical review. Psychol. Bull. 83, 482-504.

Whitlock, J.R., Heynen, A.J., Shuler, M.G., and Bear, M.F. (2006). Learning Induces Long-Term Potentiation in the Hippocampus. Science 313, 1093-1097.

Wolf, M.E., and Tseng, K.-Y. (2012). Calcium-permeable AMPA receptors in the VTA and nucleus accumbens after cocaine exposure: when, how, and why? Front. Mol. Neurosci. 5, 72.

Wong, W.C., et al. (2013). Adolescents are more vulnerable to cocaine addiction: behavioral and electrophysiological evidence. J. Neurosci. 33, 4913-4922.

Wright, W.J., Graziane, N.M., Neumann, P.A., Hamilton, P.J., Cates, H.M., Fuerst, L., Spenceley, A., MacKinnon-Booth, N., Iyer, K., Huang, Y.H., Shaham, Y., Schlüter, O.M., Nestler, E.J. and Dong, Y. (2020). Silent synapses dictate cocaine memory destabilization and reconsolidation. Nat. Neurosci. 23, 32-46. 
Wu, G., Malinow, R., and Cline, H.T. (1996). Maturation of a central glutamatergic synapse. Science 274, 972-976.

Xia, J., Meyers, A.M. and Beeler, J.A. (2017). Chronic Nicotine Alters Corticostriatal Plasticity in the Striatopallidal Pathway Mediated By NR2B-Containing Silent Synapses. Neuropsychopharmacology 42, 2314-2324.

Xiao, M.-Y., Wasling, P., Hanse, E., and Gustafsson, B. (2004). Creation of AMPA-silent synapses in the neonatal hippocampus. Nat. Neurosci. 7, 236-243.

Wang, B., Luo, F., Zhang, W.T., Han, J.S. (2000). Stress or drug priming induces reinstatement of extinguished conditioned place preference. Neuroreport 11, 2781-2784.

Wojcik, S.M., and Brose, N. (2007). Regulation of Membrane Fusion in Synaptic Excitation-Secretion Coupling: Speed and Accuracy Matter. Neuron 55, 11-24.

Xu, W., Schlüter, O.M., Steiner, P., Czervionke, B.L., Sabatini, B., and Malenka, R.C. (2008). Molecular Dissociation of the Role of PSD-95 in Regulating Synaptic Strength and LTD. Neuron 57, 248-262.

Yao, W.D., Gainetdinov, R.R., Arbuckle, M.I., Sotnikova, T.D., Cyr, M., Beaulieu, J.M., Torres, G.E., Grant, S.G.N., and Caron, M.G. (2004). Identification of PSD-95 as a Regulator of Dopamine-Mediated Synaptic and Behavioral Plasticity. Neuron 41, 625-638.

Yuste, R., and Bonhoeffer, T. (2001). Morphological Changes in Dendritic Spines Associated with LongTerm Synaptic Plasticity. Annu. Rev. Neurosci. 24, 1071-1089.

Zhao, H., Fu, Y., Glasser, C., Andrade Alba, E.J., Mayer, M.L., Patterson, G., and Schuck, P. (2016). Monochromatic multicomponent fluorescence sedimentation velocity for the study of high-affinity protein interactions. elife 5, 5 .

Zhu, J.J., Esteban, J.A., Hayashi, Y., and Malinow, R. (2000). Postnatal synaptic potentiation: Delivery of GluR4-containing AMPA receptors by spontaneous activity. Nat. Neurosci. 3, 1098-1106. 


\section{Acknowledgements}

This is where I get to thank all those who made carrying out this work possible- and fulfilling.

Firstly, I would like to sincerely thank my supervisor, Dr. Dr. Oliver Schlüter, for his guidance, patience and support. His knowledge, determination and scientific rigor have served as a great source of inspiration. Our conversations were always motivating and constructive.

I would also like to thank Prof. André Fischer and Prof. Siegrid Löwel, my core committee members, for their input and support throughout the PhD.

To past and present members of the lab - Avani Shukla, thank you for introducing me to most techniques I used during these four years and for your commitment to diligent teaching. I want to thank Isabel Heise, whom I supervised for almost a year; she probably sacrificed more weekends than she would have liked, but her contribution to my work is substantial. I am most grateful to Alexander Engelhardt, my sole comrade in the lab; Alex, thank you for sharing the last months of the race with me. Thank you not just for being a helpful colleague but, when I needed it most, a supportive friend.

This paragraph is for two women who share the same name and whose presence has been vital throughout my studies. Sandra Gebauer, there is no job description that does you justice - lab technician certainly does not cut it. Thank you for preparing viruses for this study, for helping with organisational matters in and outside the lab and for being a source of warmth for our small family. Sandra Drube, you might be the most efficient person I have met. Thank you for having most answers, and for swiftly finding the rest. I hope you know how much we all appreciate your hard work and support.

A special thank you to the other members of the coordination office, Dr. Jonas Barth and Ms. Franziska Kühne, for making sure things run smoothly.

I want to express my sincere gratitude to Prof. Michael Hörner for his guidance during the MSc studies and the first stages of the PhD. I believe he had been instrumental in assembling the people who made each batch special; thank you, Michael, for bringing me together with the group that became my family almost six years ago -

Leo, Mar, Albert, Erik and Dennis, Ronja and Linda, Sinem, Kanishk, everyone; I am so fortunate that all it took to find all of you was a one-way ticket to Germany. You made Göttingen home. Rashad, there is no one I would rather perfuse mice with at $9 \mathrm{pm}$ on a Friday. And finally, Haris, thank you for accompanying me for part of this journey.

This paragraph is for people whom I hold very dear and who contributed, a little or a little more, to completion of this thesis. Nikoloz Sirmpilatze and Dimokratis Karamanlis, the voices of reason; thank you both for your valuable comments. Dimo, thank you for your honesty, your always well-meant critique and 
for being a true friend. Niko, the only thing more heart-warming than your integrity is your aesthetics. Thank you for being the first person to read the entire thesis and for your advice concerning visualisation of my findings. Tal Dankovich, my moral compass; thank you for supporting me as very few people have, and for encouraging me to trust in the mice. I hope we manage to realise at least one of the joint projects we have envisioned. Robert Epple, a never-ending source of ideas and probably the biggest surprise of the last years; thank you for nit-picking my thesis and for enthusing over crazy concepts with me. I look forward to our adventures. Artemis Kontomichalou and Alex Tsompanidis, my oldest friends and pillars; I would be neither who, nor where I am today, if it weren't for you two. Artemis, thank you for always -always-being there- and, when it came down to it, for pulling me through. Alex, though I am not sure when this journey really began, I know we started it together. Thank you, all, for flying by my side.

During my BSc studies, I was very lucky to have two people as my mentors. I am indebted to Prof. Spiros Efthimiopoulos for his guidance during my first steps in research. I also thank Prof. Dimitris Stravopodis for his inspired and inspiring lectures. Thank you both for fuelling the fire; thank you for giving me wings.

Last but not the least, I want to thank my family - my sister, Daphne, who makes me proud. Most of all, my parents, Olga and Leonidas, who have provided for me wholeheartedly. Thank you for supporting me, despite not fully understanding my field of work... or not being too fond of airplanes. Thank you for letting me fly.

My work could have been carried out by someone else, perhaps, but not without the sacrifice of mice. I am thankful for these creatures, who helped me answer many questions and ask even more. Photogenic \# 3098 is also gracing this thesis with his personality- a real wild type.

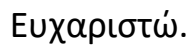

